medRxiv preprint doi: https://doi.org/10.1101/2020.05.08.20095687; this version posted May 14, 2020. The copyright holder for this preprint (which was not certified by peer review) is the author/funder, who has granted medRxiv a license to display the preprint in perpetuity.

All rights reserved. No reuse allowed without permission.

\title{
Rapid implementation of real-time SARS-CoV-2 sequencing to investigate healthcare- associated COVID-19 infections
}

\section{Authors}

Luke W. Meredith ${ }^{\# * 1}$, William L. Hamilton ${ }^{\# 2,3}$, Ben Warne ${ }^{2,3}$, Charlotte J. Houldcroft ${ }^{2}$, Myra Hosmillo ${ }^{1}$, Aminu S. Jahun ${ }^{1}$, Martin D. Curran ${ }^{4}$, Surendra Parmar ${ }^{4}$, Laura G. Caller ${ }^{1,5}$, Sarah L. Caddy $^{2}$, Fahad A. Khokhar ${ }^{2}$, Anna Yakovleva ${ }^{1}$, Grant Hall ${ }^{1}$, Theresa Feltwell ${ }^{2}$, Sally Forrest ${ }^{2}$, Sushmita Sridhar², Michael P. Weekes ${ }^{2}$, Stephen Baker ${ }^{2}$, Nicholas Brown ${ }^{4}$, Elinor Moore ${ }^{3}$, Ashley Popay $^{5}$, lain Roddick ${ }^{5}$, Mark Reacher ${ }^{5}$, Theodore Gouliouris ${ }^{3,6}$, Sharon J. Peacock ${ }^{2,7}$, Gordon Dougan $^{2}$, M. Estée Török ${ }^{\# 2,6}$ and lan Goodfellow $\$ \$ 1$

\# These authors contributed equally to the work:

* Joint first author

\$ Joint last author

\section{Affiliations}

1. Department of Pathology, University of Cambridge, Cambridge, UK

2. Department of Medicine, University of Cambridge, Cambridge, UK

3. Cambridge University Hospitals NHS Foundation Trust, UK

4. Public Health England Clinical Microbiology and Public Health Laboratory, Cambridge, UK

5. Francis Crick Institute, London, United Kingdom

6. Field Epidemiology, Field Service, National Infection Service, Public Health England, Cambridge, United Kingdom

7. National Infection Service, London, Public Health England

\section{Corresponding Authors:}

Dr M. Estée Török

et317@cam.ac.uk

Professor lan Goodfellow ig299@cam.ac.uk 
medRxiv preprint doi: https://doi.org/10.1101/2020.05.08.20095687; this version posted May 14, 2020. The copyright holder for this preprint (which was not certified by peer review) is the author/funder, who has granted medRxiv a license to display the preprint in perpetuity.

\section{Abstract \\ Background}

The burden and impact of healthcare-associated COVID-19 infections is unknown. We aimed to examine the utility of rapid sequencing of SARS-CoV-2 combined with detailed epidemiological analysis to investigate healthcare-associated COVID-19 infections and to inform infection control measures.

\section{Methods}

We set up rapid viral sequencing of SARS-CoV-2 from PCR-positive diagnostic samples using nanopore sequencing, enabling sample-to-sequence in less than 24 hours. We established a rapid review and reporting system with integration of genomic and epidemiological data to investigate suspected cases of healthcare-associated COVID-19.

\section{Results}

Between 13 March and 24 April 2020 we collected clinical data and samples from 5191 COVID19 patients in the East of England. We sequenced 1000 samples, producing 747 complete viral genomes. We conducted combined epidemiological and genomic analysis of 299 patients at our hospital and identified 26 genomic clusters involving 114 patients. 66 cases $(57.9 \%)$ had a strong epidemiological link and 15 cases $(13.2 \%)$ had a plausible epidemiological link. These results were fed back to clinical, infection control and hospital management teams, resulting in infection control interventions and informing patient safety reporting.

\section{Conclusions}

We established real-time genomic surveillance of SARS-CoV-2 in a UK hospital and demonstrated the benefit of combined genomic and epidemiological analysis for the investigation of healthcare-associated COVID-19 infections. This approach enabled us to detect cryptic transmission events and identify opportunities to target infection control interventions to reduce further healthcare-associated infections. 
medRxiv preprint doi: https://doi.org/10.1101/2020.05.08.20095687; this version posted May 14, 2020. The copyright holder for this preprint (which was not certified by peer review) is the author/funder, who has granted medRxiv a license to display the preprint in perpetuity.

All rights reserved. No reuse allowed without permission.

\section{Introduction}

SARS-CoV-2 emerged in the human population in December $2019^{1}$, originating from an intermediate animal host ${ }^{2}$. Owing to the error prone nature of the viral replication process, RNA viruses, such as SARS-CoV-2, accumulate mutations over time which results in sequence diversity. The current mutation rate of SARS-CoV-2 is estimated to be $\sim 2.5$ nucleotides per month $^{3,4}$. Sequencing of SARS-CoV-2 can provide valuable information on virus biology, transmission and population dynamics ${ }^{5-8}$. When linked with detailed epidemiological data and performed in a timescale of days, genomic data can support epidemiological investigations of potential hospital-acquired infections (HAl). On a larger population scale, genomic surveillance of SARS-CoV-2 can inform which lineages of the virus are currently circulating in the human population, how these change over time as an indicator of the success of control measures, how often new sources of virus are introduced from other geographic areas, and how the virus evolves in response to interventions.

Healthcare-associated infections ( $\mathrm{HCAl}$ ) can affect patients, resulting in increased morbidity and mortality, and healthcare workers (HCW), impacting on staff sickness and morale, to the detriment of patient care. It is crucial to rapidly detect and manage HCAl effectively to prevent both complications and onward transmission to susceptible patients and staff. The burden of nosocomial COVID-19 infections is unknown but one study from China has reported a $41 \%$ prevalence $^{9}$ Worldwide, over 22,000 cases of COVID-19 infection in healthcare workers have been reported, but is likely to be an underestimate ${ }^{10}$. As the number of community-acquired COVID-19 cases reduces, healthcare settings are likely to act as reservoirs of infection. Identifying transmission events in these settings will therefore become increasingly important to manage outbreaks and monitor effective infection control.

We aimed to examine the utility of rapid sequencing of SARS-CoV-2, combined with detailed epidemiological analysis, to investigate healthcare-associated COVID-19 infections and to inform infection control measures in our hospital.

\section{Methods}

\section{Study design, setting and participants}

A prospective surveillance study of COVID-19 infections was conducted at Cambridge University Hospitals NHS Foundation Trust (CUH), a secondary care provider and tertiary referral centre in the East of England (EoE). Clinical specimens collected from patients presenting to 18 hospitals in EoE were submitted to the Public Health England Clinical Microbiology and Public Health Laboratory (CMPHL) at CUH for diagnostic testing. Samples underwent nucleic acid extraction and were tested for presence of SARS-CoV-2 using a validated in-house RT qPCR assay developed by CMPHL (Supplementary Methods). The test was reported as SARS-CoV-2 PCR positive if the cycle threshold $(\mathrm{Ct})$ value was $\leq 36$.

\section{Study procedures}

Demographic, clinical and laboratory data were extracted from the hospital information system (EPIC Systems Corporation, Verona, USA). All PCR-positive diagnostic samples were identified 
medRxiv preprint doi: https://doi.org/10.1101/2020.05.08.20095687; this version posted May 14, 2020. The copyright holder for this preprint (which was not certified by peer review) is the author/funder, who has granted medRxiv a license to display the preprint in perpetuity.

All rights reserved. No reuse allowed without permission.

and transferred from the CMPHL to the Department of Virology for nanopore sequencing. All CUH samples and a selection of samples from East of England hospitals were selected for sequencing.

\section{Sequencing}

Where Ct values were available prior to sample selection, positive samples with a Ct value $\leq 33$ were sequenced using a multiplex PCR based approach according to the modified ARTIC v2 protocol v3 primer set ${ }^{11,12}$. Amplicon libraries were sequenced using MinION flow cells v9.4.1 (Oxford Nanopore Technologies, Oxford, UK). Genomes were assembled using reference-based assembly and a bioinformatic pipeline ${ }^{13}$ using $20 x$ minimum coverage cut-off for any region of the genome and $50.1 \%$ cut-off for calling single nucleotide polymorphisms.

\section{Genomic analysis}

All sequences underwent quality control (QC) filtering and de-duplication to remove repeat samples from the same patient. Multiple sequence alignment was performed using MAFFT ${ }^{14}$. Phylogenetic trees were produced using IQ-TREE ${ }^{15}$ and visualised in Microreact ${ }^{16}$ for weekly hospital reports and the R package ggtree ${ }^{17}$. A pairwise SNP distance matrix was produced from the alignment (Supplementary Methods). Viral lineages ${ }^{18}$ were assigned with the PANGOLIN package (https://github.com/hCoV-2019/pangolin) v1.07.

\section{Epidemiological analysis}

Patient movement data for all SARS-CoV-2 PCR positive samples were extracted from the hospital information system and transferred to the PHE Field Service (Epidemiology). Epidemiological analysis was performed using a cloud-based plotter application (Cluster Track, Camart Ltd, Cambridge, UK).

\section{Review of healthcare-associated infections}

Clusters of COVID-19 cases including HCWs were identified by the clinical and infection control teams and reviewed at a weekly meeting, co-ordinated by the Patient Safety team. The genomic and epidemiological analyses were presented, to help determine whether infections were healthcare-associated and to identify possible causes and interventions. A weekly report was fed back to the clinical, infection control and hospital management teams to inform changes in infection control practice and comply with patient safety procedures.

\section{Ethical considerations}

The study was conducted as part of surveillance for COVID-19 infections under the auspices of Section 251 of the NHS Act 2006. It therefore did not require individual patient consent or ethical approval. The COG-UK study protocol was approved by the Public Health England Research Ethics Governance Group.

\section{Results}

\section{Baseline characteristics and COVID-19 epidemic curve}

368 PCR-confirmed COVID-19 patients were admitted to CUH between 10 March and 24 April 2020 (Figure 1, Table 1). The median age was 66 years (range 0 to 98 years) and $63 \%$ were male. $19.6 \%$ of patients were admitted to critical care units and $20.1 \%$ died. Between 13 March 
medRxiv preprint doi: https://doi.org/10.1101/2020.05.08.20095687; this version posted May 14, 2020. The copyright holder for this preprint (which was not certified by peer review) is the author/funder, who has granted medRxiv a license to display the preprint in perpetuity.

All rights reserved. No reuse allowed without permission.

to 24 April 20201000 samples were selected for sequencing and, after QC and de-duplication, 747 were used for downstream analysis (Supplementary Figure 1). 256/368 (69.6\%) of CUH COVID-19 admissions had sequencing data available (Supplementary Table 1). 52/368 (14.1\%) of admissions were suspected or highly likely hospital-acquired, of which 47 (90.4\%) had genome sequences available. A further $10.3 \%$ of admissions were community-acquired but likely healthcare-associated, and $2.2 \%$ were healthcare workers (Supplementary Table 1). The CUH epidemic curve showed that weekly admissions peaked in week 4 (commencing 30 March 2020) and then declined (Figure 2). The UK went into full lockdown on 23 March 2020. In the early stages of the epidemic community-onset community-acquired infections predominated but the frequency of healthcare-associated infections increased over time.

\section{Genomic analysis}

Each week a sample set was locked and underwent bioinformatic analysis. Out of 1,000 sequenced genomes, 253 were excluded from downstream analysis because they failed to pass QC thresholds, metadata were missing or they were repeat samples from the same patient (Figure 1). The median genome depth of coverage was 6,612x. We compared Ct value versus depth of coverage and found that the latter declined at Ct values $>30$ (Supplementary Figure 2). We also examined the location and frequency of SNPs across the genomes (Supplementary Figure 2). Genomes were assigned to a lineage based on the combination of mutations that have accumulated since the virus emerged. As of 23 March 2020, 12 lineages had been described in the $\mathrm{UK}^{19}$. The vast majority of samples in both the EoE and CUH belonged to lineage B.1. There were no lineage A samples, which have mainly been identified in China, USA, South Korea and Australia $^{18}$ (Figure 3, Supplementary Figure 3).

Phylogenetic trees were used to explore potential genetic clustering and correlation with sampling ward location and/or cases of suspected HAl (Figure 4). Samples collected from the Emergency Department (ED) were phylogenetically dispersed, likely reflecting unconnected recent transmission events in community-acquired infections (Supplementary Figure 4). In contrast, samples collected from several wards in $\mathrm{CUH}$ and an outpatient dialysis unit were genetically clustered (Figure 4). The putative ward clusters include a high proportion of suspected HAI, suggestive of linked transmission chains in the hospital.

Due to its recent introduction into the human population, SARS-CoV-2 has low genetic diversity; here, a median of 8 single nucleotide polymorphisms (SNPs) separated any two samples at CUH (Supplementary Figure 5). This low sequence diversity makes interpretation of putative clusters challenging, as samples may be identical "by chance" rather than because of a recent connected transmission chain. To investigate genomic clustering further we adopted a combined genetic, clinical and epidemiological approach. Samples with zero SNP differences were identified and clusters named numerically by decreasing sample size (Supplementary Table 2).

Overall 114 genomes in 26 clusters shared at least one identical sequence. The two largest clusters each had 15 identical genomes. Patients' medical records (including address, social setting, clinical details and ward movements) were reviewed for all putative genomic clusters to assess whether cases had plausible or likely linked recent transmission (Supplementary 
medRxiv preprint doi: https://doi.org/10.1101/2020.05.08.20095687; this version posted May 14, 2020. The copyright holder for this preprint (which was not certified by peer review) is the author/funder, who has granted medRxiv a license to display the preprint in perpetuity.

All rights reserved. No reuse allowed without permission.

Methods). Of 114 cases from 26 putative clusters, 63 cases $(55.3 \%)$ had strong epidemiological evidence to support recent transmission, 27 cases $(23.7 \%)$ had intermediate evidence, and 24 $(21.1 \%)$ no evidence of connected transmission. Clusters with strong evidence of linked recent transmission include cases where a connection was already suspected, such as groups of likely $\mathrm{HAl}$ seen on several CUH hospital wards (Figure 4), and clusters that were previously not recognised as being linked, such as a care home outbreak involving HCWs based in hospital and community settings. These are described further below.

\section{Application and impact of combined epidemiological and genomic analyses}

Directed by clinical and infection control teams we established a process to conduct focused genomic and epidemiological analyses of suspected HAI cases (Supplementary Figure 6). These were discussed in weekly meetings with an accompanying written report submitted to the hospital. Anonymised examples are described here.

Hospital cluster 1. Six surgical patients on ward A (a non-COVID area) were diagnosed with COVID-19 infection (Figure 4B). All cases had been on the ward for $>14$ days prior to their specimen date and were classified as probable HAI. Genomic data were available for all cases; five differed by zero SNPs and one by a single SNP, consistent with recent ward-based transmission events. In response to this, universal mask use was introduced.

Hospital cluster 2. Four transplant patients on ward B (a non-COVID area) were diagnosed with COVID-19 infection between 3 and 20 April 2020 (Supplementary Figure 7A). A fifth patient, who had been recently discharged from the ward, presented to the ED with COVID-19 infection. Genomic analysis revealed that all 5 cases had identical genomes. Three HCWs were found to have identical genomes in the same cluster as the ward B cases; two had worked on ward B, one of whom had professional contact with the other HCW. These findings led to a review of infection control and PPE procedures for staff and patients in the transplant service.

Dialysis unit cluster. Renal dialysis patients are among the most vulnerable to COVID-19 (up to $19 \%$ mortality ${ }^{20}$ ), with challenging infection control arrangements as most units consist of large open rooms with no barriers between patients. Six patients with end-stage renal failure were diagnosed with COVID-19 between 1 and 20 April 2020, testing positive in several locations including ED and an acute admissions ward (Supplementary Figure 7B). Their viral genomes were identical, and epidemiological investigation revealed they dialysed at the same outpatient dialysis unit on the same days of the week. This suggests linked recent transmission of community-onset healthcare-associated infections. These findings led to a review of infection control procedures in dialysis patients and identified shared patient transportation as a possible risk factor. Genomics can also be used to "rule out" linked transmission. The renal ward (which shares patients with the outpatient dialysis unit) also had a group of COVID-19 cases at around the same time. However, the dialysis unit genomes belonged to lineage B.2 (relatively rare in EoE), whereas the renal ward genomes were the common B.1 lineage, making it very unlikely that infections between the two patient groups were related. 
medRxiv preprint doi: https://doi.org/10.1101/2020.05.08.20095687; this version posted May 14, 2020. The copyright holder for this preprint (which was not certified by peer review) is the author/funder, who has granted medRxiv a license to display the preprint in perpetuity.

All rights reserved. No reuse allowed without permission.

Community cluster. Fifteen patients were admitted to CUH with COVID-19 between 7 and 21 April 2020 with genetically identical viruses. Eight patients were residents at a community care home (care home A). A review of the medical records revealed that another patient in this genetic cluster worked in care home $A$ and one was a retired nurse who worked in an unknown care home. Two cases were paramedics and two were nurses (who worked in different wards at CUH but lived with paramedics). The final case did not have any discernible epidemiological links with the others. In summary, this investigation revealed a cluster of cases with evidence of linked transmission coming from the same care home with potential links between HCW and the care home, none of which had been detected by clinicians or infection control.

The information from these combined epidemiological / genomic investigations was fed back to the clinical, infection control, and hospital management teams. This triggered further investigations of patient isolation, ward cleaning procedures, use of personal protective equipment (PPE) and staff social distancing behaviour. HCAl were also assessed in relation to potential harm caused to patients and recorded in hospital's patient safety reporting system for follow-up and further action.

\section{Discussion}

The value of real-time viral genome sequencing has been demonstrated in previous epidemics ${ }^{21-26}$ We sought to embed genomic surveillance as part of an active SARS-CoV-2 infection control process in a large UK hospital. A rapid sequencing workflow was established on 23 March 2020 using multiplex PCR-based nanopore sequencing, which has been proven to be effective in a wide range of clinical samples and viral loads ${ }^{27}$. We aimed to sequence all available positive samples from $\mathrm{CUH}$ and a selection from each of the EoE regional hospitals submitted to the diagnostic microbiology laboratory, linking with clinical metadata pulled from the hospital electronic patient records system. We also included 44 samples collected as part of a local HCW screening programme (Rivett et al, unpublished). In 5 weeks, over 1,000 SARS-CoV-2 genomes had been sequenced including the majority of $\mathrm{CUH}$ samples from this phase of the epidemic. We applied this system to investigate nosocomial and HCW COVID-19 infections at CUH, integrating genomics with epidemiological and clinical data.

We examined the diversity in SARS-CoV-2 at CUH and found that overall genetic diversity was low and reflected the pattern seen in the EoE as a whole, with most viruses belonging to the B.1 lineage. We identified a median of 8 (range 0 to 24) SNP differences between viruses, and 4.5\% of pairwise comparisons between CUH genomes had 0 to 1 SNP differences. Given the virus's mutation rate and infectious timeframe, cases may share linked recent transmission if there are fewer than $\sim 2$ SNP differences. However, unravelling potential transmission networks requires rapid integration with in-depth epidemiological data.

We investigated clusters of patients and $\mathrm{HCW}$ cases at $\mathrm{CUH}$ in response to queries from the clinical and infection control teams. Using ward location data for patients and HCWs we performed epidemiological analyses to determine if there had been ward-based contact. We compared the genomes of patients and HCWs in the suspected clusters with those of other patients at CUH and in EoE hospitals to examine relatedness. This approach enabled us to confirm or refute evidence 
medRxiv preprint doi: https://doi.org/10.1101/2020.05.08.20095687; this version posted May 14, 2020. The copyright holder for this preprint (which was not certified by peer review) is the author/funder, who has granted medRxiv a license to display the preprint in perpetuity.

All rights reserved. No reuse allowed without permission.

for transmission between patients and / or HCWs within these clusters. Genomic analysis also enabled us to identify cryptic transmission i.e. additional cases that were not initially suspected to be linked to the original ward or HCW clusters. We were also able to use genomic data to refute suspected transmission events (e.g. different lineages between two isolates that were epidemiologically linked), also important as a mechanism to monitor infection control measures. These cases illustrate the power of combining rapid genomic and epidemiological analyses in near real time. In contrast to previous studies ${ }^{28-31}$, we reported results of our investigations to the clinical, infection control and management teams on a weekly basis, thus enabling them to respond to this information and act accordingly within the timeframe of ongoing ward outbreaks. The genomic data informed reviews of patient placement and isolation procedures, assessment of PPE use and staff break arrangements, supporting us to better focus efforts at a time of unprecedented demand on infection control teams. Finally, these analyses are currently being used to inform existing patient safety review processes within our hospital, including investigations related to hospital-onset COVID-19 where the patient has come to harm.

Our study highlights the importance of understanding SARS-CoV-2 transmission within healthcare settings in managing the pandemic. The possible transmission networks that we have identified were complex, involving patients and HCW in both community and hospital settings. However, we have also identified potential transmission networks in other environments including care homes, outpatient units and ambulance services, that have been poorly studied. Although there are strong epidemiological and genomic associations between cases, the mechanism and direction of transmissions remain unclear. The role of asymptomatic intermediates, fomites (including PPE) and the environment are not well understood and require further investigation. During the time frame of this study a number of infection control interventions were implemented across the hospital, as well as national public health measures to reduce community spread. Understanding the interaction between such interventions and nosocomial transmission are complex (especially in the context of the comparably long incubation period for SARS-CoV-2 relative to other respiratory viruses), but critical in enabling healthcare providers to safely deliver existing services in the context of a pandemic.

We acknowledge several limitations to our study. Firstly, we were unable to sequence all of the genomes from samples that were collected during the study period. We may therefore have missed the opportunity to investigate all potential transmission events. Furthermore, we only had main ward location data for most of the HCW and could have overlooked potential epidemiological links with patients with whom they had contact on other wards. Similarly, we were unable to track $\mathrm{HCW}$ movements outside their main ward location to identify potential contact with patients on other wards or HCW within shared communal areas. Finally, due to the recent introduction of SARS-CoV-2 into the human population, highly similar genomes are not sufficient evidence to infer a recent transmission, in the absence of confirmatory epidemiological data. However, our experience indicates that further investigation of genomic clusters with highly similar genomes can uncover previously unknown epidemiological links. Furthermore, we were able to use rapidly generated genomic data to investigate $\mathrm{HCAl}$ within the hospital setting. The next initiative is to expand this platform into a more detailed analysis of infections in HCW and in community settings, such as residential homes. As the practical challenges associated with implementing real-time 
medRxiv preprint doi: https://doi.org/10.1101/2020.05.08.20095687; this version posted May 14, 2020. The copyright holder for this preprint (which was not certified by peer review) is the author/funder, who has granted medRxiv a license to display the preprint in perpetuity.

All rights reserved. No reuse allowed without permission.

genome sequencing during epidemics are overcome, unlocking the real power of genomic epidemiology will require its integration with clinical and public health systems to support decisionmaking on local, national and international scales.

\section{Acknowledgments}

We acknowledge the assistance of the laboratory staff of CMPHL for processing the diagnostic samples and the clinical teams (infectious diseases, microbiology, virology, infection control) at $\mathrm{CUH}$ for their assistance with the investigation of healthcare-associated infections. We are grateful to Richard Smith (CUH Patient Safety Lead), Lucy Rivett, Dominic Sparkes, Nick K. Jones and Matthew Routledge (for providing some HCW data), and Anthony Underwood (Centre for Genomic Pathogen Surveillance) for helpful discussions and advice.

\section{Funding}

This work was funded COG-UK, which is supported by funding from the Medical Research Council (MRC) part of UK Research \& Innovation (UKRI), the National Institute of Health Research (NIHR) and Genome Research Limited, operating as the Wellcome Sanger Institute. It was also supported by the Wellcome Trust (Senior Fellowship 207498/Z/17/Z and ARTIC Network Collaborative Award 206298/B/17/Z to IG, Collaborative Award 204870/Z/16/Z supporting CJH, Senior Research Fellowship to SGB 215515/Z/19/Z, Senior Clinical Research Fellowship $108070 / Z / 15 / Z$ to MPW), the Academy of Medical Sciences and the Health Foundation (Clinician Scientist Fellowship to MET), and the National Institute for Health Research Cambridge Biomedical Research Centre at the Cambridge University Hospitals NHS Foundation Trust (BW, $\mathrm{GD}, \mathrm{MET}$ ). The views expressed are those of the authors and not necessarily those of the NHS, the NIHR or the Department of Health and Social Care.

\section{References}

1. Zhou P, Yang X Lou, Wang XG, et al. A pneumonia outbreak associated with a new coronavirus of probable bat origin. Nature 2020;579(7798):270-3.

2. Andersen KG, Rambaut A, Lipkin WI, Holmes EC, Garry RF. The proximal origin of SARS-CoV-2. Nat. Med. 2020;26(4):450-2.

3. Duchene S, Featherstone L, Haritopoulou-Sinanidou M, Rambaut A, Lemey P, Baele G. Temporal signal and the phylodynamic threshold of SARS-CoV-2. bioRxiv 2020;2020.05.04.077735.

4. Bedford T, Greninger AL, Roychoudhury P, et al. Cryptic transmission of SARS-CoV-2 in Washington State. medRxiv 2020;2020.04.02.20051417.

5. Grubaugh ND, Ladner JT, Lemey P, et al. Tracking virus outbreaks in the twenty-first century. Nat. Microbiol. 2019;4(1):10-9.

6. Gardy JL, Loman NJ. Towards a genomics-informed, real-time, global pathogen surveillance system. Nat Rev Genet 2018;19(1):9-20.

7. Houldcroft CJ, Beale MA, Breuer J. Clinical and biological insights from viral genome sequencing. Nat Rev Microbiol 2017;15(3):183-92.

8. Grubaugh ND, Ladner JT, Kraemer MUG, et al. Genomic epidemiology reveals multiple introductions of Zika virus into the United States. Nature 2017;546(7658):401-5.

9. Wang D, Hu B, Hu C, et al. Clinical Characteristics of 138 Hospitalized Patients with 2019 Novel Coronavirus-Infected Pneumonia in Wuhan, China. JAMA - J Am Med Assoc 
medRxiv preprint doi: https://doi.org/10.1101/2020.05.08.20095687; this version posted May 14, 2020. The copyright holder for this preprint (which was not certified by peer review) is the author/funder, who has granted medRxiv a license to display the preprint in perpetuity.

All rights reserved. No reuse allowed without permission.

2020;323(11):1061-9.

10. WHO. Coronavirus disease 2019 (COVID-19) Situation Report - 82 [Internet]. 2020 [cited 2020 May 8];Available from: https://www.who.int/docs/defaultsource/coronaviruse/situation-reports/20200411-sitrep-82-covid-19.pdf

11. Quick J. artic-ncov2019/primer_schemes/nCoV-2019/V3 at master · artic-network/articncov2019 [Internet]. 2020 [cited 2020 May 6];Available from: https://github.com/articnetwork/artic-ncov2019/tree/master/primer_schemes/nCoV-2019/V3

12. Quick J. nCoV-2019 sequencing protocol [Internet]. 2020 [cited 2020 May 6];Available from: https://www.protocols.io/view/ncov-2019-sequencing-protocol-bbmuik6w

13. Loman N, Rowe W, Rambaut A. nCoV-2019 novel coronavirus bioinformatics protocol [Internet]. 2020 [cited 2020 May 6];Available from: https://artic.network/ncov2019/ncov2019-bioinformatics-sop.html

14. Katoh K, Standley DM. MAFFT Multiple Sequence Alignment Software Version 7: Improvements in Performance and Usability. Mol Biol Evol 2013;30(4):772-80.

15. Nguyen LT, Schmidt HA, Von Haeseler A, Minh BQ. IQ-TREE: A fast and effective stochastic algorithm for estimating maximum-likelihood phylogenies. Mol Biol Evol 2015;32(1):268-74.

16. Argimón S, Abudahab K, Goater RJE, et al. Microreact: visualizing and sharing data for genomic epidemiology and phylogeography. Microb genomics 2016;2(11):e000093.

17. Yu G, Smith DK, Zhu H, Guan Y, Lam TTY. ggtree: an r package for visualization and annotation of phylogenetic trees with their covariates and other associated data. Methods Ecol Evol 2017;8(1):28-36.

18. Rambaut A, Holmes EC, Hill V, et al. A dynamic nomenclature proposal for SARS-CoV-2 to assist genomic epidemiology. bioRxiv 2020;2020.04.17.046086.

19. Consortium C-U. COVID-19 Genomics UK (COG-UK) Consortium Weekly Report \#1 23rd March 2020 [Internet]. 2020 [cited 2020 May 7];Available from:

https://www.cogconsortium.uk/wp-content/uploads/2020/04/14-COG-UK-Weekly-Report23rd-March-20204.pdf

20. Association TR. COVID-19 data [Internet]. 2020 [cited 2020 May 8];Available from: https://renal.org/covid-19/data/

21. Arias A, Watson SJ, Asogun D, et al. Rapid outbreak sequencing of Ebola virus in Sierra Leone identifies transmission chains linked to sporadic cases. Virus Evol 2016;2(1).

22. Quick J, Loman NJ, Duraffour S, et al. Real-time, portable genome sequencing for Ebola surveillance. Nature 2016;530(7589):228-32.

23. Dudas G, Carvalho LM, Bedford T, et al. Virus genomes reveal factors that spread and sustained the Ebola epidemic. Nature 2017;544(7650):309-15.

24. Gardy JL, Naus M, Amlani A, et al. Whole-genome sequencing of measles virus genotypes $\mathrm{H} 1$ and D8 during outbreaks of infection following the 2010 Olympic Winter Games reveals viral transmission routes. J Infect Dis 2015;212(10):1574-8.

25. MacFadden DR, McGeer A, Athey $T$, et al. Use of genome sequencing to define institutional influenza outbreaks, Toronto, Ontario, Canada, 2014-15. Emerg Infect Dis 2018;24(3):492-7.

26. Andersen KG, Shapiro BJ, Matranga CB, et al. Clinical Sequencing Uncovers Origins and Evolution of Lassa Virus. Cell 2015;162(4):738-50.

27. Quick J, Grubaugh ND, Pullan ST, et al. Multiplex PCR method for MinION and Illumina sequencing of Zika and other virus genomes directly from clinical samples. Nat Protoc 2017;12(6):1261-6.

28. Köser CU, Holden MTG, Ellington MJ, et al. Rapid Whole-Genome Sequencing for Investigation of a Neonatal MRSA Outbreak. N Engl J Med 2012;366(24):2267-75.

29. Harris SR, Cartwright EJP, Török ME, et al. Whole-genome sequencing for analysis of an outbreak of meticillin-resistant Staphylococcus aureus: A descriptive study. Lancet Infect 
medRxiv preprint doi: https://doi.org/10.1101/2020.05.08.20095687; this version posted May 14, 2020. The copyright holder for this preprint

(which was not certified by peer review) is the author/funder, who has granted medRxiv a license to display the preprint in perpetuity.

All rights reserved. No reuse allowed without permission.

Dis $2013 ; 13(2): 130-6$.

30. Coll F, Harrison EM, Toleman MS, et al. Longitudinal genomic surveillance of MRSA in the UK reveals transmission patterns in hospitals and the community. Sci Transl Med 2017;9(413).

31. Houldcroft CJ, Roy S, Morfopoulou S, et al. Use of Whole-Genome Sequencing of Adenovirus in Immunocompromised Pediatric Patients to Identify Nosocomial Transmission and Mixed-Genotype Infection. J Infect Dis 2018;218(8):1261-71.

32. Kalyaanamoorthy S, Minh BQ, Wong TKF, Von Haeseler A, Jermiin LS. ModelFinder: Fast model selection for accurate phylogenetic estimates. Nat Methods 2017;14(6):5879.

33. Paradis E, Schliep K. Ape 5.0: An environment for modern phylogenetics and evolutionary analyses in R. Bioinformatics 2019;35(3):526-8. 
medRxiv preprint doi: https://doi.org/10.1101/2020.05.08.20095687; this version posted May 14, 2020. The copyright holder for this preprint (which was not certified by peer review) is the author/funder, who has granted medRxiv a license to display the preprint in perpetuity. All rights reserved. No reuse allowed without permission.

Figure 1. Study flow diagram.

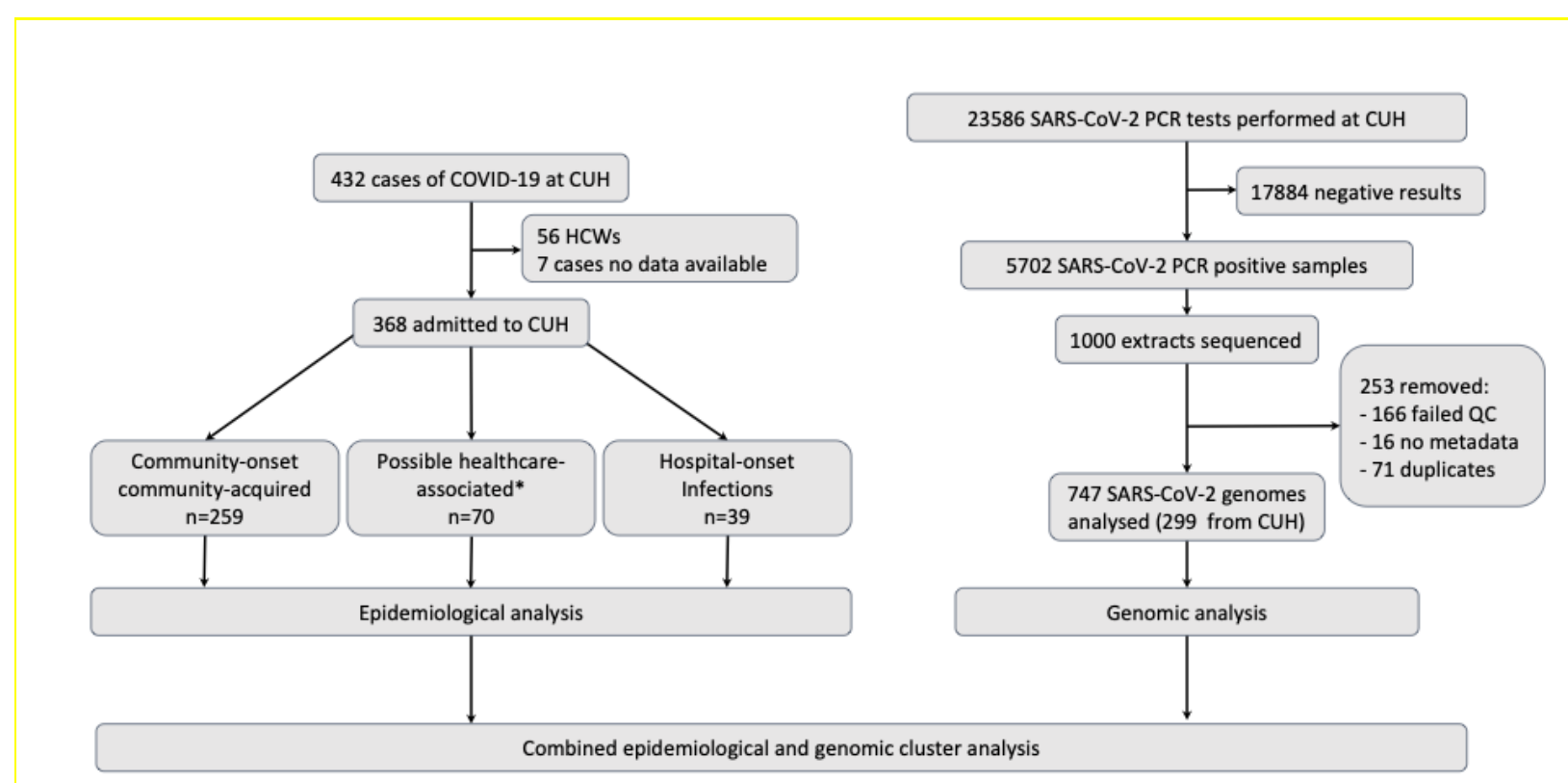

${ }^{*}$ Possible healthcare-associated infections. This category includes (i) Community onset suspected healthcareassociated; (ii) Hospital onset indeterminate healthcare-associated; (iii) Hospital onset suspected healthcareassociated; (iv) healthcare workers tested as part of routine clinical care.

Out of 1,000 sequenced genomes, 166 failed QC ( 2 were removed as <29Kb, 164 removed as $>2,990 \mathrm{~N}$ ) 
medRxiv preprint doi: https://doi.org/10.1101/2020.05.08.20095687; this version posted May 14, 2020. The copyright holder for this preprint (which was not certified by peer review) is the author/funder, who has granted medRxiv a license to display the preprint in perpetuity.

Table 1. Baseline characteristics of COVID-19 patients at CUH

\begin{tabular}{|c|c|}
\hline Baseline characteristics & \\
\hline Number of patients & 374 \\
\hline $\begin{array}{l}\text { Age in years, mean (range) } \\
\text { Age in years, median (IQR) }\end{array}$ & $\begin{array}{l}64(0-98) \\
67(51-79)\end{array}$ \\
\hline Male sex & $233(62.3 \%)$ \\
\hline Female sex & $141(37.7 \%)$ \\
\hline Ethnicity - White & $267(71.4 \%)$ \\
\hline Ethnicity - Black, Asian and minority ethnic & $28(7.5 \%)$ \\
\hline Ethnicity - not stated/missing & $79(21.1 \%)$ \\
\hline \multicolumn{2}{|l|}{ Co-morbidities } \\
\hline Hypertension & $115(31.3 \%)$ \\
\hline Ischaemic heart disease & $53(14.4 \%)$ \\
\hline Cardiac failure & $25(6.8 \%)$ \\
\hline Asthma & $45(12.8 \%)$ \\
\hline Chronic obstructive pulmonary disease & $30(8.2 \%)$ \\
\hline Diabetes mellitus & $78(21.2 \%)$ \\
\hline Chronic kidney disease & $37(9.9 \%)$ \\
\hline Hepatic cirrhosis & $16(4.4 \%)$ \\
\hline Dementia & $32(8.7 \%)$ \\
\hline
\end{tabular}


medRxiv preprint doi: https://doi.org/10.1101/2020.05.08.20095687; this version posted May 14, 2020. The copyright holder for this preprint (which was not certified by peer review) is the author/funder, who has granted medRxiv a license to display the preprint in perpetuity.

\begin{tabular}{|l|c|}
\hline Obesity & $51(13.9 \%)$ \\
\hline Classification of infection* & \\
\hline Community onset, community associated & $261(69.9 \%)$ \\
\hline Community onset, suspected healthcare-associated & $40(10.7 \%)$ \\
\hline Hospital onset, indeterminate healthcare-associated & $11(2.9 \%)$ \\
\hline Hospital onset, suspected healthcare-associated & $13(3.5 \%)$ \\
\hline Hospital onset, healthcare-associated & $39(10.5 \%)$ \\
\hline Healthcare worker & $9(2.4 \%)$ \\
\hline Unknown & $1(0.3 \%)$ \\
\hline Outcome & $72(19.3 \%)$ \\
\hline Admission to hospital & $347(92.5 \%)$ \\
\hline Admission to critical care & \\
\hline Died as an inpatient & \\
\hline
\end{tabular}

\section{Definitions of COVID-19 infections}

1. Community onset, community associated $=$ diagnostic sample positive within 48 hours of admission and no healthcare contact during the previous 14 days

2. Community onset, suspected healthcare-associated = diagnostic sample positive within 48 hours of admission with healthcare contact during the previous 14 days

3. Hospital onset, indeterminate healthcare-associated $=$ diagnostic sample positive after 48 hours but less than 7 days post-admission

4. Hospital onset, suspected healthcare-associated $=$ diagnostic sample positive 7 to 14 days post admission

5. Hospital onset, healthcare-associated $=$ diagnostic sample positive $>14$ days post-admission

6. Healthcare worker 
medRxiv preprint doi: https://doi.org/10.1101/2020.05.08.20095687; this version posted May 14, 2020. The copyright holder for this preprint (which was not certified by peer review) is the author/funder, who has granted medRxiv a license to display the preprint in perpetuity.

All rights reserved. No reuse allowed without permission.

Figure 2. Epidemic curve of COVID-19 infections at CUH

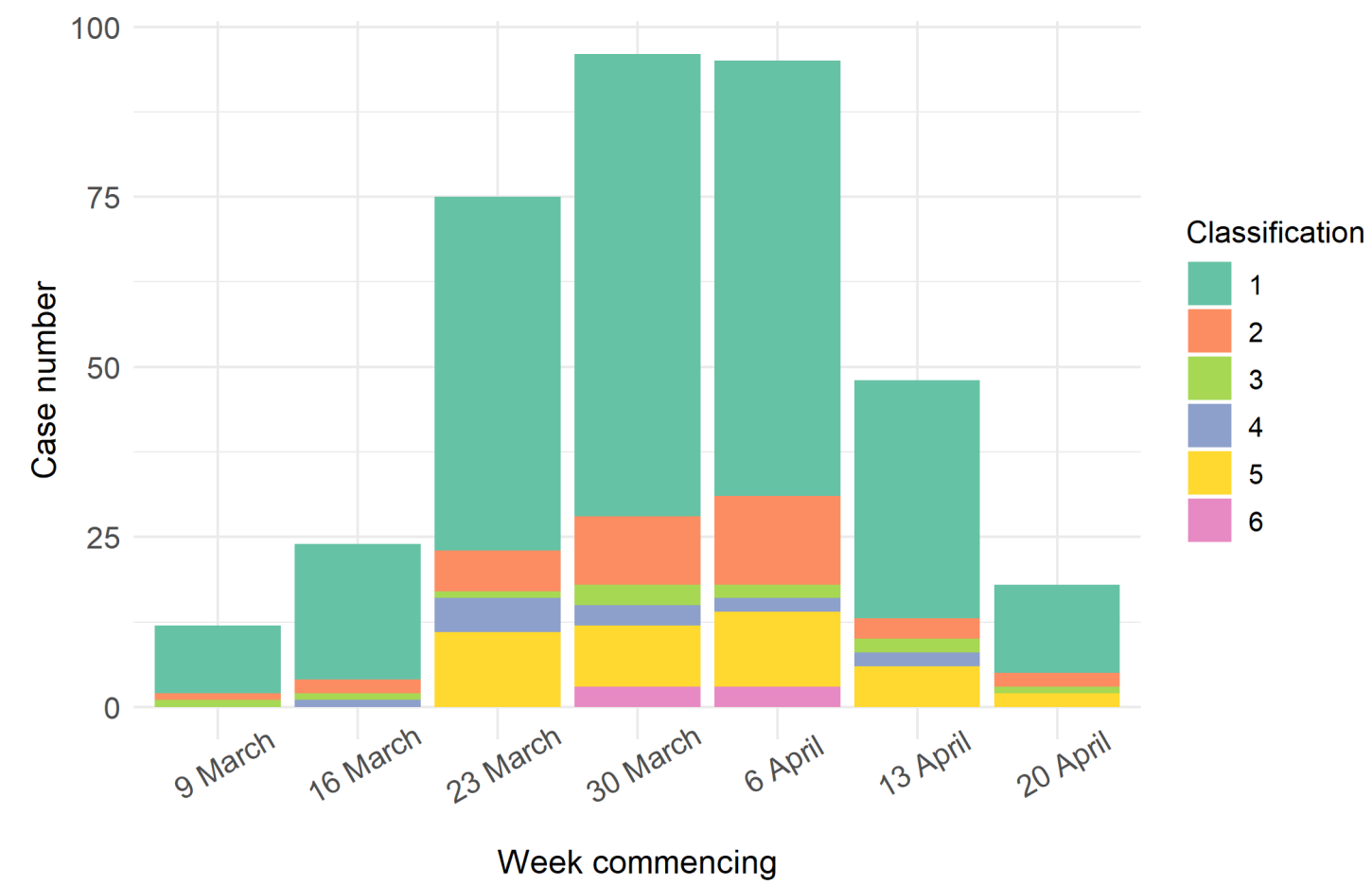

Classification of infection: 1. Community onset, community associated; 2 . Community onset, suspected healthcareassociated; 3. Hospital onset, indeterminate healthcare-associated; 4. Hospital onset, suspected healthcareassociated; 5 . Hospital onset, healthcare-associated; 6 . Healthcare worker 
medRxiv preprint doi: https://doi.org/10.1101/2020.05.08.20095687; this version posted May 14, 2020. The copyright holder for this preprint (which was not certified by peer review) is the author/funder, who has granted medRxiv a license to display the preprint in perpetuity.

All rights reserved. No reuse allowed without permission.

Figure 3. SARS-CoV-2 lineages identified in the East of England and CUH.

3A. Map of the EoE showing the distribution of SARS CoV-2 lineages in different sites

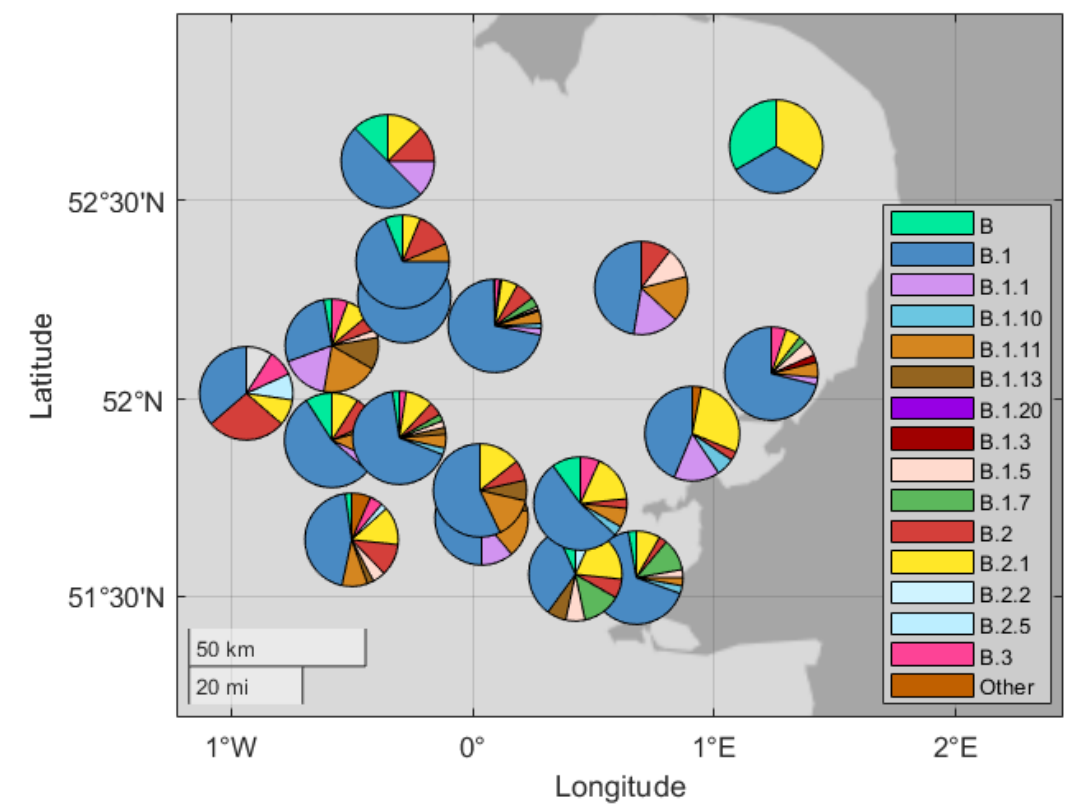

Map of East of England showing the different hospital sites (in circles) and the breakdown on SARS-CoV-2 lineages by site.

3B. Comparison of the frequency of SARS-CoV-2 lineages in CUH versus other sites in the EoE

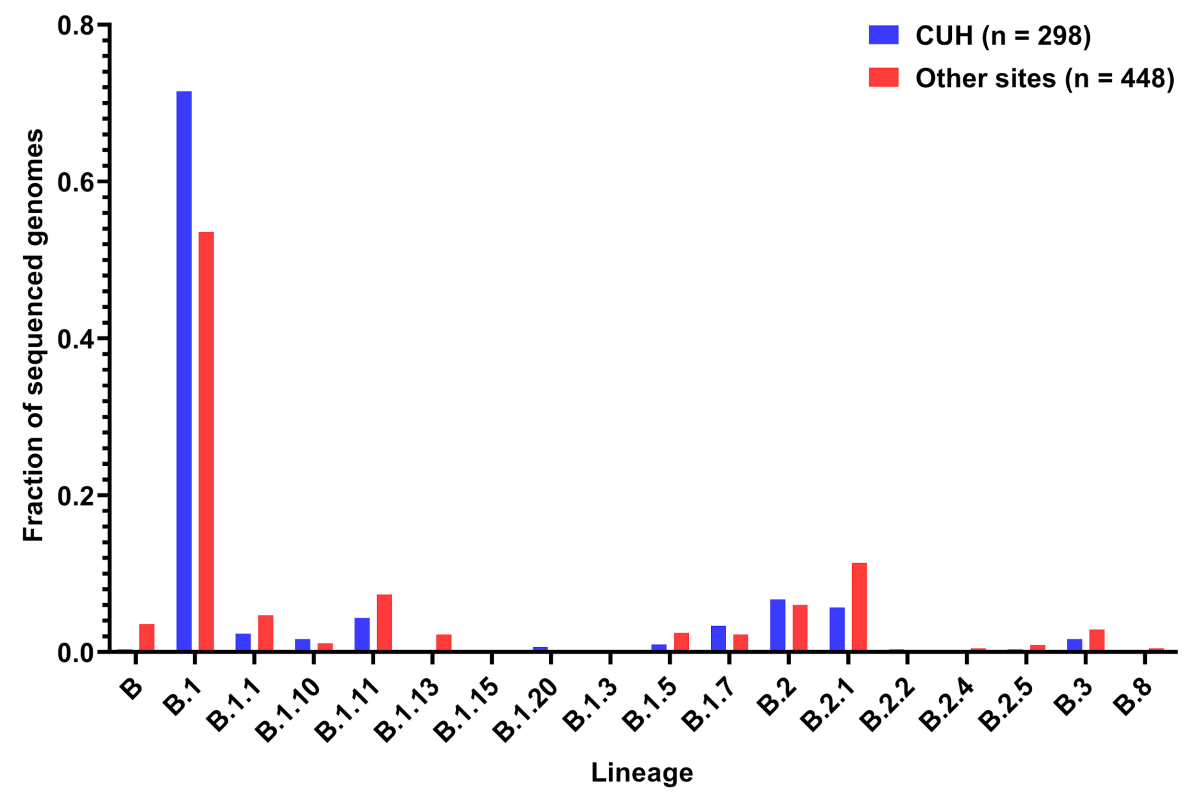

Frequency distribution of SARS-CoV-2 lineages in CUH (blue) versus other sites in the East of England (shown in red). One sample was excluded due to missing location metadata. 
medRxiv preprint doi: https://doi.org/10.1101/2020.05.08.20095687; this version posted May 14, 2020. The copyright holder for this preprint (which was not certified by peer review) is the author/funder, who has granted medRxiv a license to display the preprint in perpetuity.

Figure 4. Phylogenetic tree and epidemiological timeline from $\mathrm{CUH}$

\section{A. Phylogenetic tree of SARS-CoV-2 genomes from CUH}

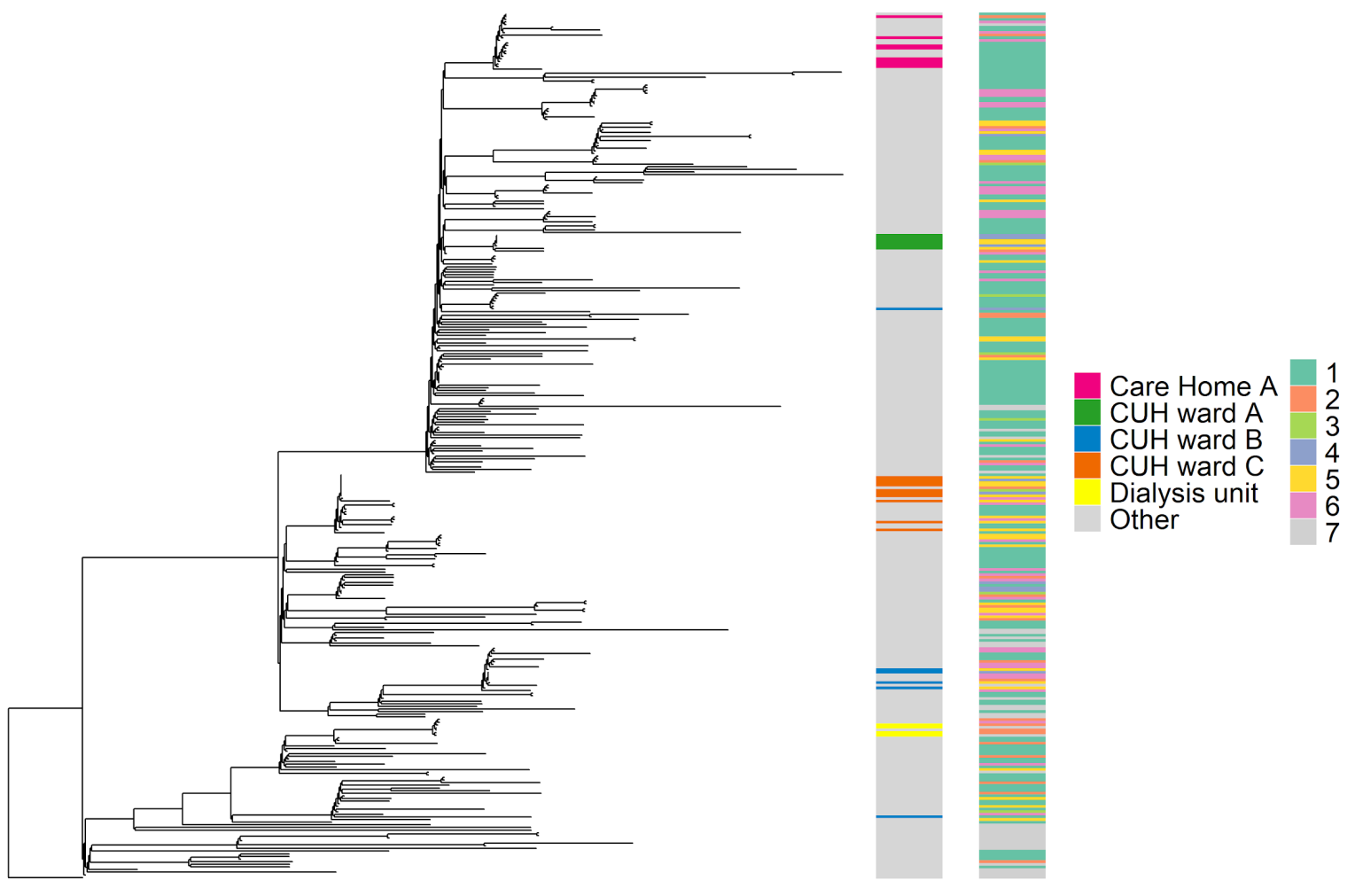

Phylogenetic tree of 299 SARS-CoV-2 genomes form CUH and 30 international genomes (Supplementary Methods, Supplementary Figure 4). The tree is rooted on a December 2019 genome from Wuhan, China. The left hand column highlights the hospital and community clusters in colours. Wards A, B and C all had clusters of HAI cases with viruses $<2$ SNPs different. Eight Ward C cases are contained within one of the largest clusters of identical viruses ( $n=15$ ). Genomic clusters containing the cases for Wards B and C, the dialysis unit and Care home A all include HCWs. The right hand column shows the classification of infection: 1. Community onset, community associated; 2 . Community onset, suspected healthcare-associated; 3. Hospital onset, indeterminate healthcare-associated; 4. Hospital onset, suspected healthcare-associated; 5 . Hospital onset, healthcare-associated; 6. Healthcare worker; 7 . Unable to determine/ data missing. 
medRxiv preprint doi: https://doi.org/10.1101/2020.05.08.20095687; this version posted May 14,2020 . The copyright holder for this preprint (which was not certified by peer review) is the author/funder, who has granted medRxiv a license to display the preprint in perpetuity.

All rights reserved. No reuse allowed without permission.

\section{B. Epidemiological timeline of ward A cluster}

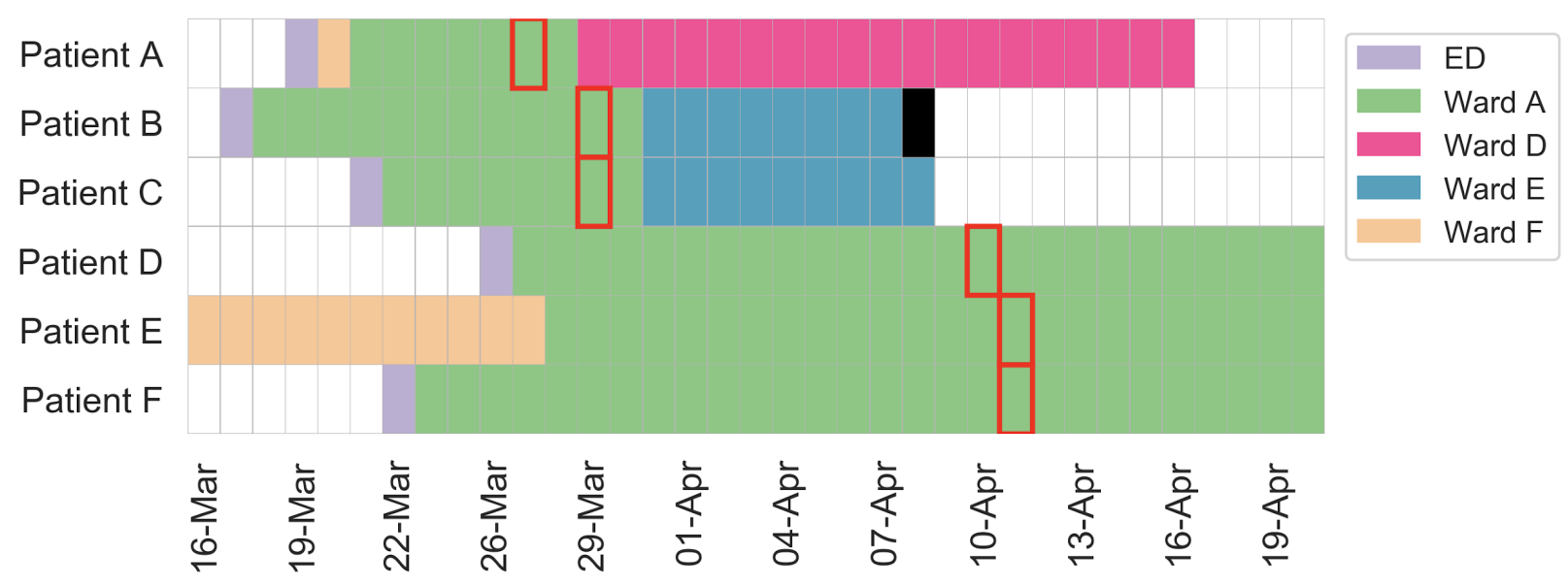

Six patients on ward A were diagnosed with COVID-19 infection. All had been on the ward for $>14$ days prior to their specimen date and were considered likely to be hospital-acquired infections. The date of the first positive sample collection is shown with a red box. Five of the viral genomes (Patients A to E) had zero SNP differences between them, and one of the viral genomes (Patient F) differed by 1 SNP. 
medRxiv preprint doi: https://doi.org/10.1101/2020.05.08.20095687; this version posted May 14, 2020. The copyright holder for this preprint (which was not certified by peer review) is the author/funder, who has granted medRxiv a license to display the preprint in perpetuity.

All rights reserved. No reuse allowed without permission.

\section{Supplementary Methods}

\section{SARS-CoV-2 molecular testing}

Nucleic acid extraction was undertaken using the NUCLISENS easyMAG platform (Biomerieux, Marcy L-Etoile), in accordance with manufacturers' instructions. Nucleic acids were extracted from $500 \mu \mathrm{L}$ of sample, with a dilution of MS2 bacteriophage added pre-extraction to act as an internal extraction and inhibition control. The presence of SARS-CoV-2 was assessed using an in-house generated and validated one-step RT q-PCR assay that detects a 222 base-pair region of the SARS-CoV-2 RdRp genes, along with an MS2 bacteriophage internal extraction control. The RdRp gene was detected using the RdRp For primer (ATGGGTTGGGATTATCCTAAATGTGA) and the RdRp Rev primer (AGCAGTTGTGGCATCTCCTGATGAG) with a FAM labelled MGB RdRp Probe 3 (ATGCTTAGAATTATGGCCTCAC). The internal extraction control was detected using the MS2 For primer (TGGCACTACCCCTCTCCGTATTCACG), the MS2 Rev primer (GTACGGGCGACCCCACGATGAC) and a ROX-BHQ2 labelled MS2 probe (CACATCGATAGATCAAGGTGCCTACAAGC). Amplification reactions and detection of PCR products were performed using the Rotorgene ${ }^{\mathrm{TM}}$ PCR instrument. A typical reaction contained $400 \mathrm{nM}$ of For and Rev primers for the RdRp genes and 200nM of the the MS2 internal control For and Rev primer pair, along with $120 \mathrm{nM}$ of the RdRpand MS2 probes. Reactions typically contained $25 \%$ extracted nucleic acid and were cycled through the following conditions $25^{\circ} \mathrm{C}$ $2 \mathrm{~min}, 50^{\circ} \mathrm{C} 15 \mathrm{~min}, 95^{\circ} \mathrm{C} 2 \mathrm{~min}$ followed by 45 cycles of $95^{\circ} \mathrm{C}$ and $60^{\circ} \mathrm{C}$. Samples that generated a $\mathrm{Ct}$ value $\leq 36$ were considered positive. Samples and negative control (molecular grade water) were individually spiked with MS2 bacteriophage internal control (4600 pfu per extraction) prior to nucleic acid extraction to identify any inhibitors or extraction issues. Positive control material, BetaCoV/England/02/2020, was obtained from PHE Colindale and was essentially purified virus RNA diluted down to give a cycle threshold value of 26-28. Negative controls included extracted molecular grade water.

\section{Sample and data collection}

Sample collection, metadata curation and linkage to sequencing IDs involved coordination between multiple teams and critically depended on good relations between the sequencing and diagnostic laboratory staff (Supplementary Figure 1). Each day samples with positive SARS-CoV2 PCR results from the last 24 to 72 hours were identified from the hospital information system and clinical metadata was extracted, formatted and integrated into a master metadata file. A 15 microlitre aliquot of the RNA extract of all CUH samples and a random selection of EoE samples were collected from the diagnostic microbiology laboratory for local sequencing. These were assigned COG-UK sequencing codes which were integrated back into the master metadata file. For samples that were not sequenced locally, the remaining RNA extract was collected from the diagnostic microbiology laboratory and sent to the Wellcome Sanger Institute for sequencing as part of the COG-UK consortium. Each week, clinical metadata and sequencing data were combined and formatted for upload to the MRC CLIMB system. Data manipulations were performed in $R(v$ 3.6.2) using the tidyverse packages $(v$ 1.3.0) installed onto computers within the Trust network. 
medRxiv preprint doi: https://doi.org/10.1101/2020.05.08.20095687; this version posted May 14, 2020. The copyright holder for this preprint (which was not certified by peer review) is the author/funder, who has granted medRxiv a license to display the preprint in perpetuity.

All rights reserved. No reuse allowed without permission.

\section{Sequencing details}

Samples were sequenced using Nanopore technology following the ARTICnetwork V3 protocol (https://dx.doi.org/10.17504/protocols.io.bbmuik6w) and assembled using the ARTICnetwork assembly pipeline (https://artic.network/ncov-2019/ncov2019-bioinformatics-sop.html). Median genome depth of coverage was 6,612x across all 747 genomes. 14 samples in our dataset were also sequenced with Illumina technology at the Wellcome Sanger Institute as part of COG-UK. There was $100 \%$ concordance in called nucleotides between sample pairs. Four genomes differed because of base pairs called in the Illumina data that were missing in the Nanopore sequences. The accession numbers of the samples included in this study are available in Supplementary Table 4.

\section{Bioinformatic analysis}

Consensus fasta sequence quality control cutoffs were: size $>29 \mathrm{~Kb}, \mathrm{~N}$ count $<2990(\sim 10 \%)$. After QC filtering, de-duplication and matching with metadata, the first sample set analysed comprised 197 genomes collected up to 10th April 2020; set 2 had 444 genomes up to 15th April, and set 3 (presented here) had 747 genomes up to 24th April. 30 reference genomes were added to the sample sets downloaded from GISAID (https://www.gisaid.org/; Supplementary Table 3). The reference genomes were chosen to represent the major branches of the global phylogenetic tree as visualised in Nextstrain (https://nextstrain.org/) to provide broader context, including a sample from December 2019 collected in Wuhan, China, used to root the tree. Multiple sequence alignment was performed using MAFFT ( $v$ 7.458) with default settings, command:

/PATH/mafft" --retree 2 --inputorder "multi_fasta.fasta" > "aligned_multi_fasta

The alignment was manually inspected using AliView. Maximum likelihood trees were produced using IQ-TREE software ${ }^{15}$ for all samples passing QC filters and the subset of samples from CUH ( $n=299$ for this dataset). Initial tests with the ModelFinder Plus option ${ }^{32}$, which selects the optimal nucleotide substitution model out of over 200 options

(http://www.iqtree.org/doc/Substitution-Models), consistently identified GTR+F+l as the best model. Therefore from 24th April (including analysis presented here) we specified GTR+F+I. Command using ModelFinder Plus:

/PATH/iqtree -s aligned_filtered_multi_fasta -m MFP

Command with GTR+F+I model specified:

/PATH/iqtree -s aligned_filtered_multi_fasta $-m$ GTR+F+I

Trees were manually inspected in FigTree, rooted on the 2019 Wuhan sample (EPI ISL 402123), ordered by descending node and exported as Newick files. Trees were visualised in online software Microreact ${ }^{16}$ in a private account to explore relationships between wards and clinicoepidemiological questions for our weekly reports. Further visualisations were produced in $\mathrm{R}$ using the packages $A_{p e}{ }^{33}$ ( $\left.v 5.3\right)$ and ggtree ${ }^{17}$ ( $v$ 2.0.4).

A SNP difference matrix was produced from the multiple sequence alignment using the snp-dists package (v 0.7.0; https://github.com/tseemann/snp-dists; installed into a conda environment), command:

snp-dists -c aligned_filtered_multi_fasta.aln > snp_dist_matrix.csv 
medRxiv preprint doi: https://doi.org/10.1101/2020.05.08.20095687; this version posted May 14, 2020. The copyright holder for this preprint (which was not certified by peer review) is the author/funder, who has granted medRxiv a license to display the preprint in perpetuity.

All rights reserved. No reuse allowed without permission.

The matrix was exported as .csv and manipulated in $\mathrm{R}$ using the Matrix and tidyverse packages for ward and pairwise SNP comparisons and plotted using the ggplot2 ( $v$ 3.3.0) package. A heatmap was produced in python using the seaborn ( $v 0.10 .0)$ clustermap function. To identify clusters with zero SNP differences we used the scipy.cluster.hierarchy functions linkage and fcluster setting a maximum distance of zero (scipy $\vee 1.4 .1$ ). Clusters were named in descending size order and linked with sample metadata and lineage data.

\section{Investigation of genetic clusters with zero SNP differences}

Patient records from each case within a putative genomic cluster were manually reviewed in detail by authors BW, WLH and MET and assigned a score of 1 (strong evidence supporting a recent linked transmission chain, e.g. patients co-located on the same ward becoming positive within the incubation period of the virus), 2 (a plausible transmission chain is present e.g. patients becoming positive while located in nearby wards within the hospital but who did not appear to be in direct contact), and 3 (no evidence of any transmission connections between cases).

\section{Epidemiological analysis methods}

\section{Timeline plotting}

Space time relationships between patients were plotted using patient specific time lines by exporting the bed and ward admission dates, dates of transfer, dates of discharge or date of death obtained from hospital information system (EPIC Systems Corporation, Verona, USA) and importing them into a cloud-based timeline plotter application (Cluster Track, Camart Ltd, Cambridge available at Clusterack.com). Earliest positive specimen date for COVID19 was obtained from the laboratory records and date of onset of symptoms from the clinical records and uploaded.

The application aided visualisation of ward and time relations by assigning unique colours to wards and then ward presence by date along the $x$ axis shown in days, such that a solid timeline bar by colour and by date permitted the visualisation of the location of each patient over time. The positive specimen date for COVID 19, genomic cluster, death and discharge were each overlaid on the patient timeline using standard visual representation built into the application. Visualisation was aided by using the sort command within the application on admission date, earliest positive specimen date, or first ward to which admitted. Separate plots of subset of the total cases were created to provide clearer visualisation when needed

\section{Ward time and genomic cluster plots}

A clustering and network analysis function was used in the Cluster track application in which an algorithm links patients with admission days to the same ward on the same date and displays a network diagram to indicate these overlapping cases.

More advanced space time clustering was undertaken by exporting these timeline data sets into an SQL database running a more advanced clustering algorithm in which time parameters were set for the presumed susceptible, infectious and non-infectious/ recovered intervals counting from the earliest positive specimen date. The algorithm identified and linked cases in which two or more patients had an overlap on the same ward of the time interval of infectiousness of an earlier 
medRxiv preprint doi: https://doi.org/10.1101/2020.05.08.20095687; this version posted May 14, 2020. The copyright holder for this preprint (which was not certified by peer review) is the author/funder, who has granted medRxiv a license to display the preprint in perpetuity. All rights reserved. No reuse allowed without permission.

case with the interval of susceptibility in a later case or cases. Links continue to be made until no further overlaps of the infectious interval in an earlier case occurred with the interval of susceptibility in a later case on the same ward: this ended the space time cluster.

The cluster diagrams of the space time clustered cases were reviewed. Cases within the same space time cluster that belonged to the same genomic cluster were deemed to be supportive of a recent transmission event. 


\section{Supplementary Figures}

\section{Supplementary Figure 1. Data and Sample Processing at CUH}

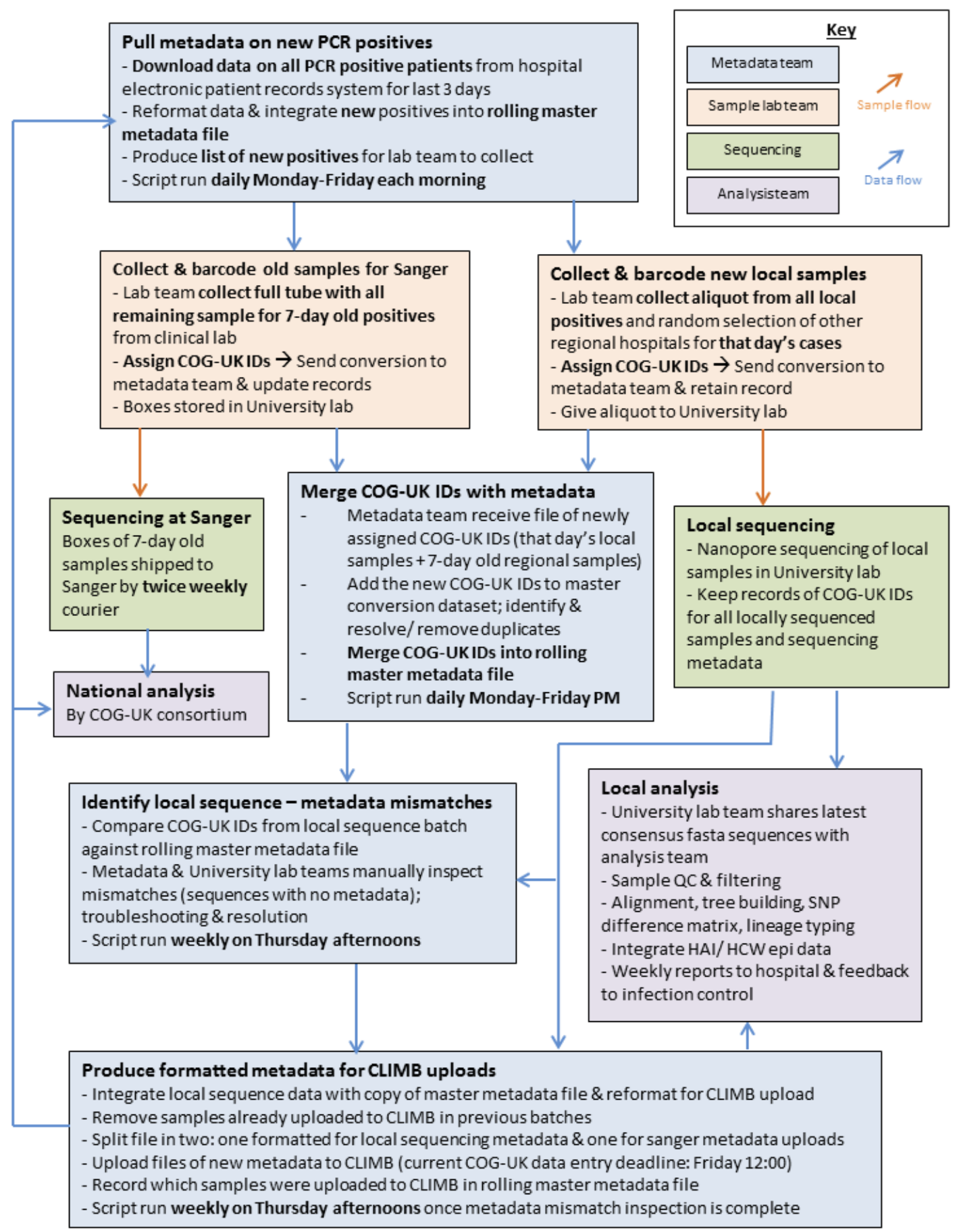


medRxiv preprint doi: https://doi.org/10.1101/2020.05.08.20095687; this version posted May 14, 2020. The copyright holder for this preprint (which was not certified by peer review) is the author/funder, who has granted medRxiv a license to display the preprint in perpetuity.

\section{Supplementary Figure 2.}

\section{A. Ct value plotted against percentage coverage for 947 SARS-CoV-2 genomes}

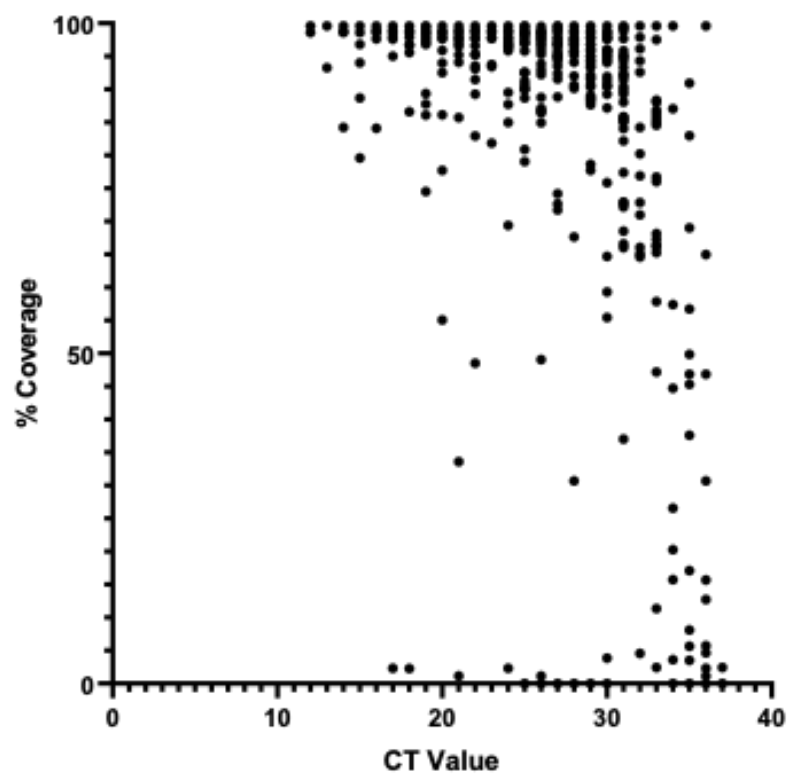

The Ct value plotted against the percent of SARS-CoV-2 genome sequenced prior to internal screening and for which a Ct value is available $(\mathrm{N}=947)$

\section{B. Location and frequency of SNPs across sequenced genomes.}

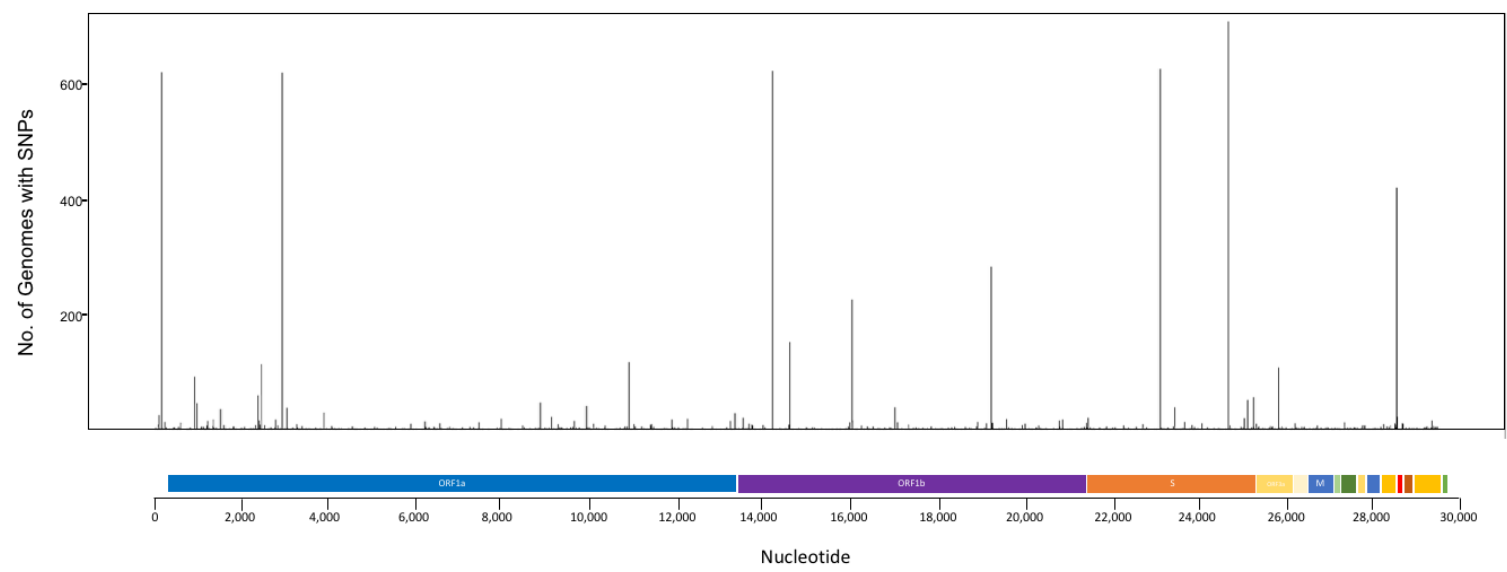

Cumulative number and location of SNPs compared to the original Wuhan strain (Accession No. MN908947) observed across 747 genomes sequenced in East of England. This shows the total occurrence of SNPs, 10,536nt across $22,337,541$ nt sequenced $(0.005 \%)$ occurring at 1,196 positions. Of the 1,196 positions, 1,192 SNPs were found to be single SNPs, while 4 sites had 2 SNPs. 5 common SNPs were found in the majority of sequenced genomes (A23403G, C14408T, C241T, C3037T, T deletion at 24981) while G28881A, G28882A, G28883 were also found in $50 \%$ of samples. These are not unique mutations and have been observed in other cases in the global NextStrain analysis. 
medRxiv preprint doi: https://doi.org/10.1101/2020.05.08.20095687; this version posted May 14, 2020. The copyright holder for this preprint (which was not certified by peer review) is the author/funder, who has granted medRxiv a license to display the preprint in perpetuity.

All rights reserved. No reuse allowed without permission.

\section{Supplementary Figure 3. SARS-CoV-2 lineages over time}

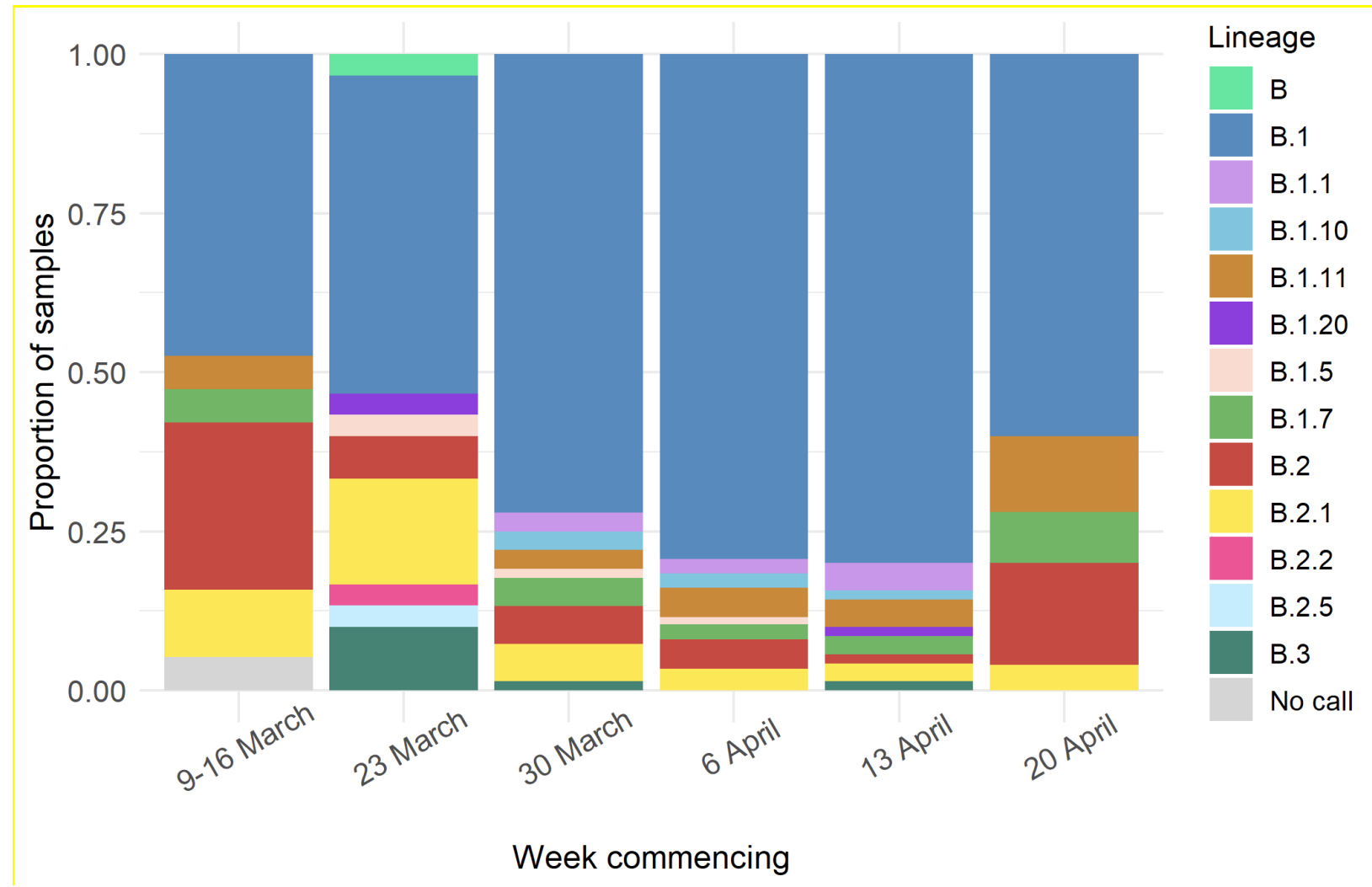

In the weeks commencing 9 and 13 March 2020 lineages (and descendent lineages) of B, B.1, B.2, B.3 and B.8 were present in the EoE (amalgamated here as there were only 2 samples for week commencing 9 March). Diversification of lineages already present from earlier weeks was seen over time, with the detection of descendants of lineages B.1 and B.2, but no new lineages emerged during this period, likely an impact of lockdown measures preventing new viruses being introduced from other regions. Changes in lineage frequency may be stochastic due to changes in the available sample size during each week of the sampling period. Lineage B.8 was only detected in the week commencing 16 March 2020. Lineage B.4 viruses (associated with export from Iran) were not seen in our sample set. Lineage A viruses (or A descendants), most commonly reported in China, USA, South Korea and Australia, were not detected in our EoE samples. 
medRxiv preprint doi: https://doi.org/10.1101/2020.05.08.20095687; this version posted May 14, 2020. The copyright holder for this preprint (which was not certified by peer review) is the author/funder, who has granted medRxiv a license to display the preprint in perpetuity.

All rights reserved. No reuse allowed without permission.

\section{Supplementary Figure 4. Phylogenetic trees of East of England and CUH genomes}

\section{A. Phylogenetic tree of East of England SARS-CoV-2 genomes}

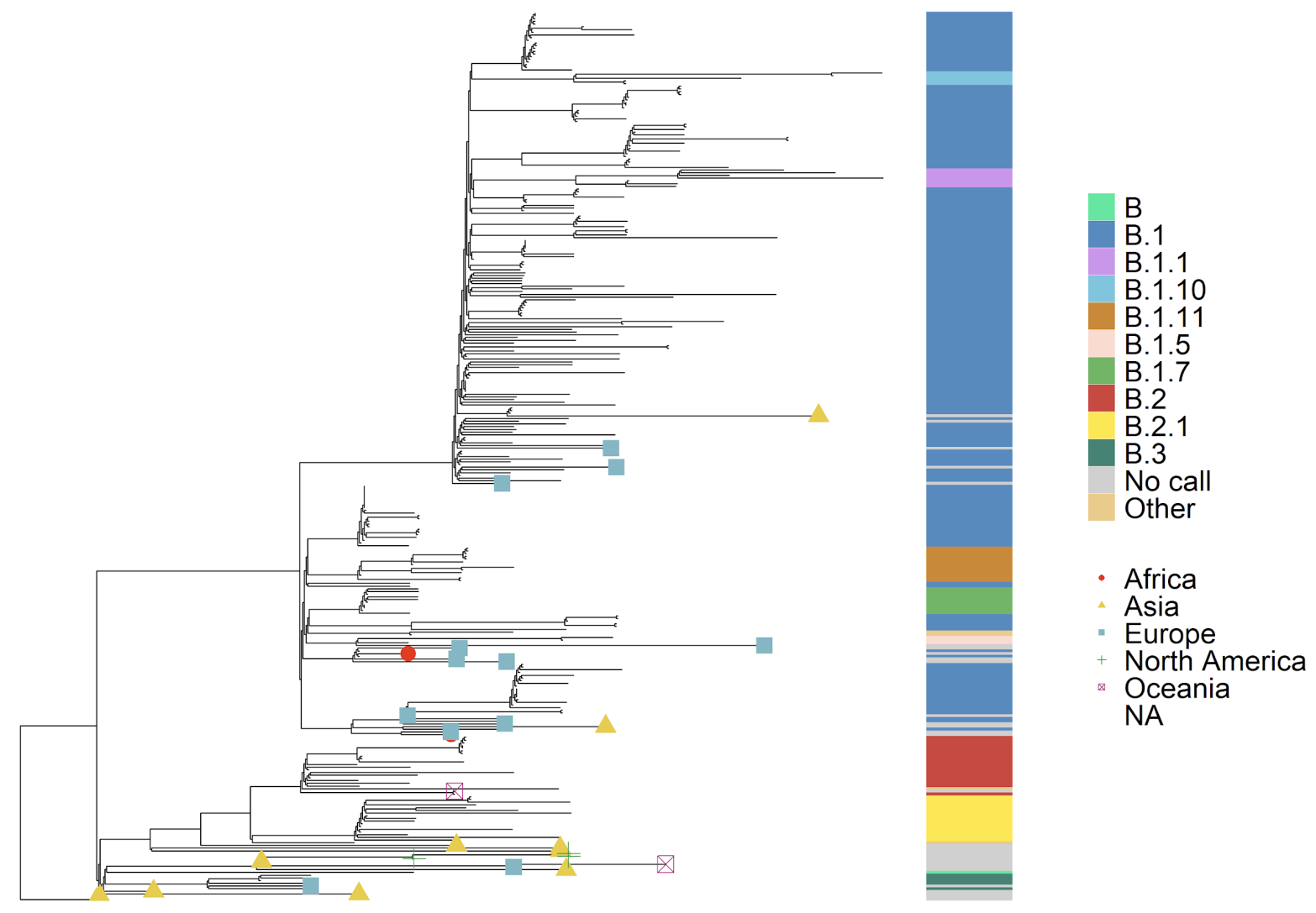

Phylogenetic tree of 747 East of England SARS-CoV-2 genomes and 30 reference genomes used to provide further genetic and geographic context. The reference genomes are highlighted with coloured tips and are the same used in Figure 4A. As with Figure 4A, the tree is rooted on a December 2019 sample from Wuhan, China, with older samples from Asia represented at the base of the tree as expected. The lineages are indicated by the colour bar. 
medRxiv preprint doi: https://doi.org/10.1101/2020.05.08.20095687; this version posted May 14, 2020. The copyright holder for this preprint (which was not certified by peer review) is the author/funder, who has granted medRxiv a license to display the preprint in perpetuity. All rights reserved. No reuse allowed without permission.

\section{B. Phylogenetic tree of CUH SARS-CoV-2 genomes}

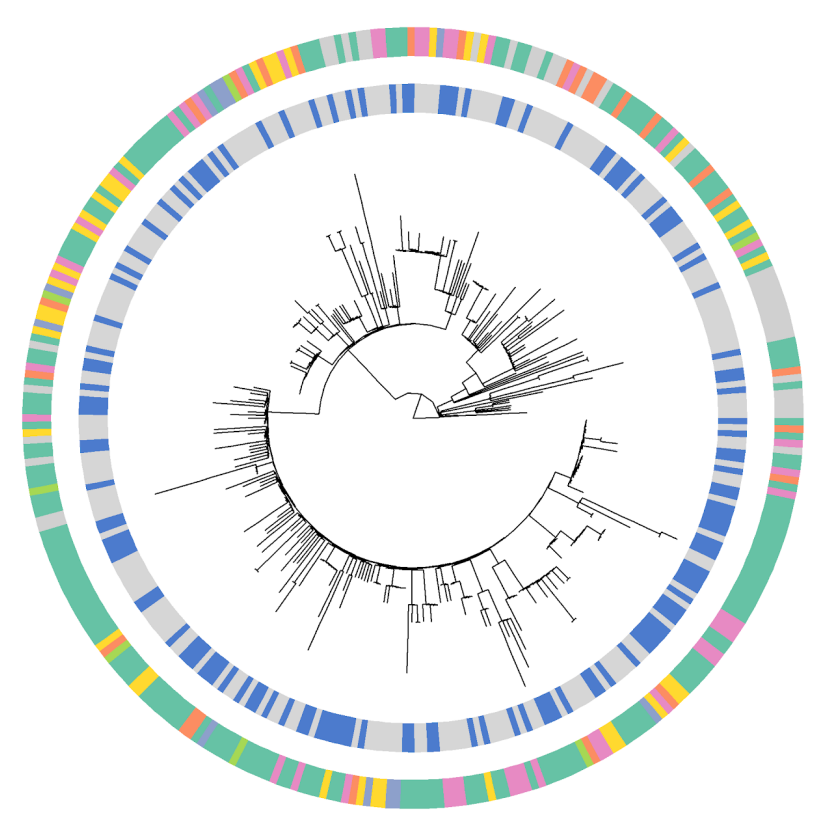

ED

Other

Phylogenetic tree of 299 CUH SARS-CoV-2 genomes and 30 reference genomes. The inner ring shows emergency department (ED) samples in blue and samples collected from all other sites in grey. The outer ring shows the different classifications of infection: 1 . Community onset, community associated; 2 . Community onset, suspected healthcareassociated; 3. Hospital onset, indeterminate healthcare-associated; 4. Hospital onset, suspected healthcareassociated; 5. Hospital onset, healthcare-associated; 6. Healthcare worker; 7. Unable to determine/ data missing. 
medRxiv preprint doi: https://doi.org/10.1101/2020.05.08.20095687; this version posted May 14, 2020. The copyright holder for this preprint (which was not certified by peer review) is the author/funder, who has granted medRxiv a license to display the preprint in perpetuity.

All rights reserved. No reuse allowed without permission.

\section{Supplementary Figure 5. SNP difference matrix, distribution and box plots}

\section{A. SNP difference matrix}

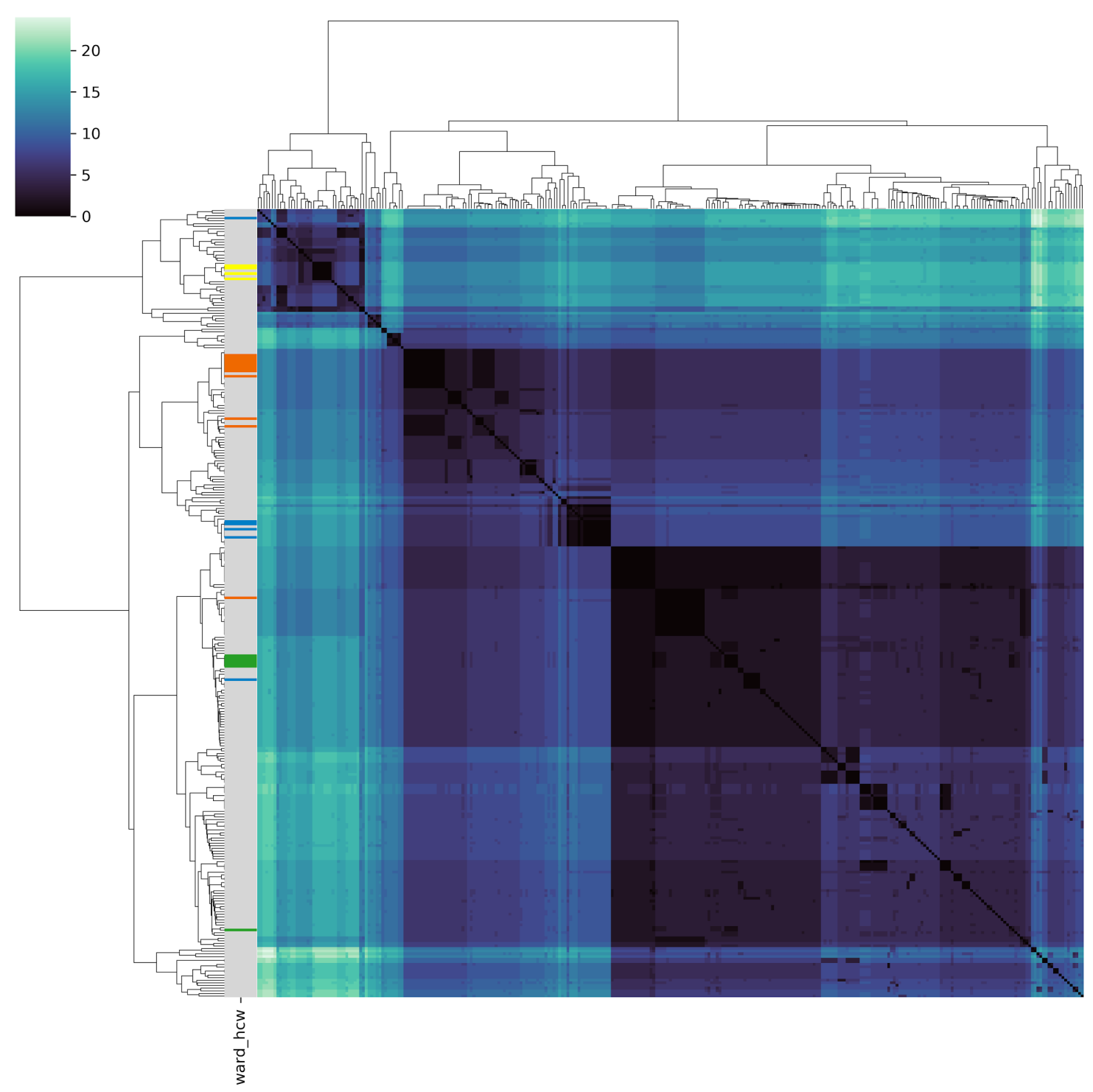

SNP difference matrix for 299 SARS-CoV-2 genomes from CUH. Darker colouring indicates more similar genomes. Several clusters of identical viruses are present in the dataset, as discussed in main text. The left hand bar shows wards A, B, C and the dialysis unit highlighted in colour and other wards in grey 
medRxiv preprint doi: https://doi.org/10.1101/2020.05.08.20095687; this version posted May 14, 2020. The copyright holder for this preprint (which was not certified by peer review) is the author/funder, who has granted medRxiv a license to display the preprint in perpetuity.

\section{B. Distribution of SNP differences among CUH samples}

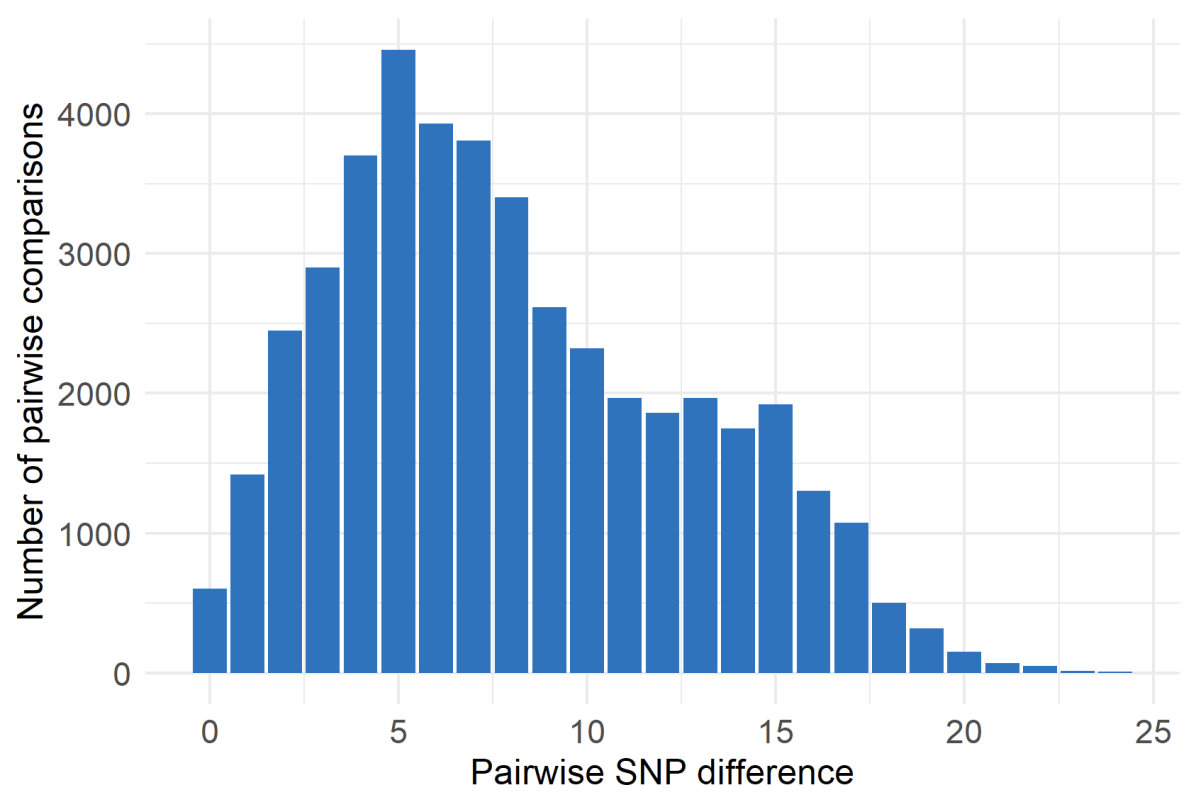

Distribution of pairwise SNP differences for $299 \mathrm{CUH}$ samples. The total number of pairwise comparisons is 44,551 . The median difference was 8 SNPs (range 0 to 24 SNPs). $4.5 \%$ of genomes were identical or 1 -SNP different.

\section{C. Box plot of SNP differences between SARS-CoV-2 genomes}

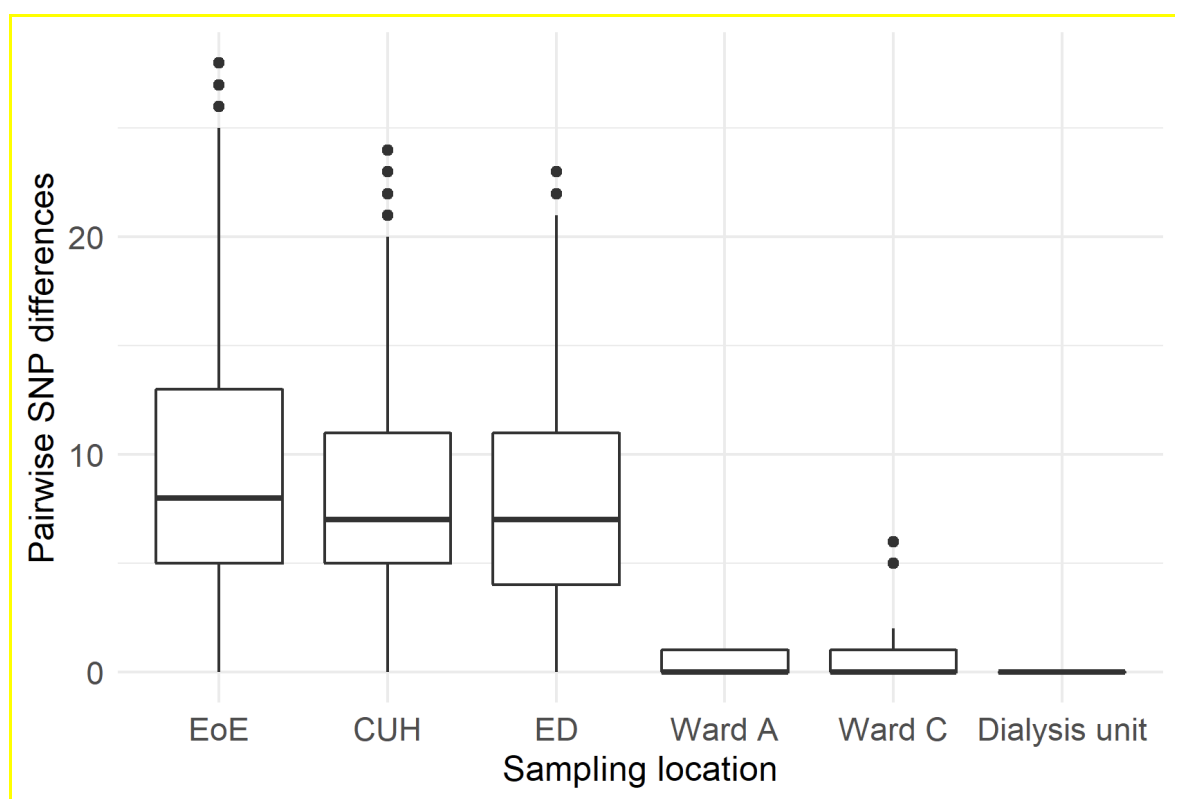

Box plot of SNP differences between SARS-CoV-2 genomes at CUH within different sampling locations. The number of SNP differences was very low on certain wards (0 to 1 SNPs) compared with the emergency department (ED), the Trust $(\mathrm{CUH})$ and the East of England (EoE) as a whole, consistent with shared recent transmission events on these wards (discussed in main text). 
medRxiv preprint doi: https://doi.org/10.1101/2020.05.08.20095687; this version posted May 14, 2020. The copyright holder for this preprint (which was not certified by peer review) is the author/funder, who has granted medRxiv a license to display the preprint in perpetuity.

All rights reserved. No reuse allowed without permission.

\section{Supplementary Figure 6. Process for investigating healthcare associated COVID-19 infections at Cambridge University Hospitals NHS Foundation Trust}

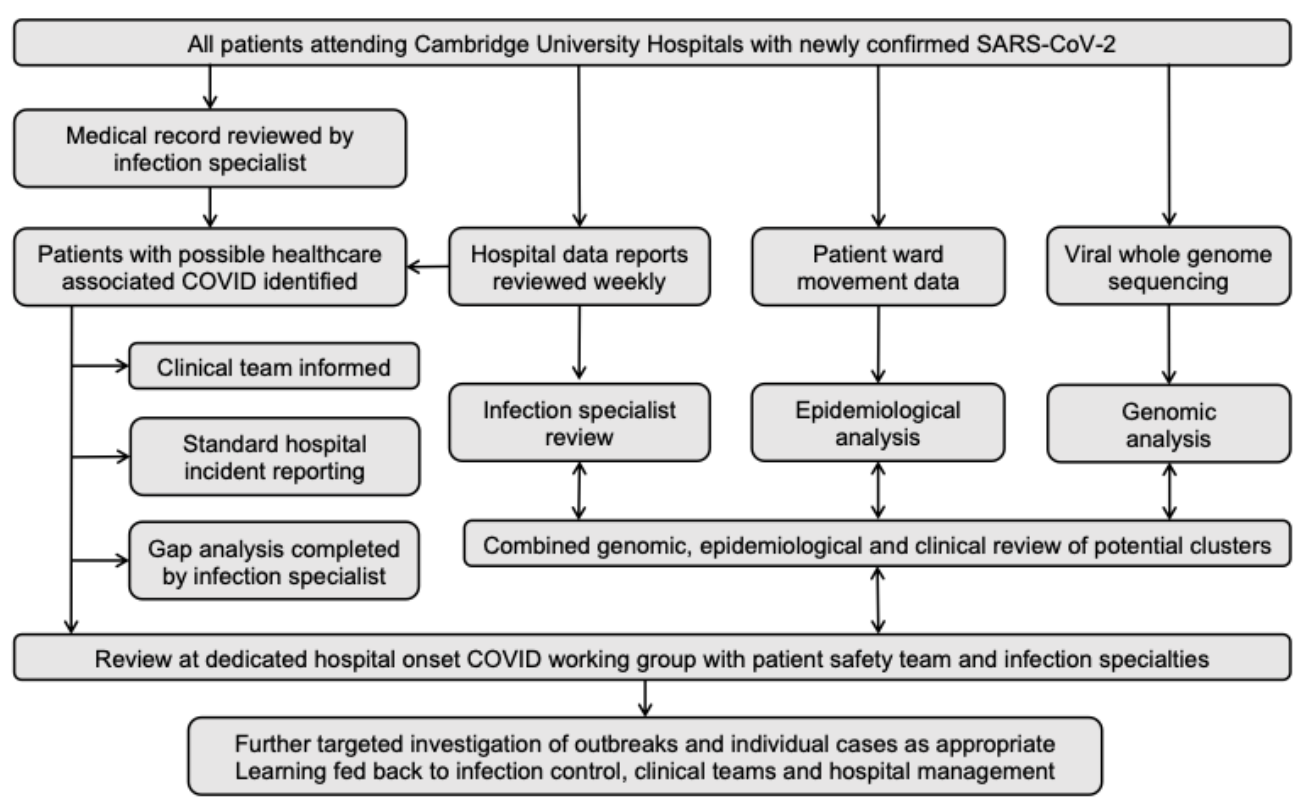


medRxiv preprint doi: https://doi.org/10.1101/2020.05.08.20095687; this version posted May 14, 2020. The copyright holder for this preprint (which was not certified by peer review) is the author/funder, who has granted medRxiv a license to display the preprint in perpetuity.

\section{Supplementary Figure 7. Epidemiological timelines of hospital clusters}

\section{A. Hospital cluster 2 (Ward B)}

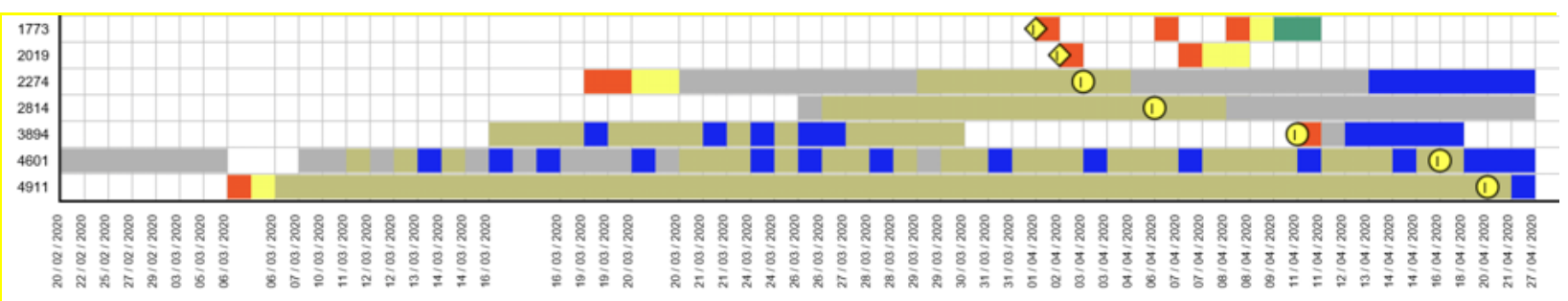

Four transplant patients on ward B (shown in khaki) were diagnosed with COVID-19 infection between 3 and 20 April 2020. A fifth patient, who had been recently discharged from the ward, presented to the ED with COVID-19 infection. The sample dates are shown in yellow circles (patients) and diamonds (HCW). Genomic analysis revealed that all 5 patients had identical genomes. Two HCW were found to have identical genomes in the same cluster as the ward $\mathrm{B}$ cases; one had worked on ward B and had professional contact with the other HCW.

\section{B. Dialysis unit cluster}

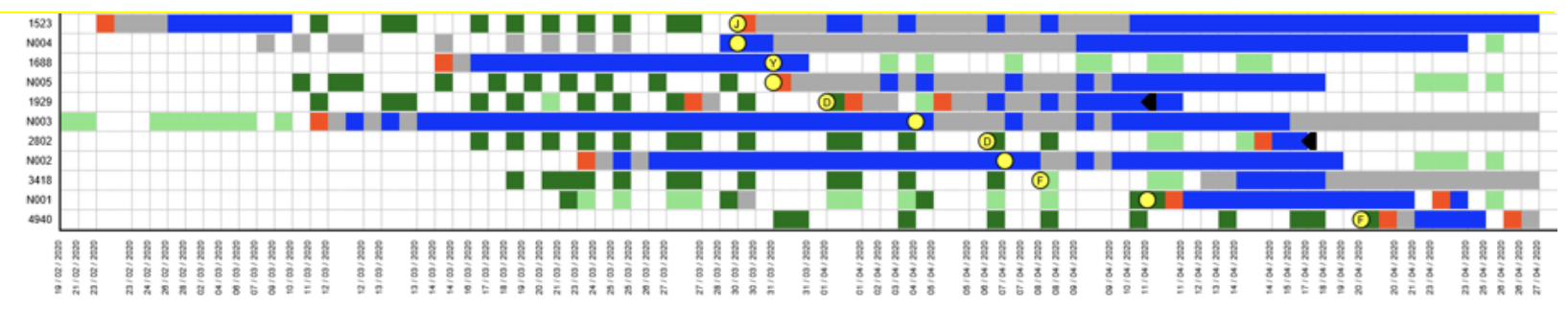

Six patients with end-stage renal failure were diagnosed with COVID-19 between 1 and 20 April 2020, testing positive in several locations including ED and an acute admissions ward. The sample dates are shown in yellow circles. Their viral genomes were identical, and epidemiological investigation revealed they dialysed at the same outpatient dialysis unit. This suggests linked recent transmission of community-onset healthcare-associated infections. 


\section{Supplementary Tables}

\section{Supplementary Table 1. CUH COVID-19 infections and sequence data availability}

\begin{tabular}{|l|c|c|}
\hline Classification of infection & No. & $\begin{array}{c}\text { No. with available } \\
\text { sequence (\%) }\end{array}$ \\
\hline Community onset, community associated & 261 & $174(66.7 \%)$ \\
\hline $\begin{array}{l}\text { Community onset, suspected healthcare- } \\
\text { associated }\end{array}$ & 40 & $27(67.5 \%)$ \\
\hline $\begin{array}{l}\text { Hospital onset, indeterminate healthcare- } \\
\text { associated }\end{array}$ & 11 & $7(63.6 \%)$ \\
\hline Hospital onset, suspected healthcare-associated & 13 & $36(84.6 \%)$ \\
\hline Hospital onset, healthcare-associated & 39 & $6(66.7 \%)$ \\
\hline Healthcare worker & 9 & $1(100 \%)$ \\
\hline Unknown & & \\
\hline
\end{tabular}




\section{Supplementary Table 2. Transmission cluster table}

\begin{tabular}{|c|c|c|c|c|c|c|c|c|c|c|c|}
\hline No. & Size & CAls & $\begin{array}{l}\text { Possible } \\
\text { HAls* }\end{array}$ & HAls & HCWs & $\begin{array}{l}\text { First } \\
\text { Case }\end{array}$ & $\begin{array}{l}\text { Last } \\
\text { Case }\end{array}$ & $\begin{array}{l}\text { Cases } \\
\text { with } \\
\text { good } \\
\text { epi } \\
\text { links }\end{array}$ & $\begin{array}{l}\text { Cases } \\
\text { with } \\
\text { possible } \\
\text { epi links }\end{array}$ & $\begin{array}{l}\text { Cases } \\
\text { with } \\
\text { no epi } \\
\text { links }\end{array}$ & Notes \\
\hline 1 & 15 & 4 & 4 & 5 & 2 & $20 / 3 / 20$ & $16 / 4 / 20$ & 14 & 0 & 1 & $\begin{array}{l}\text { Eight patients swabbed during a suspected } \\
\text { outbreak on ward } 1 \text {. The first patient to be } \\
\text { swabbed was recently discharged from ward } 2 \text { and } \\
\text { then re-admitted to ward } 3 \text {. The two HCWs worked } \\
\text { on ward 3; one had direct contact with the first } \\
\text { patient to be swabbed in this cluster. Two patients, } \\
\text { distinct from the larger outbreak, co-habit } \\
\text { (spouses). The final patient has no identifiable } \\
\text { association with any other case in this cluster. }\end{array}$ \\
\hline 2 & 15 & 10 & 1 & 0 & 4 & $27 / 3 / 20$ & $20 / 4 / 20$ & 9 & 5 & 1 & $\begin{array}{l}8 \text { patients were resident in the care home A. One } \\
\text { patient works as a carer in the same home. } \\
\text { Another patient also works as a carer in an } \\
\text { unspecified home. Two of the HCWs were } \\
\text { paramedics. The other two HCWs work in different } \\
\text { clinical areas, but both live with paramedics. One } \\
\text { patient had no identifiable contact with the other } \\
\text { cases in this cluster. }\end{array}$ \\
\hline
\end{tabular}




\begin{tabular}{|c|c|c|c|c|c|c|c|c|c|c|c|}
\hline 3 & 10 & 1 & 2 & 3 & 4 & $1 / 4 / 20$ & $20 / 4 / 20$ & 7 & 1 & 2 & $\begin{array}{l}\text { Four patients swabbed during a suspected } \\
\text { outbreak on ward } 4 \text { (ward B); a fifth patient was } \\
\text { discharged from ward } 4 \text { and re-admitted with } \\
\text { COVID within } 2 \text { weeks of discharge. Two HCWs } \\
\text { work on ward } 4 \text { and a third works in the same } \\
\text { department as one of these HCWs. There are no } \\
\text { identified associations between the remaining } \\
\text { patient or the fourth HCW. }\end{array}$ \\
\hline 4 & 8 & 7 & 0 & 0 & 1 & $20 / 3 / 20$ & $17 / 4 / 20$ & 1 & 0 & 7 & $\begin{array}{l}\text { No identified epidemiological link between the } \\
\text { seven patients. The HCW had direct contact with } \\
\text { two of these patients. }\end{array}$ \\
\hline 5 & 5 & 0 & 3 & 2 & 0 & $27 / 3 / 20$ & $11 / 4 / 20$ & 5 & 0 & 0 & Five patients all swabbed on ward 5 (ward A) \\
\hline 6 & 5 & 4 & 0 & 1 & 0 & $27 / 3 / 20$ & $19 / 4 / 20$ & 0 & 0 & 5 & $\begin{array}{l}\text { No identified epidemiological link between the } 5 \\
\text { patients. }\end{array}$ \\
\hline 7 & 5 & 0 & 4 & 0 & 1 & $20 / 3 / 20$ & $16 / 4 / 20$ & 4 & 1 & 0 & $\begin{array}{l}\text { Three patients swabbed during a suspected } \\
\text { outbreak on ward } 2 \text {. HCW works on ward } 2 \text {. The } \\
\text { first patient in this cluster was recently discharged } \\
\text { from ward } 8 \text { and readmitted to ward } 8 \text {. Wards } 2 \\
\text { and } 8 \text { are in the same department and share some } \\
\text { staff }\end{array}$ \\
\hline 8 & 5 & 2 & 0 & 0 & 3 & $7 / 4 / 20$ & $17 / 4 / 20$ & 5 & 0 & 0 & $\begin{array}{l}\text { Two patients resident in care home B; one of these } \\
\text { patients admitted to ward } 6 \text {. Two HCWs work on }\end{array}$ \\
\hline
\end{tabular}




\begin{tabular}{|c|c|c|c|c|c|c|c|c|c|c|c|}
\hline & & & & & & & & & & & $\begin{array}{l}\text { ward } 6 \text {, including one with direct contact with this } \\
\text { patient. The third HCW works on ward } 8 .\end{array}$ \\
\hline 9 & 4 & 2 & 0 & 0 & 2 & $4 / 4 / 20$ & $16 / 4 / 20$ & 4 & 0 & 0 & $\begin{array}{l}\text { One patient resident in care home } \mathrm{B} \text {, admitted to } \\
\text { ward } 7 \text {. Second patient is a carer in care home } \mathrm{B} \text {. } \\
\text { One HCW works on wards } 7 \text { and } 8 \text {. The second } \\
\mathrm{HCW} \text { works on ward } 8 \text {. The isolates from clusters } 8 \\
\text { and } 9 \text { diverge by } 1 \mathrm{SNP} \text {, but share epidemiological } \\
\text { links of both patients and HCWs. }\end{array}$ \\
\hline 10 & 6 & 0 & 6 & 0 & 0 & $1 / 4 / 20$ & $20 / 4 / 20$ & 6 & 0 & 0 & All six patients receive dialysis at the same unit \\
\hline 11 & 3 & 2 & 1 & 0 & 0 & $9 / 4 / 20$ & $17 / 4 / 20$ & 0 & 0 & 3 & $\begin{array}{l}\text { Two patients live in separate care homes. The third } \\
\text { patient is a community carer but has no other } \\
\text { identified association with these patients }\end{array}$ \\
\hline 12 & 3 & 3 & 0 & 0 & 0 & $11 / 4 / 20$ & $20 / 4 / 20$ & 0 & 2 & 1 & $\begin{array}{l}\text { One patient is a resident in a specialist dementia } \\
\text { care home. A second patient works in a specialist } \\
\text { dementia care home, but it is unclear whether this } \\
\text { is the same home as the first patient. The third } \\
\text { patient has no other identified associations with the } \\
\text { other patients. }\end{array}$ \\
\hline 13 & 3 & 0 & 0 & 1 & 2 & $31 / 3 / 20$ & $17 / 4 / 20$ & 0 & 0 & 3 & $\begin{array}{l}\text { The first patient acquired infection in hospital. The } \\
\text { HCWs have no known association with each other } \\
\text { or the patient. }\end{array}$ \\
\hline
\end{tabular}




\begin{tabular}{|c|c|c|c|c|c|c|c|c|c|c|c|}
\hline 14 & 3 & 0 & 0 & 2 & 1 & $12 / 4 / 20$ & $20 / 4 / 20$ & 3 & 0 & 0 & $\begin{array}{l}\text { The two patients were co-located on ward } 10 \text {. The } \\
\text { HCW worked on the same ward, but there is no } \\
\text { documented direct contact with either patient. }\end{array}$ \\
\hline 15 & 2 & 1 & 0 & 0 & 1 & $2 / 4 / 20$ & $13 / 4 / 20$ & 2 & 0 & 0 & $\begin{array}{l}\text { The patient was admitted to ward } 6 \text { with } \\
\text { documented direct contact with the HCW. }\end{array}$ \\
\hline 16 & 2 & 1 & 1 & 0 & 0 & $4 / 4 / 20$ & $5 / 4 / 20$ & 2 & 0 & 0 & Two patients co-located on ward 9. \\
\hline 17 & 2 & 0 & 0 & 0 & 2 & $16 / 4 / 20$ & $17 / 4 / 20$ & 0 & 2 & 0 & $\begin{array}{l}\text { Two HCWs, working in separate wards in the same } \\
\text { department. }\end{array}$ \\
\hline 18 & 2 & 1 & 0 & 0 & 1 & $15 / 4 / 20$ & $18 / 4 / 20$ & 0 & 0 & 2 & $\begin{array}{l}\text { The HCW lives with a care assistant in an } \\
\text { unspecified care home. The patient was admitted } \\
\text { from a care home. No other identified association }\end{array}$ \\
\hline 19 & 2 & 1 & 0 & 0 & 1 & $19 / 4 / 20$ & $20 / 4 / 20$ & 0 & 0 & 2 & $\begin{array}{l}\text { The patient works in a local community hospital. } \\
\text { The HCW works in a rehabilitation unit. There are } \\
\text { no other known epidemiological associations. }\end{array}$ \\
\hline 20 & 2 & 0 & 0 & 1 & 1 & $9 / 4 / 20$ & $12 / 4 / 20$ & 0 & 0 & 2 & $\begin{array}{l}\text { The HCW and patient have moved between } \\
\text { multiple ward areas. No direct contact } \\
\text { documented. }\end{array}$ \\
\hline 21 & 2 & 1 & 0 & 1 & 0 & $3 / 4 / 20$ & $3 / 4 / 20$ & 0 & 2 & 0 & $\begin{array}{l}\text { Two patients briefly co-located within } 24 \text { hrs of } \\
\text { testing, likely insufficient duration for transmission. } \\
\text { One patient was resident with community acquired }\end{array}$ \\
\hline
\end{tabular}




\begin{tabular}{|c|c|c|c|c|c|c|c|c|c|c|c|}
\hline & & & & & & & & & & & $\begin{array}{l}\text { infection in a care home; the second patient was } \\
\text { on a rehabilitation ward prior to swabbing }\end{array}$ \\
\hline 22 & 2 & 1 & 0 & 1 & 0 & $22 / 3 / 20$ & $27 / 3 / 20$ & 0 & 0 & 2 & No identified associations between the two patients \\
\hline 23 & 2 & 1 & 1 & 0 & 0 & $30 / 3 / 20$ & $19 / 4 / 20$ & 0 & 2 & 0 & $\begin{array}{l}\text { No direct associations between two patients, but } \\
\text { they were co-located on neighbouring wards } \\
\text { (wards 1, } 4 \text { and 10), which share some HCWs }\end{array}$ \\
\hline 24 & 2 & 2 & 0 & 0 & 0 & $29 / 3 / 20$ & $7 / 4 / 20$ & 0 & 0 & 2 & No identified associations between the two patients \\
\hline 25 & 2 & 0 & 0 & 2 & 0 & $29 / 3 / 20$ & $7 / 4 / 20$ & 2 & 0 & 0 & Two patients co-located on ward 11 \\
\hline 26 & 2 & 2 & 0 & 0 & 0 & $1 / 4 / 20$ & $2 / 4 / 20$ & 2 & 0 & 0 & Two patients co-habiting (siblings) \\
\hline Total & 114 & & 23 & 19 & 25 & & & 66 & 15 & 33 & \\
\hline
\end{tabular}


medRxiv preprint doi: https://doi.org/10.1101/2020.05.08.20095687; this version posted May 14, 2020. The copyright holder for this preprint (which was not certified by peer review) is the author/funder, who has granted medRxiv a license to display the preprint in perpetuity.

All rights reserved. No reuse allowed without permission.

Supplementary Table 3. GISAID genomes included in phylogenetic tree

\begin{tabular}{|l|l|}
\hline GISAID ID & $\begin{array}{l}\text { Country of } \\
\text { origin }\end{array}$ \\
\hline EPI_ISL_402123* & China \\
\hline EPI_ISL_406716 & China \\
\hline EPI_ISL_406801 & China \\
\hline EPI_ISL_414598 & Spain \\
\hline EPI_ISL_416396 & China \\
\hline EPI_ISL_416757 & France \\
\hline EPI_ISL_417969 & Spain \\
\hline EPI_ISL_418034 & USA \\
\hline EPI_ISL_419228 & China \\
\hline EPI_ISL_419232 & China \\
\hline EPI_ISL_420064 & France \\
\hline EPI_ISL_421905 & UK \\
\hline EPI_ISL_422024 & UK \\
\hline
\end{tabular}




\begin{tabular}{|l|l|}
\hline EPI_ISL_427119 & Australia \\
\hline EPI_ISL_427144 & Australia \\
\hline EPI_ISL_427322 & Russia \\
\hline EPI_ISL_427391 & Turkey \\
\hline EPI_ISL_427441 & USA \\
\hline EPI_ISL_428482 & India \\
\hline EPI_ISL_428848 & Singapore \\
\hline EPI_ISL_428857 & The Gambia \\
\hline EPI_ISL_429061 & USA \\
\hline EPI_ISL_429175 & Thailand \\
\hline EPI_ISL_429177 & Thailand \\
\hline EPI_ISL_429206 & Switzerland \\
\hline
\end{tabular}

*Sample from China used to root the tree 
medRxiv preprint doi: https://doi.org/10.1101/2020.05.08.20095687; this version posted May 14, 2020. The copyright holder for this preprint

(which was not certified by peer review) is the author/funder, who has granted medRxiv a license to display the preprint in perpetuity. All rights reserved. No reuse allowed without permission.

\section{Supplementary Table 4. Table of sequences / accession numbers}

\begin{tabular}{|c|c|c|c|c|c|}
\hline GISAID Accession ID & $\begin{array}{l}\text { Virus name } \\
\end{array}$ & COG-UK & GISAID Accession ID & Virus name & COG-UK \\
\hline EPI_ISL_425231 & hCoV-19/England/CAMB-7374F/2020 & CAMB-7374F & EPI_ISL_433840 & hCoV-19/England/CAMB-7AB00/2020 & CAMB-7AB00 \\
\hline EPI_ISL_425232 & hCoV-19/England/CAMB-7375E/2020 & CAMB-7375E & EPI_ISL_433841 & hCoV-19/England/CAMB-7AB1F/2020 & CAMB-7AB1F \\
\hline EPI_ISL_425233 & hCoV-19/England/CAMB-7376D/2020 & CAMB-7376D & EPI_ISL_433842 & hCoV-19/England/CAMB-7AB2E/2020 & CAMB-7AB2E \\
\hline EPI_ISL_425234 & hCoV-19/England/CAMB-7377C/2020 & CAMB-7377C & EPI_ISL_-433843 & hCoV-19/England/CAMB-7AB3D/2020 & CAMB-7AB3D \\
\hline EPI_ISL_425235 & hCoV-19/England/CAMB-7378B/2020 & CAMB-7378B & EPI_ISL_433844 & hCoV-19/England/CAMB-7AB79/2020 & CAMB-7AB79 \\
\hline EPI_ISL_-425236 & hCoV-19/England/CAMB-7379A/2020 & CAMB-7379A & EPI_ISL_-433845 & hCoV-19/England/CAMB-7AB88/2020 & CAMB-7AB88 \\
\hline EPI_ISL_-425237 & hCoV-19/England/CAMB-737A9/2020 & CAMB-737A9 & EPI_ISL_-433846 & hCoV-19/England/CAMB-7AB97/2020 & CAMB-7AB97 \\
\hline EPI_ISL_425238 & hCoV-19/England/CAMB-737B8/2020 & CAMB-737B8 & EPI_ISL_433847 & hCoV-19/England/CAMB-7ABA6/2020 & CAMB-7ABA6 \\
\hline EPI_ISL_425239 & hCoV-19/England/CAMB-737C7/2020 & CAMB-737C7 & EPI_ISL_433848 & hCoV-19/England/CAMB-7ABB5/2020 & CAMB-7ABB5 \\
\hline EPI_ISL_425240 & hCoV-19/England/CAMB-737D6/2020 & CAMB-737D6 & EPI_ISL_433849 & hCoV-19/England/CAMB-7ABC4/2020 & CAMB-7ABC4 \\
\hline EPI_ISL_425241 & hCoV-19/England/CAMB-737E5/2020 & CAMB-737E5 & EPI_ISL_-433850 & hCoV-19/England/CAMB-7ABE2/2020 & CAMB-7ABE2 \\
\hline EPI_ISL_425242 & hCoV-19/England/CAMB-737F4/2020 & CAMB-737F4 & EPI_ISL_433851 & hCoV-19/England/CAMB-7ABF1/2020 & CAMB-7ABF1 \\
\hline EPI_ISL_425243 & hCoV-19/England/CAMB-73800/2020 & CAMB-73800 & EPI_ISL_433852 & hCoV-19/England/CAMB-7ACOD/2020 & CAMB-7ACOD \\
\hline EPI_ISL_425244 & hCoV-19/England/CAMB-7381F/2020 & CAMB-7381F & EPI_ISL_433853 & hCoV-19/England/CAMB-7AC1C/2020 & CAMB-7AC1C \\
\hline EPI_ISL_425245 & hCoV-19/England/CAMB-7382E/2020 & CAMB-7382E & EPI_ISL_433854 & hCoV-19/England/CAMB-7AC2B/2020 & CAMB-7AC2B \\
\hline EPI_ISL_-425246 & hCoV-19/England/CAMB-7386A/2020 & CAMB-7386A & EPI_ISL_-433855 & hCoV-19/England/CAMB-7AC3A/2020 & CAMB-7AC3A \\
\hline EPI_ISL_-425247 & hCoV-19/England/CAMB-73879/2020 & CAMB-73879 & EPI_ISL_-433856 & hCoV-19/England/CAMB-7AC49/2020 & CAMB-7AC49 \\
\hline EPI_ISL_-425248 & hCoV-19/England/CAMB-73888/2020 & CAMB-73888 & EPI_ISL_-433857 & hCoV-19/England/CAMB-7AC58/2020 & CAMB-7AC58 \\
\hline EPI_ISL_-425249 & hCoV-19/England/CAMB-738A6/2020 & CAMB-738A6 & EPI_ISL_-433858 & hCoV-19/England/CAMB-7AC67/2020 & CAMB-7AC67 \\
\hline EPI_ISL_425250 & hCoV-19/England/CAMB-738B5/2020 & CAMB-738B5 & EPI_ISL_433859 & hCoV-19/England/CAMB-7AC76/2020 & CAMB-7AC76 \\
\hline EPI_ISL_425251 & hCoV-19/England/CAMB-738C4/2020 & CAMB-738C4 & EPI_ISL_433860 & hCoV-19/England/CAMB-7AC85/2020 & CAMB-7AC85 \\
\hline EPI_ISL_425252 & hCoV-19/England/CAMB-738D3/2020 & CAMB-738D3 & EPI_ISL_433861 & hCoV-19/England/CAMB-7AC94/2020 & CAMB-7AC94 \\
\hline EPI_ISL_425253 & hCoV-19/England/CAMB-738E2/2020 & CAMB-738E2 & EPI_ISL_433862 & hCoV-19/England/CAMB-7ACA3/2020 & CAMB-7ACA3 \\
\hline EPI_ISL_425254 & hCoV-19/England/CAMB-738F 1/2020 & CAMB-738F1 & EPI_ISL_433863 & hCoV-19/England/CAMB-7ACB2/2020 & CAMB-7ACB2 \\
\hline EPI_ISL_425255 & hCoV-19/England/CAMB-7391C/2020 & CAMB-7391C & EPI_ISL_433864 & hCoV-19/England/CAMB-7ACC1/2020 & CAMB-7ACC1 \\
\hline EPI_ISL_425256 & hCoV-19/England/CAMB-7393A/2020 & CAMB-7393A & EPI_ISL_433865 & hCoV-19/England/CAMB-7ACDO/2020 & CAMB-7ACDO \\
\hline EPI_ISL_-425257 & hCoV-19/England/CAMB-73949/2020 & CAMB-73949 & EPI_ISL_-433866 & hCoV-19/England/CAMB-7ACFE/2020 & CAMB-7ACFE \\
\hline EPI_ISL_425258 & hCoV-19/England/CAMB-73976/2020 & CAMB-73976 & EPI_ISL_433867 & hCoV-19/England/CAMB-7ADOA/2020 & CAMB-7ADOA \\
\hline EPI_ISL_425259 & hCoV-19/England/CAMB-73985/2020 & CAMB-73985 & EPI_ISL_433868 & hCoV-19/England/CAMB-7AD28/2020 & CAMB-7AD28 \\
\hline EPI_ISL_-425260 & hCoV-19/England/CAMB-73994/2020 & CAMB-73994 & EPI_ISL_-433869 & hCoV-19/England/CAMB-7AD37/2020 & CAMB-7AD37 \\
\hline EPI_ISL_-425261 & hCoV-19/England/CAMB-739A3/2020 & CAMB-739A3 & EPI_ISL_-433870 & hCoV-19/England/CAMB-7AD46/2020 & CAMB-7AD46 \\
\hline EPI_ISL_425262 & hCoV-19/England/CAMB-739B2/2020 & CAMB-739B2 & EPI_ISL_433871 & hCoV-19/England/CAMB-7AD55/2020 & CAMB-7AD55 \\
\hline EPI_ISL_425263 & hCoV-19/England/CAMB-739D0/2020 & CAMB-739DO & EPI_ISL_433872 & hCoV-19/England/CAMB-7AD64/2020 & CAMB-7AD64 \\
\hline EPI_ISL_425264 & hCoV-19/England/CAMB-739EF/2020 & CAMB-739EF & EPI_ISL_433873 & hCoV-19/England/CAMB-7AD82/2020 & CAMB-7AD82 \\
\hline EPI_ISL_425265 & hCoV-19/England/CAMB-739FE/2020 & CAMB-739FE & EPI_ISL_-433874 & hCoV-19/England/CAMB-7AD91/2020 & CAMB-7AD91 \\
\hline EPI_ISL_-425266 & hCoV-19/England/CAMB-73A0A/2020 & CAMB-73A0A & EPI_ISL_-433875 & hCoV-19/England/CAMB-7ADA0/2020 & CAMB-7ADAO \\
\hline EPI_ISL_425267 & hCoV-19/England/CAMB-73A19/2020 & CAMB-73A19 & EPI_ISL_433876 & hCoV-19/England/CAMB-7ADBF/2020 & CAMB-7ADBF \\
\hline EPI_ISL_425268 & hCoV-19/England/CAMB-73A28/2020 & CAMB-73A28 & EPI_ISL_433877 & hCoV-19/England/CAMB-7ADDD/2020 & CAMB-7ADDD \\
\hline EPI_ISL_-425269 & hCoV-19/England/CAMB-73A37/2020 & CAMB-73АЗ37 & EPI_ISL_-433878 & hCoV-19/England/CAMB-7ADEC/2020 & CAMB-7ADEC \\
\hline EPI_ISL_-425270 & hCoV-19/England/CAMB-73A46/2020 & CAMB-73A46 & EPI_ISL_-433879 & hCoV-19/England/CAMB-7ADFB/2020 & CAMB-7ADFB \\
\hline EPI_ISL_425271 & hCoV-19/England/CAMB-73A64/2020 & CAMB-73A64 & EPI_ISL_433880 & hCoV-19/England/CAMB-7AE07/2020 & CAMB-7AE07 \\
\hline EPI_ISL_425272 & hCoV-19/England/CAMB-73A73/2020 & CAMB-73A73 & EPI_ISL_433881 & hCoV-19/England/CAMB-7AE25/2020 & CAMB-7AE25 \\
\hline EPI_ISL_425273 & hCoV-19/England/CAMB-73A82/2020 & CAMB-73A82 & EPI_ISL_-433882 & hCoV-19/England/CAMB-7AE34/2020 & CAMB-7AE34 \\
\hline EPI_ISL_425274 & hCoV-19/England/CAMB-73AA0/2020 & CAMB-73AAO & EPI_ISL_433883 & hCoV-19/England/CAMB-7AE43/2020 & CAMB-7AE43 \\
\hline EPI_ISL_425275 & hCoV-19/England/CAMB-73ABF/2020 & CAMB-73ABF & EPI_ISL_433884 & hCoV-19/England/CAMB-7AE52/2020 & CAMB-7AE52 \\
\hline EPI_ISL_425276 & hCoV-19/England/CAMB-73ACE/2020 & CAMB-73ACE & EPI_ISL_433885 & hCoV-19/England/CAMB-7AE61/2020 & CAMB-7AE61 \\
\hline EPI_ISL_-425277 & hCoV-19/England/CAMB-73ADD/2020 & CAMB-73ADD & EPI_ISL_-433886 & hCoV-19/England/CAMB-7AE70/2020 & CAMB-7AE70 \\
\hline EPI_ISL_425278 & hCoV-19/England/CAMB-73AEC/2020 & CAMB-73AEC & EPI_ISL_-433887 & hCoV-19/England/CAMB-7AE9E/2020 & CAMB-7AE9E \\
\hline EPI_ISL_425279 & hCoV-19/England/CAMB-73AFB/2020 & CAMB-73AFB & EPI_ISL_433888 & hCoV-19/England/CAMB-7AEAD/2020 & CAMB-7AEAD \\
\hline EPI_ISL_-433666 & hCoV-19/England/CAMB-73B16/2020 & CAMB-73B16 & EPI_ISL_-433889 & hCoV-19/England/CAMB-7AECB/2020 & CAMB-7AECB \\
\hline EPI_ISL_-433667 & hCoV-19/England/CAMB-73B61/2020 & CAMB-73B61 & EPI_ISL_-433890 & hCoV-19/England/CAMB-7AEDA/2020 & CAMB-7AEDA \\
\hline EPI_ISL_433668 & hCoV-19/England/CAMB-73B70/2020 & CAMB-73B70 & EPI_ISL_433891 & hCoV-19/England/CAMB-7AEE9/2020 & CAMB-7AEE9 \\
\hline EPI_ISL_-433669 & hCoV-19/England/CAMB-73B8F/2020 & CAMB-73B8F & EPI_ISL_433892 & hCoV-19/England/CAMB-7AEF8/2020 & CAMB-7AEF8 \\
\hline EPI_ISL_433670 & hCoV-19/England/CAMB-73B9E/2020 & CAMB-73B9E & EPI_ISL_433893 & hCoV-19/England/CAMB-7AF04/2020 & CAMB-7AF04 \\
\hline EPI_ISL_433671 & hCoV-19/England/CAMB-73BAD/2020 & CAMB-73BAD & EPI_ISL_433894 & hCoV-19/England/CAMB-7AF13/2020 & CAMB-7AF13 \\
\hline EPI_ISL_433672 & hCoV-19/England/CAMB-73BBC/2020 & CAMB-73BBC & EPI_ISL_433895 & hCoV-19/England/CAMB-7AF22/2020 & CAMB-7AF22 \\
\hline EPI_ISL_-433673 & hCoV-19/England/CAMB-73BCB/2020 & CAMB-73BCB & EPI_ISL_-433896 & hCoV-19/England/CAMB-7AF31/2020 & CAMB-7AF31 \\
\hline EPI_ISL_433674 & hCoV-19/England/CAMB-73BDA/2020 & CAMB-73BDA & EPI_ISL_433897 & hCoV-19/England/CAMB-7AF40/2020 & CAMB-7AF40 \\
\hline EPI_ISL_433675 & hCoV-19/England/CAMB-73BF8/2020 & CAMB-73BF8 & EPI_ISL_-433898 & hCoV-19/England/CAMB-7AF5F/2020 & CAMB-7AF5F \\
\hline EPI_ISL_433676 & hCoV-19/England/CAMB-73C04/2020 & CAMB-73C04 & EPI_ISL_433899 & hCoV-19/England/CAMB-7AF6E/2020 & CAMB-7AF6E \\
\hline EPI_ISL_433677 & hCoV-19/England/CAMB-73C13/2020 & CAMB- 73 C 13 & EPI_ISL_433900 & hCoV-19/England/CAMB-7AF7D/2020 & CAMB-7AF7D \\
\hline EPI_ISL_433678 & hCoV-19/England/CAMB-73C31/2020 & CAMB-73C 31 & EPI_ISL_-433901 & hCoV-19/England/CAMB-7AF8C/2020 & CAMB-7AF8C \\
\hline EPI_ISL_433679 & hCoV-19/England/CAMB-73C40/2020 & CAMB- 73 C40 & EPI_ISL_433902 & hCoV-19/England/CAMB-7AFAA/2020 & CAMB-7AFAA \\
\hline EPI_ISL_433680 & hCoV-19/England/CAMB-73C5F/2020 & CAMB-73C5F & EPI_ISL_-433903 & hCoV-19/England/CAMB-7AFB9/2020 & CAMB-7AFB9 \\
\hline EPI_ISL_433681 & hCoV-19/England/CAMB-73C7D/2020 & CAMB-73C7D & EPI_ISL_433904 & hCoV-19/England/CAMB-7AFF5/2020 & CAMB-7AFF5 \\
\hline EPI_ISL_433682 & hCoV-19/England/CAMB-73C9B/2020 & CAMB-73C9B & EPI_ISL_433905 & hCoV-19/England/CAMB-7B000/2020 & CAMB-7B000 \\
\hline EPI_ISL_433683 & hCoV-19/England/CAMB-73CAA/2020 & CAMB-73CAA & EPI_ISL_433906 & hCoV-19/England/CAMB-7B01F/2020 & CAMB-7B01F \\
\hline EPI_ISL_-433684 & hCoV-19/England/CAMB-73CC8/2020 & CAMB- 73 CC 8 & EPI_ISL_-433907 & hCoV-19/England/CAMB-7B02E/2020 & CAMB-7B02E \\
\hline EPI_ISL_433685 & hCoV-19/England/CAMB-73CD7/2020 & CAMB-73CD7 & EPI_ISL_433908 & hCoV-19/England/CAMB-7B05B/2020 & CAMB-7B05B \\
\hline EPI_ISL_433686 & hCoV-19/England/CAMB-73D01/2020 & CAMB-73D01 & EPI_ISL_433909 & hCoV-19/England/CAMB-7B06A/2020 & CAMB-7B06A \\
\hline EPI_ISL_-433687 & hCoV-19/England/CAMB-73D10/2020 & CAMB-73D 10 & EPI_ISL_-433910 & hCoV-19/England/CAMB-7B079/2020 & CAMB-7B079 \\
\hline EPI_ISL_-433688 & hCoV-19/England/CAMB-73D2F/2020 & CAMB-73D2F & EPI_ISL_-433911 & hCoV-19/England/CAMB-7B088/2020 & CAMB-7B088 \\
\hline EPI_ISL_433689 & hCoV-19/England/CAMB-73D3E/2020 & CAMB-73D3E & EPI_ISL_433912 & hCoV-19/England/CAMB-7B097/2020 & CAMB-7B097 \\
\hline & hCoV-19/England/CAMB-73D4D/2020 & CAMB-73D4D & EPI_ISL_433913 & hCoV-19/England/CAMB-7BOA6/2020 & CAMB-7B0A6 6 \\
\hline EPI_ISL_433691 & hCoV-19/England/CAMB-73D5C/2020 & CAMB-73D5C & EPI_ISL_433914 & hCoV-19/England/CAMB-7B0B5/2020 & CAMB-7B0B5 \\
\hline EPI_ISL_433692 & hCoV-19/England/CAMB-73D6B/2020 & CAMB-73D6B & EPI_ISL_433915 & hCoV-19/England/CAMB-7BOC4/2020 & CAMB-7BOC4 \\
\hline EPI_ISL_433693 & hCoV-19/England/CAMB-73D7A/2020 & CAMB-73D7A & EPI_ISL_433916 & hCoV-19/England/CAMB-7BOD3/2020 & CAMB-7B0D3 \\
\hline EPI_ISL_433694 & hCoV-19/England/CAMB-73D89/2020 & CAMB-73D89 & EPI_ISL_433917 & hCoV-19/England/CAMB-7BOE2/2020 & CAMB-7B0E2 \\
\hline EPI_ISL_-433695 & hCoV-19/England/CAMB-73D98/2020 & CAMB-73D98 & EPI_ISL_-433918 & hCoV-19/England/CAMB-7BOF1/2020 & CAMB-7B0F1 \\
\hline EPI_ISL_-433696 & hCoV-19/England/CAMB-73DA7/2020 & CAMB-73DA7 & EPI_ISL_-433919 & hCoV-19/England/CAMB-7B10D/2020 & CAMB-7B10D \\
\hline EPI_ISL_433697 & hCoV-19/England/CAMB-73DB6/2020 & CAMB-73DB6 & EPI_ISL_433920 & hCoV-19/England/CAMB-7B11C/2020 & CAMB-7B11C \\
\hline EPI_ISL_433698 & hCoV-19/England/CAMB-73DC5/2020 & CAMB-73DC5 & EPI_ISL_433921 & hCoV-19/England/CAMB-7B12B/2020 & CAMB-7B12B \\
\hline EPI_ISL_433699 & hCoV-19/England/CAMB-73DD4/2020 & CAMB-73DD4 & EPI_ISL_-433922 & hCoV-19/England/CAMB-7B13A/2020 & CAMB-7B13A \\
\hline EPI_ISL_425280 & hCoV-19/England/CAMB-74359/2020 & CAMB-74359 & EPI_ISL_433923 & hCoV-19/England/CAMB-7B149/2020 & CAMB-7B149 \\
\hline
\end{tabular}


medRxiv preprint doi: https://doi.org/10.1101/2020.05.08.20095687; this version posted May 14, 2020. The copyright holder for this preprint

(which was not certified by peer review) is the author/funder, who has granted medRxiv a license to display the preprint in perpetuity. All rights reserved. No reuse allowed without permission.

\begin{tabular}{|c|c|c|c|c|c|}
\hline GISAID Accession ID & Virus name & COG-UK & GISAID Accession ID & Virus name & COG-UK \\
\hline EPI_ISL_425281 & hCoV-19/England/CAMB-74368/2020 & CAMB-74368 & EPI_ISL_433924 & hCoV-19/England/CAMB-7B158/2020 & CAMB-7B158 \\
\hline EPI_ISL_425282 & hCoV-19/England/CAMB-74377/2020 & CAMB- 74377 & EPI_ISL_433925 & hCoV-19/England/CAMB-7B167/2020 & CAMB-7B167 \\
\hline EPI_ISL_425283 & hCoV-19/England/CAMB-74386/2020 & CAMB-74386 & EPI_ISL_433926 & hCoV-19/England/CAMB-7B194/2020 & CAMB-7B194 \\
\hline EPI_ISL_425284 & hCoV-19/England/CAMB-74395/2020 & CAMB-74395 & EPI_ISL_433927 & hCoV-19/England/CAMB-7B1A3/2020 & CAMB-7B1A3 \\
\hline EPI_ISL_425285 & hCoV-19/England/CAMB-743D $1 / 2020$ & CAMB-743D1 1 & EPI_ISL_433928 & hCoV-19/England/CAMB-7B1B2/2020 & CAMB-7B1B2 \\
\hline EPI_ISL_425286 & hCoV-19/England/CAMB-743E0/2020 & CAMB-743EO & EPI_ISL_433929 & hCoV-19/England/CAMB-7B1C1/2020 & CAMB-7B1C1 \\
\hline EPI_ISL_425287 & hCoV-19/England/CAMB-743FF/2020 & CAMB-743FF & EPI_ISL_433930 & hCoV-19/England/CAMB-7B1D0/2020 & CAMB-7B1D0 \\
\hline EPI_ISL_425288 & hCoV-19/England/CAMB-7440B/2020 & CAMB- $7440 B$ & EPI_ISL_433931 & hCoV-19/England/CAMB-7B1EF/2020 & CAMB-7B1EF \\
\hline EPI_ISL_425289 & hCoV-19/England/CAMB-7441A/2020 & CAMB-7441A & EPI_ISL_433932 & hCoV-19/England/CAMB-7B20A/2020 & CAMB-7B20A \\
\hline EPI_ISL_425290 & hCoV-19/England/CAMB-74438/2020 & CAMB-74438 & EPI_ISL_433933 & hCoV-19/England/CAMB-7B237/2020 & CAMB-7B237 \\
\hline EPI_ISL_425291 & hCoV-19/England/CAMB-74456/2020 & CAMB- 74456 & EPI_ISL_433934 & hCoV-19/England/CAMB-7B273/2020 & CAMB-7B273 \\
\hline EPI_ISL_425292 & hCoV-19/England/CAMB-74465/2020 & CAMB-74465 & EPI_ISL_433935 & hCoV-19/England/CAMB-7B291/2020 & CAMB-7B291 \\
\hline EPI ISL 425293 & hCoV-19/England/CAMB-74474/2020 & CAMB-74474 & EPI ISL 433936 & hCoV-19/England/CAMB-7B2A0/2020 & CAMB-7B2AO \\
\hline EPI_ISL_425294 & hCoV-19/England/CAMB-74483/2020 & CAMB- 74483 & EPI_ISL_433937 & hCoV-19/England/CAMB-7B2BF/2020 & CAMB-7B2BF \\
\hline EPI_ISL_425295 & hCoV-19/England/CAMB-74492/2020 & CAMB-74492 & EPI_ISL_433938 & hCoV-19/England/CAMB-7B2CE/2020 & CAMB-7B2CE \\
\hline EPI_ISL_425296 & hCoV-19/England/CAMB-744A1/2020 & CAMB-744A1 & EPI_ISL_433939 & hCoV-19/England/CAMB-7B2EC/2020 & CAMB-7B2EC \\
\hline EPI_ISL_425297 & hCoV-19/England/CAMB-744B0/2020 & CAMB-744BO & EPI_ISL-433940 & hCoV-19/England/CAMB-7B307/2020 & CAMB-7B307 \\
\hline EPI_ISL_425298 & $\mathrm{hCoV}-19 /$ England/CAMB-744CF/2020 & CAMB-744CF & EPI ISL 433941 & hCoV-19/England/CAMB-7B316/2020 & CAMB-7B316 \\
\hline EPI_ISL_425299 & hCoV-19/England/CAMB-744DE/2020 & CAMB-744DE & EPI_ISL_433942 & hCoV-19/England/CAMB-7B325/2020 & CAMB-7B325 \\
\hline EPI_ISL_425300 & hCoV-19/England/CAMB-74508/2020 & CAMB-74508 & EPI_ISL_433943 & hCoV-19/England/CAMB-7B334/2020 & CAMB-7B334 \\
\hline EPI_ISL_425301 & hCoV-19/England/CAMB-74517/2020 & CAMB-74517 & EPI_ISL_433944 & hCoV-19/England/CAMB-7B343/2020 & CAMB-7B343 \\
\hline EPI_ISL_425302 & hCoV-19/England/CAMB-74526/2020 & CAMB- 74526 & EPI_ISL_433945 & hCoV-19/England/CAMB-7B361/2020 & CAMB-7B361 \\
\hline EPI_ISL_425303 & hCoV-19/England/CAMB-74535/2020 & CAMB-74535 & EPI_ISL_433946 & hCoV-19/England/CAMB-7B370/2020 & CAMB-7B370 \\
\hline EPI_ISL_425304 & hCoV-19/England/CAMB-74544/2020 & CAMB-74544 & EPI_ISL_433947 & hCoV-19/England/CAMB-7B38F/2020 & CAMB-7B38F \\
\hline EPI_ISL_425305 & hCoV-19/England/CAMB-74553/2020 & CAMB- 74553 & EPI_ISL_433948 & hCoV-19/England/CAMB-7B39E/2020 & CAMB-7B39E \\
\hline EPI ISL 425306 & $\mathrm{hCoV}-19 /$ England/CAMB-74562/2020 & CAMB-74562 & EPI ISL 433949 & $\mathrm{hCoV}-19 /$ England/CAMB-7B3BC/2020 & CAMB-7B3BC \\
\hline EPI_ISL_425307 & hCoV-19/England/CAMB-74571/2020 & CAMB-74571 & EPI_ISL_433950 & hCoV-19/England/CAMB-7B3CB/2020 & CAMB-7B3CB \\
\hline EPI_ISL_425308 & hCoV-19/England/CAMB-74580/2020 & CAMB-74580 & EPI_ISL_433951 & hCoV-19/England/CAMB-7B3DA/2020 & CAMB-7B3DA \\
\hline EPI_ISL_425309 & hCoV-19/England/CAMB-7459F/2020 & CAMB-7459F & EPI_ISL_433952 & hCoV-19/England/CAMB-7B3E9/2020 & CAMB-7B3E9 \\
\hline EPI_ISL_425310 & hCoV-19/England/CAMB-745AE/2020 & CAMB-745AE & EPI_ISL_433953 & hCoV-19/England/CAMB-7B3F8/2020 & CAMB-7B3F8 \\
\hline EPI_ISL_425311 & hCoV-19/England/CAMB-745BD/2020 & CAMB-745BD & EPI_ISL_433954 & hCoV-19/England/CAMB-7B404/2020 & CAMB-7B404 \\
\hline EPI_ISL_425312 & hCoV-19/England/CAMB-745CC/2020 & CAMB- $745 \mathrm{CC}$ & EPI_ISL_433955 & hCoV-19/England/CAMB-7B413/2020 & CAMB-7B413 \\
\hline EPI_ISL_425313 & hCoV-19/England/CAMB-745DB/2020 & CAMB-745DB & EPI_ISL_433956 & hCoV-19/England/CAMB-7B422/2020 & CAMB-7B422 \\
\hline EPI_ISL 425314 & hCoV-19/England/CAMB-745EA/2020 & CAMB-745EA & EPI ISL 433957 & hCoV-19/England/CAMB-7B431/2020 & CAMB-7B431 \\
\hline EPI_ISL 425315 & hCoV-19/England/CAMB-74605/2020 & CAMB-74605 & EPI ISL 433958 & hCoV-19/England/CAMB-7B440/2020 & CAMB-7B440 \\
\hline EPI_ISL_425316 & hCoV-19/England/CAMB-74614/2020 & CAMB-74614 & EPI_ISL_433959 & hCoV-19/England/CAMB-7B45F/2020 & CAMB-7B45F \\
\hline EPI_ISL_425317 & hCoV-19/England/CAMB-74623/2020 & CAMB-74623 & EPI_ISL_433960 & hCoV-19/England/CAMB-7B47D/2020 & CAMB-7B47D \\
\hline EPI_ISL_425318 & hCoV-19/England/CAMB-74641/2020 & CAMB-74641 & EPI_ISL_433961 & hCoV-19/England/CAMB-7B48C/2020 & CAMB-7B48C \\
\hline EPI_ISL_425319 & hCoV-19/England/CAMB-74650/2020 & CAMB-74650 & EPI_ISL_433962 & hCoV-19/England/CAMB-7B49B/2020 & CAMB-7B49B \\
\hline EPI_ISL_425320 & hCoV-19/England/CAMB-7467E/2020 & CAMB-7467E & EPI_ISL_433963 & hCoV-19/England/CAMB-7B4AA/2020 & CAMB-7B4AA \\
\hline EPI_ISL_425321 & hCoV-19/England/CAMB-7468D/2020 & CAMB-7468D & EPI_ISL_433964 & hCoV-19/England/CAMB-7B4B9/2020 & CAMB-7B4B9 \\
\hline EPI_ISL_425322 & hCoV-19/England/CAMB-7469C/2020 & CAMB-7469C & EPI_ISL_433965 & hCoV-19/England/CAMB-7B4C8/2020 & CAMB-7B4C8 \\
\hline EPI_ISL_425323 & hCoV-19/England/CAMB-746AB/2020 & CAMB-746AB & EPI_ISL_433966 & hCoV-19/England/CAMB-7B4D7/2020 & CAMB-7B4D7 \\
\hline EPI_ISL_425324 & hCoV-19/England/CAMB-746BA/2020 & CAMB-746BA & EPI_ISL_433967 & hCoV-19/England/CAMB-7B4E6/2020 & CAMB-7B4E6 \\
\hline EPI_ISL_425325 & hCoV-19/England/CAMB-746D8/2020 & CAMB-746D8 & EPI_ISL_433968 & hCoV-19/England/CAMB-7B4F5/2020 & CAMB-7B4F5 \\
\hline EPI_ISL_425326 & hCoV-19/England/CAMB-74702/2020 & CAMB-74702 & EPI_ISL_433969 & hCoV-19/England/CAMB-7B501/2020 & CAMB-7B501 \\
\hline EPI_ISL_425327 & hCoV-19/England/CAMB-74711/2020 & CAMB-74711 & EPI_ISL_433970 & hCoV-19/England/CAMB-7B510/2020 & CAMB-7B510 \\
\hline EPI_ISL_425328 & hCoV-19/England/CAMB-74720/2020 & CAMB- 74720 & EPI_ISL_433971 & hCoV-19/England/CAMB-7B52F/2020 & CAMB-7B52F \\
\hline EPI_ISL_425329 & hCoV-19/England/CAMB-7473F/2020 & CAMB-7473F & EPI_ISL_433972 & hCoV-19/England/CAMB-7B53E/2020 & CAMB-7B53E \\
\hline EPI ISL 425330 & $\mathrm{hCoV}-19 /$ England/CAMB-7474E/2020 & CAMB-7474E & EPI ISL 433973 & hCoV-19/England/CAMB-7B54D/2020 & CAMB-7B54D \\
\hline EPI_ISL_425331 & $\mathrm{hCoV}-19 /$ England/CAMB-7475D/2020 & CAMB-7475D & EPI_ISL_433974 & hCoV-19/England/CAMB-7B55C/2020 & CAMB-7B55C \\
\hline EPI_ISL_425332 & hCoV-19/England/CAMB-7476C/2020 & CAMB-7476C & EPI_ISL_433975 & hCoV-19/England/CAMB-7B56B/2020 & CAMB-7B56B \\
\hline EPI_ISL_425333 & hCoV-19/England/CAMB-7477B/2020 & CAMB-7477B & EPI_ISL_433976 & hCoV-19/England/CAMB-7BFD6/2020 & CAMB-7BFD6 \\
\hline EPI_ISL_425334 & hCoV-19/England/CAMB-748D2/2020 & CAMB-748D2 & EPI_ISL_433977 & hCoV-19/England/CAMB-7BFE5/2020 & CAMB-7BFE5 \\
\hline EPI_ISL_425335 & hCoV-19/England/CAMB-748E $1 / 2020$ & CAMB-748E1 & EPI_ISL_433978 & hCoV-19/England/CAMB-7BFF4/2020 & CAMB-7BFF4 \\
\hline EPI_ISL_425336 & hCoV-19/England/CAMB-748FO/2020 & CAMB-748FO & EPI_ISL_433979 & hCoV-19/England/CAMB-7COOF/2020 & CAMB-7COOF \\
\hline EPI_ISL_425337 & hCoV-19/England/CAMB-7490C/2020 & CAMB-7490C & EPI_ISL_433980 & hCoV-19/England/CAMB-7C01E/2020 & CAMB-7C01E \\
\hline EPI ISL 425338 & $\mathrm{hCoV}-19 /$ England/CAMB-7491B/2020 & CAMB-7491B & EPI ISL 433981 & hCoV-19/England/CAMB-7C02D/2020 & CAMB-7C02D \\
\hline EPI_ISL_425339 & hCoV-19/England/CAMB-7492A/2020 & CAMB-7492A & EPI_ISL_433982 & hCoV-19/England/CAMB-7CO3C/2020 & CAMB-7CO3C \\
\hline EPI_ISL_425340 & hCoV-19/England/CAMB-74984/2020 & CAMB-74984 & EPI_ISL_433983 & hCoV-19/England/CAMB-7C04B/2020 & CAMB-7CO4B \\
\hline EPI_ISL_425341 & hCoV-19/England/CAMB-749A2/2020 & CAMB-749A2 & EPI_ISL_433984 & hCoV-19/England/CAMB-7C05A/2020 & CAMB-7C05A \\
\hline EPI_ISL_425342 & hCoV-19/England/CAMB-74A09/2020 & CAMB-74A09 & EPI_ISL_433985 & hCoV-19/England/CAMB-7C069/2020 & CAMB-7C069 \\
\hline EPI_ISL_425343 & hCoV-19/England/CAMB-74A18/2020 & CAMB-74A18 & EPI_ISL_433986 & hCoV-19/England/CAMB-7C078/2020 & CAMB-7C078 \\
\hline EPI_ISL_425344 & hCoV-19/England/CAMB-74A72/2020 & CAMB-74A72 & EPI_ISL_433987 & hCoV-19/England/CAMB-7C087/2020 & CAMB-7C087 \\
\hline EPI_ISL_425345 & hCoV-19/England/CAMB-74ABE/2020 & CAMB-74ABE & EPI_ISL_433988 & hCoV-19/England/CAMB-7C096/2020 & CAMB-7C096 \\
\hline EPI_ISL_425346 & hCoV-19/England/CAMB-74B24/2020 & CAMB-74B24 & EPI_ISL_433989 & hCoV-19/England/CAMB-7COA5/2020 & CAMB-7COA5 \\
\hline EPI_ISL_425347 & hCoV-19/England/CAMB-74B33/2020 & CAMB-74B33 & EPI_ISL_433990 & hCoV-19/England/CAMB-7COB4/2020 & CAMB-7COB4 \\
\hline EPI_ISL_425348 & $\mathrm{hCoV}-19 /$ England/CAMB-74B42/2020 & CAMB-74B42 & EPI_ISL_433991 & hCoV-19/England/CAMB-7COC3/2020 & CAMB-7COC3 \\
\hline EPI_ISL_425349 & hCoV-19/England/CAMB-74B51/2020 & CAMB-74B51 & EPI_ISL_433992 & hCoV-19/England/CAMB-7COD2/2020 & CAMB-7COD2 \\
\hline EPI_ISL_425350 & hCoV-19/England/CAMB-74B60/2020 & CAMB-74B60 & EPI_ISL_433993 & hCoV-19/England/CAMB-7COE1/2020 & CAMB-7COE1 \\
\hline EPI_ISL_425351 & hCoV-19/England/CAMB-74B9D/2020 & CAMB-74B9D & EPI_ISL_433994 & hCoV-19/England/CAMB-7COFO/2020 & CAMB-7COFO \\
\hline EPI_ISL_425352 & hCoV-19/England/CAMB-74BAC/2020 & CAMB-74BAC & EPI_ISL_433995 & hCoV-19/England/CAMB-7C10C/2020 & CAMB-7C $10 \mathrm{C}$ \\
\hline EPI_ISL_425353 & hCoV-19/England/CAMB-74BBB/2020 & CAMB-74BBB & EPI_ISL_433996 & hCoV-19/England/CAMB-7C11B/2020 & CAMB-7C11B \\
\hline EPI_ISL_425354 & hCoV-19/England/CAMB-74BCA/2020 & CAMB-74BCA & EPI_ISL_433997 & hCoV-19/England/CAMB-7C12A/2020 & CAMB-7C12A \\
\hline EPI_ISL_425355 & hCoV-19/England/CAMB-74BF7/2020 & CAMB-74BF7 & EPI ISL 433998 & hCoV-19/England/CAMB-7C139/2020 & CAMB-7C139 \\
\hline EPI ISL 425356 & hCoV-19/England/CAMB-74CO3/2020 & CAMB- $74 \mathrm{C} 03$ & EPI ISL 433999 & hCoV-19/England/CAMB-7C148/2020 & CAMB-7C148 \\
\hline EPI_ISL_425357 & hCoV-19/England/CAMB-74C12/2020 & CAMB-74C12 & EPI_ISL_434000 & hCoV-19/England/CAMB-7C157/2020 & CAMB-7C157 \\
\hline & hCoV-19/England/CAMB-74C21/2020 & CAMB-74C21 & EPI_ISL_434001 & hCoV-19/England/CAMB-7C166/2020 & CAMB-7C166 \\
\hline EPI_ISL_425359 & hCoV-19/England/CAMB-74C30/2020 & CAMB- 74 C 30 & EPI_ISL_434002 & hCoV-19/England/CAMB-7C175/2020 & CAMB-7C175 \\
\hline EPI_ISL_425360 & hCoV-19/England/CAMB-74C4F/2020 & CAMB-74C $4 \mathrm{~F}$ & EPI_ISL_434003 & hCoV-19/England/CAMB-7C184/2020 & CAMB-7C184 \\
\hline EPI_ISL_425361 & hCoV-19/England/CAMB-74C5E/2020 & CAMB-74C5E & EPI_ISL_434004 & hCoV-19/England/CAMB-7C193/2020 & CAMB-7C193 \\
\hline EPI_ISL_425362 & $\mathrm{hCoV-19/England/CAMB-74C8B/2020}$ & CAMB-74C8B & EPI_ISL_434005 & hCoV-19/England/CAMB-7C1A2/2020 & CAMB-7C1A2 \\
\hline EPI_ISL_425363 & hCoV-19/England/CAMB-74CA9/2020 & CAMB-74CA9 & EPI_ISL_434006 & hCoV-19/England/CAMB-7C1B1/2020 & CAMB-7C1B1 \\
\hline EPI_ISL_425364 & hCoV-19/England/CAMB-74CC7/2020 & CAMB-74CC7 & EPI ISL 434007 & hCoV-19/England/CAMB-7C1CO/2020 & CAMB-7C1C0 \\
\hline
\end{tabular}


medRxiv preprint doi: https://doi.org/10.1101/2020.05.08.20095687; this version posted May 14, 2020. The copyright holder for this preprint

(which was not certified by peer review) is the author/funder, who has granted medRxiv a license to display the preprint in perpetuity. All rights reserved. No reuse allowed without permission.

\begin{tabular}{|c|c|c|c|c|c|}
\hline GISAID Accession ID & Virus name & COG-UK & GISAID Accession ID & Virus name & COG-UK \\
\hline EPI_ISL_425365 & hCoV-19/England/CAMB-74CD6/2020 & CAMB-74CD6 & EPI_ISL_434008 & hCoV-19/England/CAMB-7C1DF/2020 & CAMB-7C1DF \\
\hline EPI_ISL_425366 & hCoV-19/England/CAMB-74CF4/2020 & CAMB-74CF4 & EPI_ISL_434009 & hCoV-19/England/CAMB-7C1EE/2020 & CAMB-7C1EE \\
\hline EPI_ISL_425367 & hCoV-19/England/CAMB-74D00/2020 & CAMB-74D00 & EPI_ISL_434010 & hCoV-19/England/CAMB-7C1FD/2020 & CAMB-7C1FD \\
\hline EPI_ISL_-425368 & hCoV-19/England/CAMB-74D1F/2020 & CAMB-74D1F & EPI_ISL_-434011 & hCoV-19/England/CAMB-7C209/2020 & CAMB-7C209 \\
\hline EPI_ISL_-425369 & hCoV-19/England/CAMB-74D2E/2020 & CAMB-74D2E & EPI_ISL_-434012 & hCoV-19/England/CAMB-7C218/2020 & CAMB-7C218 \\
\hline EPI_ISL_425370 & hCoV-19/England/CAMB-74D3D/2020 & CAMB-74D3D & EPI_ISL_434013 & hCoV-19/England/CAMB-7C227/2020 & CAMB-7C227 \\
\hline EPI_ISL_425371 & hCoV-19/England/CAMB-74D4C/2020 & CAMB-74D4C & EPI_ISL_434014 & hCoV-19/England/CAMB-7C236/2020 & CAMB-7C236 \\
\hline EPI_ISL_-425373 & hCoV-19/England/CAMB-74D5B/2020 & CAMB-74D5B & EPI_ISL_-434015 & hCoV-19/England/CAMB-7C245/2020 & CAMB-7C245 \\
\hline EPI_ISL_425374 & hCoV-19/England/CAMB-74D6A/2020 & CAMB-74D6A & EPI_ISL_434016 & hCoV-19/England/CAMB-7C254/2020 & CAMB-7C254 \\
\hline EPI_ISL_425375 & hCoV-19/England/CAMB-74DE2/2020 & CAMB-74DE2 & EPI_ISL_434017 & hCoV-19/England/CAMB-7C263/2020 & CAMB-7C263 \\
\hline EPI_ISL_425376 & hCoV-19/England/CAMB-74DF1/2020 & CAMB-74DF1 & EPI_ISL_434018 & hCoV-19/England/CAMB-7C272/2020 & CAMB-7C272 \\
\hline EPI_ISL_425377 & hCoV-19/England/CAMB-74EOD/2020 & CAMB-74EOD & EPI_ISL_434019 & hCoV-19/England/CAMB-7C281/2020 & CAMB-7C281 \\
\hline EPI_ISL_425378 & hCoV-19/England/CAMB-74E49/2020 & CAMB-74E49 & EPI_ISL_434020 & hCoV-19/England/CAMB-7C290/2020 & CAMB-7C290 \\
\hline EPI_ISL_425379 & hCoV-19/England/CAMB-74E58/2020 & CAMB-74E58 & EPI_ISL_434021 & hCoV-19/England/CAMB-7C2AF/2020 & CAMB-7C2AF \\
\hline EPI_ISL_425380 & hCoV-19/England/CAMB-74E67/2020 & CAMB-74E67 & EPI_ISL_434022 & hCoV-19/England/CAMB-7C2BE/2020 & CAMB-7C2BE \\
\hline EPI_ISL_-425381 & hCoV-19/England/CAMB-74E76/2020 & CAMB-74E76 & EPI_ISL_-434023 & hCoV-19/England/CAMB-7C2CD/2020 & CAMB-7C2CD \\
\hline EPI_ISL_425382 & hCoV-19/England/CAMB-74E85/2020 & CAMB-74E85 & EPI_ISL_434024 & hCoV-19/England/CAMB-7C2DC/2020 & CAMB-7C2DC \\
\hline EPI_ISL_425383 & hCoV-19/England/CAMB-74EA3/2020 & CAMB-74EA3 & EPI_ISL_434025 & hCoV-19/England/CAMB-7C2FA/2020 & CAMB-7C2FA \\
\hline EPI_ISL_-425384 & hCoV-19/England/CAMB-74EB2/2020 & CAMB-74EB2 & EPI_ISL_-434026 & hCoV-19/England/CAMB-7C306/2020 & CAMB-7C306 \\
\hline EPI_ISL_-425385 & hCoV-19/England/CAMB-74EC1/2020 & CAMB-74EC1 & EPI_ISL_-434027 & hCoV-19/England/CAMB-7C315/2020 & CAMB-7C315 \\
\hline EPI_ISL_425386 & hCoV-19/England/CAMB-7537E/2020 & CAMB-7537E & EPI_ISL_-434028 & hCoV-19/England/CAMB-7C324/2020 & CAMB-7C324 \\
\hline EPI_ISL_425387 & hCoV-19/England/CAMB-75419/2020 & CAMB-75419 & EPI_ISL_434029 & hCoV-19/England/CAMB-7C333/2020 & CAMB-7C333 \\
\hline EPI_ISL_425388 & hCoV-19/England/CAMB-75437/2020 & CAMB-75437 & EPI_ISL_434030 & hCoV-19/England/CAMB-7C342/2020 & CAMB-7C342 \\
\hline EPI_ISL_425389 & hCoV-19/England/CAMB-75455/2020 & CAMB-75455 & EPI_ISL_434031 & hCoV-19/England/CAMB-7C351/2020 & CAMB-7C351 \\
\hline EPI_ISL_-425390 & hCoV-19/England/CAMB-75464/2020 & CAMB-75464 & EPI_ISL_-434032 & hCoV-19/England/CAMB-7C360/2020 & CAMB-7C360 \\
\hline EPI_ISL_425391 & hCoV-19/England/CAMB-75473/2020 & CAMB-75473 & EPI_ISL_434033 & hCoV-19/England/CAMB-7C37F/2020 & CAMB-7C37F \\
\hline EPI_ISL_425392 & hCoV-19/England/CAMB-75482/2020 & CAMB-75482 & EPI_ISL_434034 & hCoV-19/England/CAMB-7C38E/2020 & CAMB-7C38E \\
\hline EPI_ISL_425393 & hCoV-19/England/CAMB-75491/2020 & CAMB-75491 & EPI_ISL_434035 & hCoV-19/England/CAMB-7C39D/2020 & CAMB-7C39D \\
\hline EPI_ISL_-425394 & hCoV-19/England/CAMB-754A0/2020 & CAMB-754AO & EPI_ISL_-434036 & hCoV-19/England/CAMB-7C3AC/2020 & CAMB-7C3AC \\
\hline EPI_ISL_425395 & hCoV-19/England/CAMB-754B7/2020 & CAMB-754B7 & EPI_ISL_434037 & hCoV-19/England/CAMB-7C3BB/2020 & CAMB-7C3BB \\
\hline EPI_ISL_425396 & hCoV-19/England/CAMB-754CE/2020 & CAMB-754CE & EPI_ISL_-434038 & hCoV-19/England/CAMB-7C3CA/2020 & CAMB-7C3CA \\
\hline EPI_ISL_425397 & hCoV-19/England/CAMB-754DD/2020 & CAMB-754DD & EPI_ISL_434039 & hCoV-19/England/CAMB-7C3E8/2020 & CAMB-7C3E8 \\
\hline EPI_ISL_425398 & hCoV-19/England/CAMB-754EC/2020 & CAMB-754EC & EPI_ISL_434040 & hCoV-19/England/CAMB-7E10A/2020 & CAMB-7E10A \\
\hline EPI_ISL_425399 & hCoV-19/England/CAMB-754FB/2020 & CAMB-754FB & EPI_ISL_434041 & hCoV-19/England/CAMB-7E119/2020 & CAMB-7E119 \\
\hline EPI_ISL_425400 & hCoV-19/England/CAMB-75507/2020 & CAMB-75507 & EPI_ISL_434042 & hCoV-19/England/CAMB-7E128/2020 & CAMB-7E128 \\
\hline EPI_ISL_-425401 & hCoV-19/England/CAMB-75516/2020 & CAMB-75516 & EPI_ISL_-434043 & hCoV-19/England/CAMB-7E137/2020 & CAMB-7E137 \\
\hline EPI_ISL_-425402 & hCoV-19/England/CAMB-75525/2020 & CAMB-75525 & EPI_ISL_-434044 & hCoV-19/England/CAMB-7E146/2020 & CAMB-7E146 \\
\hline EPI_ISL_425403 & hCoV-19/England/CAMB-75534/2020 & CAMB-75534 & EPI_ISL_434045 & hCoV-19/England/CAMB-7E155/2020 & CAMB-7E155 \\
\hline EPI_ISL_425404 & hCoV-19/England/CAMB-75543/2020 & CAMB-75543 & EPI_ISL_434046 & hCoV-19/England/CAMB-7E164/2020 & CAMB-7E164 \\
\hline EPI_ISL_-425405 & hCoV-19/England/CAMB-75552/2020 & CAMB-75552 & EPI_ISL_-434047 & hCoV-19/England/CAMB-7E1BF/2020 & CAMB-7E1BF \\
\hline EPI_ISL_-425406 & hCoV-19/England/CAMB-75570/2020 & CAMB-75570 & EPI_ISL_-434048 & hCoV-19/England/CAMB-7E1CE/2020 & CAMB-7E1CE \\
\hline EPI_ISL_425407 & hCoV-19/England/CAMB-7559E/2020 & CAMB-7559E & EPI_ISL_434049 & hCoV-19/England/CAMB-7E1DD/2020 & CAMB-7E1DD \\
\hline EPI_ISL_433700 & hCoV-19/England/CAMB-755AD/2020 & CAMB-755AD & EPI_ISL_434050 & hCoV-19/England/CAMB-7E1EC/2020 & CAMB-7E1EC \\
\hline EPI_ISL_425408 & hCoV-19/England/CAMB-755BC/2020 & CAMB-755BC & EPI_ISL_434051 & hCoV-19/England/CAMB-7E1FB/2020 & CAMB-7E1FB \\
\hline EPI_ISL_425409 & hCoV-19/England/CAMB-755CB/2020 & CAMB-755CB & EPI_ISL_434052 & hCoV-19/England/CAMB-7E207/2020 & CAMB-7E207 \\
\hline EPI_ISL_-425410 & hCoV-19/England/CAMB-755DA/2020 & CAMB-755DA & EPI_ISL_-434053 & hCoV-19/England/CAMB-7E225/2020 & CAMB-7E225 \\
\hline EPI_ISL_425411 & hCoV-19/England/CAMB-755E9/2020 & CAMB-755E9 & EPI_ISL_434054 & hCoV-19/England/CAMB-7E234/2020 & CAMB-7E234 \\
\hline EPI_ISL_425412 & hCoV-19/England/CAMB-755F8/2020 & CAMB-755F8 & EPI_ISL_-434055 & hCoV-19/England/CAMB-7E243/2020 & CAMB-7E243 \\
\hline EPI_ISL_425413 & hCoV-19/England/CAMB-75604/2020 & CAMB-75604 & EPI_ISL_434056 & hCoV-19/England/CAMB-7E252/2020 & CAMB-7E252 \\
\hline EPI_ISL_425414 & hCoV-19/England/CAMB-75613/2020 & CAMB-75613 & EPI_ISL_434057 & hCoV-19/England/CAMB-7E261/2020 & CAMB-7E261 \\
\hline EPI_ISL_425415 & hCoV-19/England/CAMB-75622/2020 & CAMB-75622 & EPI_ISL_434058 & hCoV-19/England/CAMB-7E270/2020 & CAMB-7E270 \\
\hline EPI_ISL_-425416 & hCoV-19/England/CAMB-75631/2020 & CAMB-75631 & EPI_ISL_-434059 & hCoV-19/England/CAMB-7E29E/2020 & CAMB-7E29E \\
\hline EPI_ISL_425417 & hCoV-19/England/CAMB-75640/2020 & CAMB-75640 & EPI_ISL_434060 & hCoV-19/England/CAMB-7E2AD/2020 & CAMB-7E2AD \\
\hline EPI_ISL_425418 & hCoV-19/England/CAMB-7565F/2020 & CAMB-7565F & EPI_ISL_434061 & hCoV-19/England/CAMB-7E2BC/2020 & CAMB-7E2BC \\
\hline EPI_ISL_425419 & hCoV-19/England/CAMB-7566E/2020 & CAMB-7566E & EPI_ISL_434062 & hCoV-19/England/CAMB-7E2CB/2020 & CAMB-7E2CB \\
\hline EPI_ISL_425420 & hCoV-19/England/CAMB-7567D/2020 & CAMB-7567D & EPI_ISL_433466 & hCoV-19/England/CAMB-7E2DA/2020 & CAMB-7E2DA \\
\hline EPI_ISL_-425421 & hCoV-19/England/CAMB-7569B/2020 & CAMB-7569B & EPI_ISL_-433467 & hCoV-19/England/CAMB-7E2E9/2020 & CAMB-7E2E9 \\
\hline EPI_ISL_425422 & hCoV-19/England/CAMB-756AA/2020 & CAMB-756AA & EPI_ISL_433468 & hCoV-19/England/CAMB-7E2F8/2020 & CAMB-7E2F8 \\
\hline EPI_ISL_-425423 & hCoV-19/England/CAMB-76D1D/2020 & CAMB-76D1D & EPI_ISL_-433469 & hCoV-19/England/CAMB-7E304/2020 & CAMB-7E304 \\
\hline EPI_ISL_425424 & hCoV-19/England/CAMB-76D3B/2020 & CAMB-76D3B & EPI_ISL_433470 & hCoV-19/England/CAMB-7E313/2020 & CAMB-7E 313 \\
\hline EPI_ISL_425425 & hCoV-19/England/CAMB-76D59/2020 & CAMB-76D59 & EPI_ISL_433471 & hCoV-19/England/CAMB-7E322/2020 & CAMB-7E322 \\
\hline EPI_ISL_-425426 & hCoV-19/England/CAMB-76D77/2020 & CAMB-76D77 & EPI_ISL_-433472 & hCoV-19/England/CAMB-7E331/2020 & CAMB-7E331 \\
\hline EPI_ISL_425427 & hCoV-19/England/CAMB-76D95/2020 & CAMB-76D95 & EPI_ISL_433473 & hCoV-19/England/CAMB-7E340/2020 & CAMB-7E340 \\
\hline EPI_ISL_425428 & hCoV-19/England/CAMB-76DB3/2020 & CAMB-76DB3 & EPI_ISL_433474 & hCoV-19/England/CAMB-7F7E9/2020 & CAMB-7F7E9 \\
\hline EPI_ISL_425429 & hCoV-19/England/CAMB-76DD $1 / 2020$ & CAMB-76DD1 & EPI_ISL_433475 & hCoV-19/England/CAMB-7F804/2020 & CAMB-7F804 \\
\hline EPI_ISL_425430 & hCoV-19/England/CAMB-76DFF/2020 & CAMB-76DFF & EPI_ISL_433476 & hCoV-19/England/CAMB-7F822/2020 & CAMB-7F822 \\
\hline EPI_ISL_425431 & hCoV-19/England/CAMB-76E1A/2020 & CAMB-76E1A & EPI_ISL_433477 & hCoV-19/England/CAMB-7F88C/2020 & CAMB-7F88C \\
\hline EPI_ISL_425432 & hCoV-19/England/CAMB-76E38/2020 & CAMB-76E38 & EPI_ISL_433478 & hCoV-19/England/CAMB-7F8E6/2020 & CAMB-7F8E6 \\
\hline EPI_ISL_-425433 & hCoV-19/England/CAMB-76E56/2020 & CAMB-76E56 & EPI_ISL_-433479 & hCoV-19/England/CAMB-7FB29/2020 & CAMB-7FB29 \\
\hline EPI_ISL_-425434 & hCoV-19/England/CAMB-76E74/2020 & CAMB-76E74 & EPI_ISL_-433480 & hCoV-19/England/CAMB-7FB47/2020 & CAMB-7FB47 \\
\hline EPI_ISL_425435 & hCoV-19/England/CAMB-76E92/2020 & CAMB-76E92 & EPI_ISL_433481 & hCoV-19/England/CAMB-7FB56/2020 & CAMB-7FB56 \\
\hline EPI_ISL_425436 & hCoV-19/England/CAMB-76EB0/2020 & CAMB-76EBO & EPI_ISL_433482 & hCoV-19/England/CAMB-7FB65/2020 & CAMB-7FB65 \\
\hline EPI_ISL_425437 & hCoV-19/England/CAMB-76EDE/2020 & CAMB-76EDE & EPI_ISL_-433483 & hCoV-19/England/CAMB-7FB74/2020 & CAMB-7FB74 \\
\hline & hCoV-19/England/CAMB-76EFC/2020 & CAMB-76EFC & EPI_ISL_433484 & hCoV-19/England/CAMB-7FB83/2020 & CAMB-7FB83 \\
\hline EPI_ISL_425439 & hCoV-19/England/CAMB-76F17/2020 & CAMB-76F17 & EPI_ISL_433485 & hCoV-19/England/CAMB-7FB92/2020 & CAMB-7FB92 \\
\hline EPI_ISL_425440 & hCoV-19/England/CAMB-76F35/2020 & CAMB-76F35 & EPI_ISL_433486 & hCoV-19/England/CAMB-7FBA1/2020 & CAMB-7FBA1 \\
\hline EPI_ISL_425441 & hCoV-19/England/CAMB-76F62/2020 & CAMB-76F62 & EPI_ISL_433487 & hCoV-19/England/CAMB-7FBBO/2020 & CAMB-7FBBO \\
\hline EPI_ISL_425442 & hCoV-19/England/CAMB-76F71/2020 & CAMB-76F71 & EPI_ISL_433488 & hCoV-19/England/CAMB-7FBCF/2020 & CAMB-7FBCF \\
\hline EPI_ISL_-425443 & hCoV-19/England/CAMB-76F9F/2020 & CAMB-76F9F & EPI_ISL_-433489 & hCoV-19/England/CAMB-7FBDE/2020 & CAMB-7FBDE \\
\hline EPI_ISL_-425444 & hCoV-19/England/CAMB-76FAE/2020 & CAMB-76FAE & EPI_ISL_-433490 & hCoV-19/England/CAMB-7FBFC/2020 & CAMB-7FBFC \\
\hline EPI_ISL_425445 & hCoV-19/England/CAMB-76FBD/2020 & CAMB-76FBD & EPI_ISL_433491 & hCoV-19/England/CAMB-7FC08/2020 & CAMB-7FCO8 \\
\hline EPI_ISL_425446 & hCoV-19/England/CAMB-76FCC/2020 & CAMB-76FCC & EPI_ISL_433492 & hCoV-19/England/CAMB-7FC17/2020 & CAMB-7FC17 \\
\hline EPI_ISL_425447 & hCoV-19/England/CAMB-76FDB/2020 & CAMB-76FDB & EPI_ISL_433493 & hCoV-19/England/CAMB-7FC26/2020 & CAMB-7FC26 \\
\hline EPI_ISL_425448 & hCoV-19/England/CAMB-76FEA/2020 & CAMB-76FEA & EPI_ISL_- 433494 & hCoV-19/England/CAMB-7FC35/2020 & CAMB-7FC35 \\
\hline
\end{tabular}


medRxiv preprint doi: https://doi.org/10.1101/2020.05.08.20095687; this version posted May 14, 2020. The copyright holder for this preprint

(which was not certified by peer review) is the author/funder, who has granted medRxiv a license to display the preprint in perpetuity. All rights reserved. No reuse allowed without permission.

\begin{tabular}{|c|c|c|c|c|c|}
\hline GISAID Accession ID & Virus name & COG-UK & GISAID Accession ID & Virus name & COG-UK \\
\hline EPI_ISL_425449 & hCoV-19/England/CAMB-76FF9/2020 & CAMB-76FF9 & \begin{tabular}{|l|} 
EPI_ISL_433495 \\
\end{tabular} & hCoV-19/England/CAMB-7FC44/2020 & CAMB-7FC44 \\
\hline EPI_ISL_425450 & hCoV-19/England/CAMB-77004/2020 & CAMB-77004 & EPI_ISL_433496 & hCoV-19/England/CAMB-7FC53/2020 & CAMB-7FC53 \\
\hline EPI_ISL_425451 & hCoV-19/England/CAMB-77013/2020 & CAMB-77013 & EPI_ISL_433497 & hCoV-19/England/CAMB-7FC62/2020 & CAMB-7FC62 \\
\hline EPI_ISL_425452 & hCoV-19/England/CAMB-77022/2020 & CAMB-77022 & EPI_ISL_433856 & hCoV-19/England/CAMB-7AC49/2020 & CAMB-7AC49 \\
\hline EPI_ISL_425453 & hCoV-19/England/CAMB-77031/2020 & CAMB-77031 & EPI_ISL_433857 & hCoV-19/England/CAMB-7AC58/2020 & CAMB-7AC58 \\
\hline EPI_ISL_425454 & hCoV-19/England/CAMB-77040/2020 & CAMB-77040 & EPI_ISL_433858 & hCoV-19/England/CAMB-7AC67/2020 & CAMB-7AC67 \\
\hline EPI_ISL_425455 & hCoV-19/England/CAMB-7705F/2020 & CAMB- $7705 \mathrm{~F}$ & EPI_ISL_433859 & hCoV-19/England/CAMB-7AC76/2020 & CAMB-7AC76 \\
\hline EPI_ISL_-425456 & hCoV-19/England/CAMB-7706E/2020 & CAMB-7706E & EPI_ISL_-433855 & hCoV-19/England/CAMB-7AC3A/2020 & САMB-7АСЗА \\
\hline EPI_ISL_425457 & hCoV-19/England/CAMB-7707D/2020 & CAMB-7707D & Pending & hCoV-19/England/CAMB-7FC71/2020 & CAMB-7FC71 \\
\hline EPI_ISL_425458 & hCoV-19/England/CAMB-7708C/2020 & CAMB-7708C & Pending & hCoV-19/England/CAMB-7FC80/2020 & CAMB-7FC80 \\
\hline EPI_ISL_425459 & hCoV-19/England/CAMB-7709B/2020 & CAMB- $7709 B$ & Pending & hCoV-19/England/CAMB-7FC9F/2020 & CAMB-7FC9F \\
\hline EPI_ISL_-425460 & hCoV-19/England/CAMB-770B9/2020 & CAMB-770B9 & Pending & hCoV-19/England/CAMB-7FCBD/2020 & CAMB-7FCBD \\
\hline EPI_ISL_425461 & hCoV-19/England/CAMB-770C8/2020 & CAMB-770C8 & Pending & hCoV-19/England/CAMB-7FCF9/2020 & CAMB-7FCF9 \\
\hline EPI_ISL_433701 & hCoV-19/England/CAMB-779FA/2020 & CAMB-779FA & Pending & hCoV-19/England/CAMB-7FD05/2020 & CAMB-7FD05 \\
\hline EPI_ISL_433702 & hCoV-19/England/CAMB-78197/2020 & CAMB-78197 & Pending & hCoV-19/England/CAMB-7FD23/2020 & CAMB-7FD23 \\
\hline EPI_ISL_433703 & hCoV-19/England/CAMB-781A6/2020 & CAMB-781A6 & Pending & hCoV-19/England/CAMB-7FD32/2020 & CAMB-7FD32 \\
\hline EPI_ISL_433704 & hCoV-19/England/CAMB-781B5/2020 & CAMB-781B5 & Pending & hCoV-19/England/CAMB-7FD6F/2020 & CAMB-7FD6F \\
\hline EPI_ISL_433705 & hCoV-19/England/CAMB-781E2/2020 & CAMB-781E2 & Pending & hCoV-19/England/CAMB-7FD7E/2020 & CAMB-7FD7E \\
\hline EPI_ISL_-433706 & hCoV-19/England/CAMB-7820D/2020 & CAMB-7820D & Pending & hCoV-19/England/CAMB-7FD8D/2020 & CAMB-7FD8D \\
\hline EPI_ISL_433707 & hCoV-19/England/CAMB-7822B/2020 & CAMB-7822B & Pending & hCoV-19/England/CAMB-7FDBA/2020 & CAMB-7FDBA \\
\hline EPI_ISL_433708 & hCoV-19/England/CAMB-78276/2020 & CAMB-78276 & Pending & hCoV-19/England/CAMB-7FDC9/2020 & CAMB-7FDC9 \\
\hline EPI_ISL_433709 & hCoV-19/England/CAMB-78285/2020 & CAMB-78285 & Pending & hCoV-19/England/CAMB-7FE20/2020 & CAMB-7FE20 \\
\hline EPI_ISL_433710 & hCoV-19/England/CAMB-78294/2020 & CAMB-78294 & Pending & hCoV-19/England/CAMB-7FE3F/2020 & CAMB-7FE3F \\
\hline EPI_ISL_-433711 & hCoV-19/England/CAMB-782A3/2020 & CAMB-782A3 & Pending & hCoV-19/England/CAMB-7FE4E/2020 & CAMB-7FE4E \\
\hline EPI_ISL_433712 & hCoV-19/England/CAMB-782B2/2020 & CAMB-782B2 & Pending & hCoV-19/England/CAMB-7FE5D/2020 & CAMB-7FE5D \\
\hline EPI_ISL_433713 & hCoV-19/England/CAMB-782D0/2020 & CAMB-782D0 & Pending & hCoV-19/England/CAMB-7FE7B/2020 & CAMB-7FE7B \\
\hline EPI_ISL_433714 & hCoV-19/England/CAMB-782EF/2020 & CAMB-782EF & Pending & hCoV-19/England/CAMB-7FEB $7 / 2020$ & CAMB-7FEB7 \\
\hline EPI_ISL_433715 & hCoV-19/England/CAMB-782FE/2020 & CAMB-782FE & Pending & hCoV-19/England/CAMB-7FEC6/2020 & CAMB-7FEC6 \\
\hline EPI_ISL_-433716 & hCoV-19/England/CAMB-7830A/2020 & CAMB-7830A & Pending & hCoV-19/England/CAMB-7FEE4/2020 & CAMB-7FEE4 \\
\hline EPI_ISL_433717 & hCoV-19/England/CAMB-78319/2020 & CAMB-78319 & Pending & hCoV-19/England/CAMB-80AFB/2020 & CAMB-80AFB \\
\hline EPI_ISL_433718 & hCoV-19/England/CAMB-78328/2020 & CAMB-78328 & Pending & hCoV-19/England/CAMB-80E3B/2020 & CAMB-80E3B \\
\hline EPI_ISL_433719 & hCoV-19/England/CAMB-78337/2020 & CAMB-78337 & Pending & hCoV-19/England/CAMB-80E4A/2020 & CAMB-80E4A \\
\hline EPI_ISL_433720 & hCoV-19/England/CAMB-78346/2020 & CAMB-78346 & Pending & hCoV-19/England/CAMB-80E59/2020 & CAMB-80E59 \\
\hline EPI_ISL_433721 & hCoV-19/England/CAMB-78355/2020 & CAMB-78355 & Pending & hCoV-19/England/CAMB-80E68/2020 & CAMB-80E68 \\
\hline EPI_ISL_433722 & hCoV-19/England/CAMB-78364/2020 & CAMB-78364 & Pending & hCoV-19/England/CAMB-80E77/2020 & CAMB-80E77 \\
\hline EPI_ISL_433723 & hCoV-19/England/CAMB-78373/2020 & CAMB-78373 & Pending & hCoV-19/England/CAMB-80E86/2020 & CAMB-80E86 \\
\hline EPI_ISL_433724 & hCoV-19/England/CAMB-78382/2020 & CAMB-78382 & Pending & hCoV-19/England/CAMB-80E95/2020 & CAMB-80E95 \\
\hline EPI_ISL_433725 & hCoV-19/England/CAMB-78391/2020 & CAMB-78391 & Pending & hCoV-19/England/CAMB-80EA4/2020 & CAMB-80EA4 \\
\hline EPI_ISL_433726 & hCoV-19/England/CAMB-783BF/2020 & CAMB-783BF & Pending & hCoV-19/England/CAMB-80EB3/2020 & CAMB-80EB3 \\
\hline EPI_ISL_433727 & hCoV-19/England/CAMB-783CE/2020 & CAMB-783CE & Pending & hCoV-19/England/CAMB-80EC2/2020 & CAMB-80EC2 \\
\hline EPI_ISL_433728 & hCoV-19/England/CAMB-783DD/2020 & CAMB-783DD & Pending & hCoV-19/England/CAMB-80ED1/2020 & CAMB-80ED1 \\
\hline EPI_ISL_433729 & hCoV-19/England/CAMB-783EC/2020 & CAMB-783EC & Pending & hCoV-19/England/CAMB-80EE0/2020 & CAMB-80EE0 \\
\hline EPI_ISL_433730 & hCoV-19/England/CAMB-783FB/2020 & CAMB-783FB & Pending & hCoV-19/England/CAMB-80EFF/2020 & CAMB-80EFF \\
\hline EPI_ISL_433731 & hCoV-19/England/CAMB-78407/2020 & CAMB-78407 & Pending & hCoV-19/England/CAMB-80F0B/2020 & CAMB-80F0B \\
\hline EPI_ISL_433732 & hCoV-19/England/CAMB-78416/2020 & CAMB-78416 & Pending & hCoV-19/England/CAMB-80F1A/2020 & CAMB-80F1A \\
\hline EPI_ISL_433733 & hCoV-19/England/CAMB-78425/2020 & CAMB-78425 & Pending & hCoV-19/England/CAMB-80F29/2020 & CAMB-80F29 \\
\hline EPI_ISL_433734 & hCoV-19/England/CAMB-78452/2020 & CAMB-78452 & Pending & hCoV-19/England/CAMB-80F38/2020 & CAMB-80F38 \\
\hline EPI_ISL_433735 & hCoV-19/England/CAMB-78461/2020 & CAMB-78461 & Pending & hCoV-19/England/CAMB-80F47/2020 & CAMB-80F47 \\
\hline EPI_ISL_433736 & hCoV-19/England/CAMB-78470/2020 & CAMB-78470 & Pending & hCoV-19/England/CAMB-80F56/2020 & CAMB-80F56 \\
\hline EPI_ISL_433737 & hCoV-19/England/CAMB-7848F/2020 & CAMB- $7848 \mathrm{~F}$ & Pending & hCoV-19/England/CAMB-80F65/2020 & CAMB-80F65 \\
\hline EPI_ISL_433738 & hCoV-19/England/CAMB-7849E/2020 & CAMB-7849E & Pending & hCoV-19/England/CAMB-80F74/2020 & CAMB-80F74 \\
\hline EPI_ISL_433739 & hCoV-19/England/CAMB-784AD/2020 & CAMB-784AD & Pending & hCoV-19/England/CAMB-80F83/2020 & CAMB-80F83 \\
\hline EPI_ISL_433740 & hCoV-19/England/CAMB-784BC/2020 & CAMB-784BC & Pending & hCoV-19/England/CAMB-80FB0/2020 & CAMB-80FB0 \\
\hline EPI_ISL_433741 & hCoV-19/England/CAMB-784CB/2020 & CAMB-784CB & Pending & hCoV-19/England/CAMB-80FCF/2020 & CAMB-80FCF \\
\hline EPI_ISL_433742 & hCoV-19/England/CAMB-784DA/2020 & CAMB-784DA & Pending & hCoV-19/England/CAMB-80FDE/2020 & CAMB-80FDE \\
\hline EPI_ISL_433743 & hCoV-19/England/CAMB-784E9/2020 & CAMB-784E9 & Pending & hCoV-19/England/CAMB-80FFC/2020 & CAMB-80FFC \\
\hline EPI_ISL_433744 & hCoV-19/England/CAMB-78504/2020 & CAMB-78504 & Pending & hCoV-19/England/CAMB-81007/2020 & CAMB-81007 \\
\hline EPI_ISL_433745 & hCoV-19/England/CAMB-78531/2020 & CAMB-78531 & Pending & hCoV-19/England/CAMB-81016/2020 & CAMB-81016 \\
\hline EPI_ISL_-433746 & hCoV-19/England/CAMB-78540/2020 & CAMB-78540 & Pending & hCoV-19/England/CAMB-81025/2020 & CAMB-81025 \\
\hline EPI_ISL_-433747 & hCoV-19/England/CAMB-7855F/2020 & CAMB-7855F & Pending & hCoV-19/England/CAMB-81034/2020 & CAMB-81034 \\
\hline EPI_ISL_433748 & hCoV-19/England/CAMB-7856E/2020 & CAMB-7856E & Pending & hCoV-19/England/CAMB-81043/2020 & CAMB-81043 \\
\hline EPI_ISL_433749 & hCoV-19/England/CAMB-7857D/2020 & CAMB-7857D & Pending & hCoV-19/England/CAMB-81061/2020 & CAMB-81061 \\
\hline EPI_ISL_433750 & hCoV-19/England/CAMB-7858C/2020 & CAMB-7858C & Pending & hCoV-19/England/CAMB-81070/2020 & CAMB-81070 \\
\hline EPI_ISL_433751 & hCoV-19/England/CAMB-7859B/2020 & CAMB-7859B & Pending & hCoV-19/England/CAMB-8108F/2020 & CAMB-8108F \\
\hline EPI_ISL_433752 & hCoV-19/England/CAMB-785AA/2020 & CAMB-785AA & Pending & hCoV-19/England/CAMB-8109E/2020 & CAMB-8109E \\
\hline EPI_ISL_433753 & hCoV-19/England/CAMB-785C8/2020 & CAMB- $785 \mathrm{C} 8$ & Pending & hCoV-19/England/CAMB-810AD/2020 & CAMB-810AD \\
\hline EPI_ISL_-433754 & hCoV-19/England/CAMB-785E6/2020 & CAMB-785E6 & Pending & hCoV-19/England/CAMB-810BC/2020 & CAMB-810BC \\
\hline EPI_ISL_-433755 & hCoV-19/England/CAMB-785F5/2020 & CAMB-785F5 & Pending & hCoV-19/England/CAMB-810CB/2020 & CAMB-810CB \\
\hline EPI_ISL_433756 & hCoV-19/England/CAMB-78601/2020 & CAMB-78601 & Pending & hCoV-19/England/CAMB-810E9/2020 & CAMB-810E9 \\
\hline EPI_ISL_433757 & hCoV-19/England/CAMB-7862F/2020 & CAMB-7862F & Pending & hCoV-19/England/CAMB-81104/2020 & CAMB-81104 \\
\hline EPI_ISL_-433758 & hCoV-19/England/CAMB-7864D/2020 & CAMB-7864D & Pending & hCoV-19/England/CAMB-81113/2020 & CAMB-81113 \\
\hline EPI_ISL_433759 & hCoV-19/England/CAMB-7866B/2020 & CAMB-7866B & Pending & hCoV-19/England/CAMB-81122/2020 & CAMB-81122 \\
\hline EPI_ISL_433760 & hCoV-19/England/CAMB-7867A/2020 & CAMB-7867A & Pending & hCoV-19/England/CAMB-81131/2020 & CAMB-81131 \\
\hline EPI_ISL_433761 & hCoV-19/England/CAMB-78689/2020 & CAMB-78689 & Pending & hCoV-19/England/CAMB-81140/2020 & CAMB-81140 \\
\hline EPI_ISL_433762 & hCoV-19/England/CAMB-786A7/2020 & CAMB-786A7 & Pending & hCoV-19/England/CAMB-8115F/2020 & CAMB-8115F \\
\hline EPI_ISL_433763 & hCoV-19/England/CAMB-786C5/2020 & CAMB-786C5 & Pending & hCoV-19/England/CAMB-8117D/2020 & CAMB-8117D \\
\hline EPI_ISL_-433764 & hCoV-19/England/CAMB-786E3/2020 & CAMB-786E3 & Pending & hCoV-19/England/CAMB-8118C/2020 & CAMB-8118C \\
\hline EPI_ISL_433765 & hCoV-19/England/CAMB-7870E/2020 & CAMB-7870E & Pending & hCoV-19/England/CAMB-8119B/2020 & CAMB-8119B \\
\hline EPI_ISL_433766 & hCoV-19/England/CAMB-7872C/2020 & CAMB-7872C & Pending & hCoV-19/England/CAMB-811AA/2020 & CAMB-811AA \\
\hline EPI_ISL_433767 & hCoV-19/England/CAMB-7873B/2020 & CAMB-7873B & Pending & hCoV-19/England/CAMB-811C8/2020 & CAMB-811C8 \\
\hline EPI_ISL_433768 & hCoV-19/England/CAMB-7874A/2020 & CAMB-7874A & Pending & hCoV-19/England/CAMB-81F91/2020 & CAMB-81F91 \\
\hline EPI_ISL_433769 & hCoV-19/England/CAMB-78777/2020 & CAMB-78777 & Pending & hCoV-19/England/CAMB-81FA0/2020 & CAMB-81FA0 \\
\hline EPI_ISL__433770 & hCoV-19/England/CAMB-78786/2020 & CAMB-78786 & Pending & hCoV-19/England/CAMB-81FBF/2020 & CAMB-81FBF \\
\hline EPI_ISL_433771 & hCoV-19/England/CAMB-787A4/2020 & CAMB-787A4 & Pending & hCoV-19/England/CAMB-81FCE/2020 & CAMB-81FCE \\
\hline
\end{tabular}


medRxiv preprint doi: https://doi.org/10.1101/2020.05.08.20095687; this version posted May 14, 2020. The copyright holder for this preprint

(which was not certified by peer review) is the author/funder, who has granted medRxiv a license to display the preprint in perpetuity. All rights reserved. No reuse allowed without permission.

\begin{tabular}{|c|c|c|c|c|c|}
\hline GISAID Accession ID & Virus name & COG-UK & GISAID Accession ID & Virus name & COG-UK \\
\hline EPI_ISL_433772 & hCoV-19/England/CAMB-787B3/2020 & CAMB-787B3 & \begin{tabular}{|l|} 
Pending \\
\end{tabular} & hCoV-19/England/CAMB-81FDD/2020 & CAMB-81FDD \\
\hline EPI_ISL_433773 & hCoV-19/England/CAMB-787C2/2020 & CAMB-787C2 & Pending & hCoV-19/England/CAMB-81FEC/2020 & CAMB-81FEC \\
\hline EPI_ISL_433774 & hCoV-19/England/CAMB-787D 1/2020 & CAMB-787D1 & Pending & hCoV-19/England/CAMB-81FFB/2020 & CAMB-81FFB \\
\hline EPI_ISL_433775 & hCoV-19/England/CAMB-787E0/2020 & CAMB-787E0 & Pending & hCoV-19/England/CAMB-82006/2020 & CAMB-82006 \\
\hline EPI_ISL_-433776 & hCoV-19/England/CAMB-7880B/2020 & CAMB-7880B & Pending & hCoV-19/England/CAMB-82015/2020 & CAMB-82015 \\
\hline EPI_ISL_433777 & hCoV-19/England/CAMB-7881A/2020 & CAMB-7881A & Pending & hCoV-19/England/CAMB-82024/2020 & CAMB-82024 \\
\hline EPI_ISL_433778 & hCoV-19/England/CAMB-78829/2020 & CAMB-78829 & Pending & hCoV-19/England/CAMB-82033/2020 & CAMB-82033 \\
\hline EPI_ISL_433779 & hCoV-19/England/CAMB-78838/2020 & CAMB-78838 & Pending & hCoV-19/England/CAMB-82042/2020 & CAMB-82042 \\
\hline EPI_ISL_433780 & hCoV-19/England/CAMB-78847/2020 & CAMB-78847 & Pending & hCoV-19/England/CAMB-82051/2020 & CAMB-82051 \\
\hline EPI_ISL_-433781 & hCoV-19/England/CAMB-78865/2020 & CAMB-78865 & Pending & hCoV-19/England/CAMB-82060/2020 & САМВ-82060 \\
\hline EPI_ISL_433782 & hCoV-19/England/CAMB-78874/2020 & CAMB-78874 & Pending & hCoV-19/England/CAMB-8207F/2020 & CAMB-8207F \\
\hline EPI_ISL_433783 & hCoV-19/England/CAMB-78883/2020 & CAMB-78883 & Pending & hCoV-19/England/CAMB-8208E/2020 & CAMB-8208E \\
\hline EPI_ISL_433784 & hCoV-19/England/CAMB-78892/2020 & CAMB-78892 & Pending & hCoV-19/England/CAMB-8209D/2020 & CAMB-8209D \\
\hline EPI_ISL_433785 & hCoV-19/England/CAMB-788A1/2020 & CAMB-788A1 & Pending & hCoV-19/England/CAMB-820AC/2020 & CAMB-820AC \\
\hline EPI_ISL_433786 & hCoV-19/England/CAMB-788B0/2020 & CAMB-788BO & Pending & hCoV-19/England/CAMB-820CA/2020 & CAMB-820CA \\
\hline EPI_ISL_433787 & hCoV-19/England/CAMB-788CF/2020 & CAMB-788CF & Pending & hCoV-19/England/CAMB-82103/2020 & CAMB-82103 \\
\hline EPI_ISL_433788 & hCoV-19/England/CAMB-788DE/2020 & CAMB-788DE & Pending & hCoV-19/England/CAMB-82121/2020 & CAMB-82121 \\
\hline EPI_ISL_433789 & hCoV-19/England/CAMB-788ED/2020 & CAMB-788ED & Pending & hCoV-19/England/CAMB-82130/2020 & CAMB-82130 \\
\hline EPI_ISL_433790 & hCoV-19/England/CAMB-788FC/2020 & CAMB-788FC & Pending & hCoV-19/England/CAMB-8214F/2020 & CAMB-8214F \\
\hline EPI_ISL_433791 & hCoV-19/England/CAMB-78917/2020 & CAMB-78917 & Pending & hCoV-19/England/CAMB-8216D/2020 & CAMB-8216D \\
\hline EPI_ISL_433792 & hCoV-19/England/CAMB-78926/2020 & CAMB-78926 & Pending & hCoV-19/England/CAMB-8217C/2020 & CAMB-8217C \\
\hline EPI_ISL_433793 & hCoV-19/England/CAMB-78935/2020 & CAMB-78935 & Pending & hCoV-19/England/CAMB-8218B/2020 & CAMB-8218B \\
\hline EPI_ISL_433794 & hCoV-19/England/CAMB-78944/2020 & CAMB-78944 & Pending & hCoV-19/England/CAMB-821A9/2020 & CAMB-821A9 \\
\hline EPI_ISL_433795 & hCoV-19/England/CAMB-78953/2020 & CAMB-78953 & Pending & hCoV-19/England/CAMB-821B8/2020 & CAMB-821B 8 \\
\hline EPI_ISL_433796 & hCoV-19/England/CAMB-78962/2020 & CAMB-78962 & Pending & hCoV-19/England/CAMB-821C7/2020 & CAMB-821C7 \\
\hline EPI_ISL_433797 & hCoV-19/England/CAMB-78971/2020 & CAMB-78971 & Pending & hCoV-19/England/CAMB-82200/2020 & CAMB- 82200 \\
\hline EPI_ISL_-433798 & hCoV-19/England/CAMB-78980/2020 & CAMB-78980 & Pending & hCoV-19/England/CAMB-8222E/2020 & CAMB-8222E \\
\hline EPI_ISL_433799 & hCoV-19/England/CAMB-7899F/2020 & CAMB-7899F & Pending & hCoV-19/England/CAMB-7540A/2020 & CAMB-7540A \\
\hline EPI_ISL_433800 & hCoV-19/England/CAMB-789AE/2020 & CAMB-789AE & Pending & hCoV-19/England/CAMB-756D7/2020 & CAMB-756D7 \\
\hline EPI_ISL_-433801 & hCoV-19/England/CAMB-789BD/2020 & CAMB-789BD & Pending & hCoV-19/England/CAMB-756F5/2020 & CAMB-756F5 \\
\hline EPI_ISL_433802 & hCoV-19/England/CAMB-789CC/2020 & CAMB-789CC & Pending & hCoV-19/England/CAMB-75701/2020 & CAMB-75701 \\
\hline EPI_ISL_433803 & hCoV-19/England/CAMB-789DB/2020 & CAMB-789DB & Pending & hCoV-19/England/CAMB-7572F/2020 & CAMB- $7572 \mathrm{~F}$ \\
\hline EPI_ISL_433804 & hCoV-19/England/CAMB-789EA/2020 & CAMB-789EA & Pending & hCoV-19/England/CAMB-7576B/2020 & CAMB-7576B \\
\hline EPI_ISL_433805 & hCoV-19/England/CAMB-789F9/2020 & CAMB-789F9 & Pending & hCoV-19/England/CAMB-7577A/2020 & CAMB-7577A \\
\hline EPI_ISL_433806 & hCoV-19/England/CAMB-78A05/2020 & CAMB-78A05 & Pending & hCoV-19/England/CAMB-75798/2020 & CAMB-75798 \\
\hline EPI_ISL_433807 & hCoV-19/England/CAMB-78A14/2020 & CAMB-78A14 & Pending & hCoV-19/England/CAMB-757A7/2020 & CAMB-757A7 \\
\hline EPI_ISL_433808 & hCoV-19/England/CAMB-78A32/2020 & CAMB-78A32 & Pending & hCoV-19/England/CAMB-757B6/2020 & CAMB-757B 6 \\
\hline EPI_ISL_-433809 & hCoV-19/England/CAMB-78A50/2020 & CAMB-78A50 & Pending & hCoV-19/England/CAMB-757C5/2020 & CAMB- $757 C 5$ \\
\hline EPI_ISL_433810 & hCoV-19/England/CAMB-78A7E/2020 & CAMB-78A7E & Pending & hCoV-19/England/CAMB-757E3/2020 & CAMB-757E3 \\
\hline EPI_ISL_433811 & hCoV-19/England/CAMB-78A9C/2020 & CAMB-78A9C & Pending & hCoV-19/England/CAMB-757F2/2020 & CAMB-757F2 \\
\hline EPI_ISL_-433812 & hCoV-19/England/CAMB-78ABA/2020 & CAMB-78ABA & Pending & hCoV-19/England/CAMB-7580E/2020 & CAMB- $7580 \mathrm{E}$ \\
\hline EPI_ISL_-433813 & hCoV-19/England/CAMB-79A04/2020 & CAMB-79A04 & Pending & hCoV-19/England/CAMB-7582C/2020 & CAMB-7582C \\
\hline EPI_ISL_433814 & hCoV-19/England/CAMB-79A22/2020 & CAMB-79A22 & Pending & hCoV-19/England/CAMB-7584A/2020 & CAMB-7584A \\
\hline EPI_ISL_433815 & hCoV-19/England/CAMB-79A40/2020 & CAMB-79A40 & Pending & hCoV-19/England/CAMB-75859/2020 & CAMB-75859 \\
\hline EPI_ISL_433816 & hCoV-19/England/CAMB-79A5F/2020 & CAMB-79A5F & Pending & hCoV-19/England/CAMB-75868/2020 & CAMB-75868 \\
\hline EPI_ISL_433817 & hCoV-19/England/CAMB-79A8C/2020 & CAMB-79ABC & Pending & hCoV-19/England/CAMB-75886/2020 & CAMB-75886 \\
\hline EPI_ISL_433818 & hCoV-19/England/CAMB-79A9B/2020 & CAMB-79A9B & Pending & hCoV-19/England/CAMB-75895/2020 & CAMB-75895 \\
\hline EPI_ISL_433819 & hCoV-19/England/CAMB-79AB9/2020 & CAMB-79AB9 & Pending & hCoV-19/England/CAMB-758A4/2020 & CAMB-758A4 \\
\hline EPI_ISL_433820 & hCoV-19/England/CAMB-79AC8/2020 & CAMB-79AC8 & Pending & hCoV-19/England/CAMB-758B3/2020 & CAMB-758B 3 \\
\hline EPI_ISL_-433821 & hCoV-19/England/CAMB-79AD7/2020 & CAMB-79AD7 & Pending & hCoV-19/England/CAMB-758C2/2020 & CAMB- $758 \mathrm{C} 2$ \\
\hline EPI_ISL_-433822 & hCoV-19/England/CAMB-79AE6/2020 & CAMB-79AE6 & Pending & hCoV-19/England/CAMB-758D1/2020 & CAMB-758D1 \\
\hline EPI_ISL_-433823 & hCoV-19/England/CAMB-79AF5/2020 & CAMB-79AF5 & Pending & hCoV-19/England/CAMB-758E0/2020 & CAMB-758E0 \\
\hline EPI_ISL_433824 & hCoV-19/England/CAMB-79B01/2020 & CAMB-79B01 & Pending & hCoV-19/England/CAMB-758FF/2020 & CAMB- $758 \mathrm{FF}$ \\
\hline EPI_ISL_433825 & hCoV-19/England/CAMB-79B10/2020 & CAMB-79B 10 & Pending & hCoV-19/England/CAMB-78522/2020 & CAMB-78522 \\
\hline EPI_ISL_433826 & hCoV-19/England/CAMB-7A8BE/2020 & CAMB-7A8BE & Pending & hCoV-19/England/CAMB-78768/2020 & CAMB-78768 \\
\hline EPI_ISL_433827 & hCoV-19/England/CAMB-7A8DC/2020 & CAMB-7A8DC & Pending & hCoV-19/England/CAMB-78759/2020 & CAMB-78759 \\
\hline EPI_ISL_433828 & hCoV-19/England/CAMB-7A8FA/2020 & CAMB-7A8FA & Pending & hCoV-19/England/CAMB-79934/2020 & CAMB-79934 \\
\hline EPI_ISL_433829 & hCoV-19/England/CAMB-7AA30/2020 & CAMB-7AA30 & Pending & hCoV-19/England/CAMB-79943/2020 & CAMB-79943 \\
\hline EPI_ISL_-433830 & hCoV-19/England/CAMB-7AA4F/2020 & CAMB-7AA4F & Pending & hCoV-19/England/CAMB-79961/2020 & CAMB-79961 \\
\hline EPI_ISL_433831 & hCoV-19/England/CAMB-7AA6D/2020 & CAMB-7AA6D & Pending & hCoV-19/England/CAMB-79970/2020 & CAMB-79970 \\
\hline EPI_ISL_-433832 & hCoV-19/England/CAMB-7AA7C/2020 & CAMB-7AA7C & Pending & hCoV-19/England/CAMB-7999E/2020 & CAMB-7999E \\
\hline EPI_ISL_-433833 & hCoV-19/England/CAMB-7AA8B/2020 & CAMB-7AA8B & Pending & hCoV-19/England/CAMB-799BC/2020 & CAMB-799BC \\
\hline EPI_ISL_433834 & hCoV-19/England/CAMB-7AAA9/2020 & CAMB-7AAA9 & & & \\
\hline EPI_ISL_433835 & hCoV-19/England/CAMB-7AAB8/2020 & CAMB-7AAB8 & & & \\
\hline EPI_ISL_433836 & hCoV-19/England/CAMB-7AAC7/2020 & CAMB-7AAC7 & & & \\
\hline EPI_ISL_433837 & hCoV-19/England/CAMB-7AAD6/2020 & CAMB-7AAD 6 & & & \\
\hline EPI_ISL_433838 & hCoV-19/England/CAMB-7AAE5/2020 & CAMB-7AAE5 & & & \\
\hline EPI_ISL_433839 & hCoV-19/England/CAMB-7AAF4/2020 & CAMB-7AAF4 & & & \\
\hline EPI_ISL_433840 & hCoV-19/England/CAMB-7AB00/2020 & CAMB-7AB00 & & & \\
\hline EPI_ISL_-433841 & hCoV-19/England/CAMB-7AB1F/2020 & CAMB-7AB1F & & & \\
\hline EPI_ISL_433842 & hCoV-19/England/CAMB-7AB2E/2020 & CAMB-7AB2E & & & \\
\hline EPI_ISL_433843 & hCoV-19/England/CAMB-7AB3D/2020 & CAMB-7AB3D & & & \\
\hline EPI_ISL_-433844 & hCoV-19/England/CAMB-7AB79/2020 & CAMB-7AB79 & & & \\
\hline EPI_ISL_-433845 & hCoV-19/England/CAMB-7AB88/2020 & CAMB-7AB88 & & & \\
\hline EPI_ISL_433846 & hCoV-19/England/CAMB-7AB97/2020 & CAMB-7AB97 & & & \\
\hline EPI_ISL_433847 & hCoV-19/England/CAMB-7ABA6/2020 & CAMB-7ABA6 & & & \\
\hline EPI_ISL_433848 & hCoV-19/England/CAMB-7ABB5/2020 & CAMB-7ABB5 & & & \\
\hline EPI_ISL_-433849 & hCoV-19/England/CAMB-7ABC4/2020 & CAMB-7ABC4 & & & \\
\hline EPI_ISL_433850 & hCoV-19/England/CAMB-7ABE2/2020 & CAMB-7ABE2 & & & \\
\hline EPI_ISL_433851 & hCoV-19/England/CAMB-7ABF1/2020 & CAMB-7ABF1 & & & \\
\hline EPI_ISL_433852 & hCoV-19/England/CAMB-7ACOD/2020 & CAMB-7ACOD & & & \\
\hline EPI_ISL_-433853 & hCoV-19/England/CAMB-7AC1C/2020 & CAMB-7AC1C & & & \\
\hline EPI_ISL_ 433854 & hCoV-19/England/CAMB-7AC2B/2020 & CAMB-7AC2B & & & \\
\hline
\end{tabular}

